\title{
Enabling and Threatening Factors Affecting Persistence. A Qualitative and Quantitative Study on Rural First-Generation STEM Students' and STEM Faculty's Perspectives.
}

Travis A. Miller

West Virginia University, tmille10@mix.wvu.edu

Follow this and additional works at: https://researchrepository.wvu.edu/etd

Part of the Adult and Continuing Education Commons, Curriculum and Instruction Commons, Educational Leadership Commons, Elementary and Middle and Secondary Education Administration Commons, Higher Education Commons, Higher Education Administration Commons, Life Sciences Commons, Physical Sciences and Mathematics Commons, Secondary Education Commons, Secondary Education and Teaching Commons, and the Social and Behavioral Sciences Commons

\section{Recommended Citation}

Miller, Travis A., "Enabling and Threatening Factors Affecting Persistence. A Qualitative and Quantitative Study on Rural First-Generation STEM Students' and STEM Faculty's Perspectives." (2020). Graduate Theses, Dissertations, and Problem Reports. 7674.

https://researchrepository.wvu.edu/etd/7674

This Dissertation is protected by copyright and/or related rights. It has been brought to you by the The Research Repository @ WVU with permission from the rights-holder(s). You are free to use this Dissertation in any way that is permitted by the copyright and related rights legislation that applies to your use. For other uses you must obtain permission from the rights-holder(s) directly, unless additional rights are indicated by a Creative Commons license in the record and/ or on the work itself. This Dissertation has been accepted for inclusion in WVU Graduate Theses, Dissertations, and Problem Reports collection by an authorized administrator of The Research Repository @ WVU.

For more information, please contact researchrepository@mail.wvu.edu. 
Enabling and Threatening Factors Affecting Persistence. A Qualitative and Quantitative Study on Rural First-Generation STEM Students' and STEM Faculty's Perspectives.

Travis A. Miller

Follow this and additional works at: https://researchrepository.wvu.edu/etd

Part of the Adult and Continuing Education Commons, Curriculum and Instruction Commons, Educational Leadership Commons, Elementary and Middle and Secondary Education Administration Commons, Higher Education Commons, Higher Education Administration Commons, Life Sciences Commons, Physical Sciences and Mathematics Commons, Secondary Education Commons, Secondary Education and Teaching Commons, and the Social and Behavioral Sciences Commons 
Enabling and Threatening Factors Affecting Persistence. A Qualitative and Quantitative Study on Rural First-Generation STEM Students' and STEM Faculty's Perspectives.

Travis A. Miller

\author{
Dissertation submitted to the \\ College of Education and Human Services \\ at West Virginia University \\ in partial fulfillment of the requirements \\ for the degree of \\ Doctor of Education \\ in \\ Curriculum and Instruction \\ Jeffrey S. Carver, Ed.D., Committee Chair \\ James A. Rye, Ph.D. \\ Johnna Bolyard, Ph.D. \\ Gay Stewart, Ph.D.
}

Department of Curriculum and Instruction/Literacy Studies

Morgantown, West Virginia

2020

Keywords: Rural, First-Generation, Science, Technology, Engineering, Mathematics,

Persistence, Enable, Threaten, Challenges

Copyright 2020 Travis A. Miller 


\begin{abstract}
Enabling and Threatening Factors Affecting Persistence. A Qualitative and Quantitative Study on Rural First-Generation STEM Students' and STEM Faculty's Perspectives.
\end{abstract}

\title{
Travis A. Miller
}

This study focuses on the factors that enable and threaten rural first-generation STEM students' persistence. Limited empirical studies are available that focus on rural first-generation STEM majors' persistence. Quantitative analysis was conducted using Kruskal Wallis H and Mann-Whitney U tests to determine any significant differences with the survey results. Content and thematic analysis was conducted on the student and faculty interviews to determine themes of enabling and threatening factors affecting persistence.

Enabling factors affecting persistence were found to be: Drive or Motivation, Experiences and skills, and Support. These were both faculty and student interview themes whereas a fourth theme from the faculty was, Personal characteristics.

For the threatening factors, three similar themes came from the student and faculty interviews. The first related themes were the faculty's belief of Institutional environment and faculty which related to the student theme of Drive. Faculty mentioned Lack of preparation as a threatening factor to student persistence, which correlates to the student theme of lacking Experiences or skills. Both students and faculty discussed how the lack of Support or Resources can be an adverse condition to completing a STEM degree. Another theme that was only found in the faculty interviews was that rural first-generation college (RFGC) students experience More challenges than others, those that are not RFGC students.

Drive or motivation, experiences and skills, along with support and resources impact a student's ability to adapt to the demands of college. 
ENABLING AND THREATENING FACTORS AFFECTING PERSISTENCE

\section{Dedication}

To my grandparents, Edgar Miller, Ethel Miller, Bill Guy, Peggy Guy, and Beverly Miller, thank you for taking your time to teach and nurture me. To my parents Deb Byerly and Robert Miller, thanks for bringing me into this world, giving me all the opportunities possible, and for your love. To the most influential teachers I had, Debra Jackson and Dr. Bill McCorkle, thank you for your wisdom and care. 
ENABLING AND THREATENING FACTORS AFFECTING PERSISTENCE

\section{Acknowledgements}

First and foremost, I would like to thank my advisor Dr. Jeffrey Carver for his guidance, encouragement, and wisdom, to get me through the doctorate process. Our talks about life and education will always be cherished. Dr. Pat Obenauf, I owe you many thanks as my initial advisor, Namaste. My gratitude goes out to my dissertation committee, Dr. James Rye, Dr. Johnna Bolyard, and Dr. Gay Stewart. To the participants of this study, I appreciate your time and effort in explaining your views. I am very grateful for the personnel at each WV institution that accumulated the student and faculty lists for this study: Scott Cook, Dr. Robynn Shannon, Dr. Stacey Jones, Dr. Sarah Beasley, and Dr. Joy Jones.

I am very appreciative of the First-2 Network as without this group, I would not have been introduced to the topic of rural first-generation STEM persistence. Special thanks to Caitlin Howley, Sue Ann Heatherly, Dr. Deb Hemler, and all the students involved in pilot testing and providing feedback. An extra-special thanks to Dr. Erica Harvey as she was the first person to include me in this group. To all the peer mentors and student helpers, I cannot thank you enough

for the assistance and support you provided. I especially want to thank Allison Moore, Sarah Starcovic, Garrett Devericks, Austin Cain, and David Funes.

Thanks to those that provided grammatical and comprehensive feedback. Your time and effort are greatly appreciated: Beth Thompson, Dr. Chris Lavorata, and Teresa VanAlsburg. 


\section{Table of Contents}

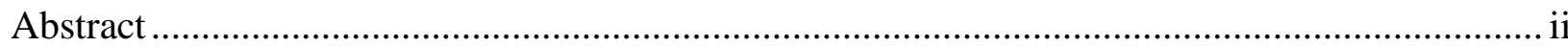

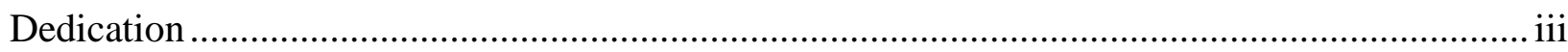

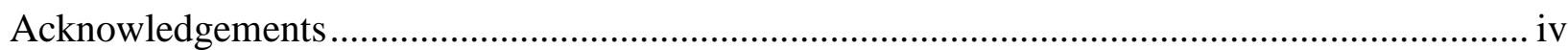

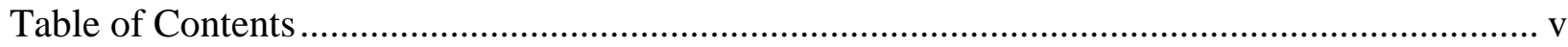

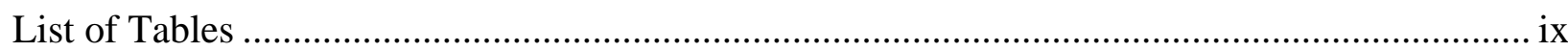

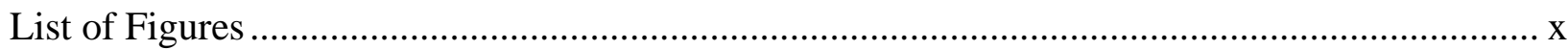

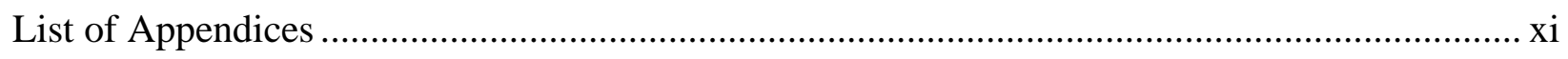

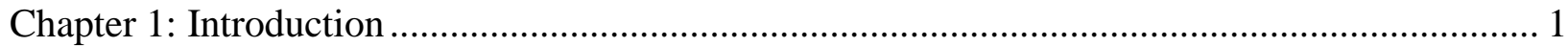

Statement of the Problem............................................................................................. 4

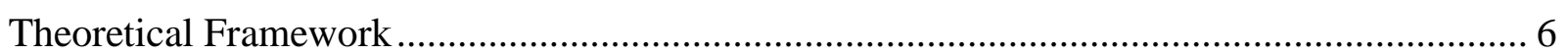

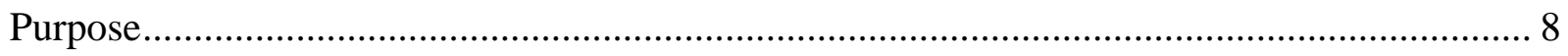

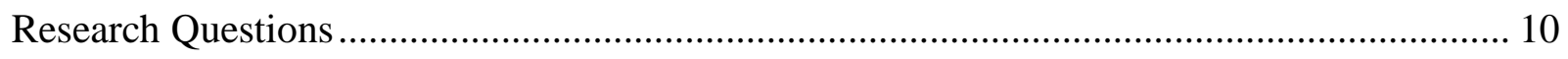

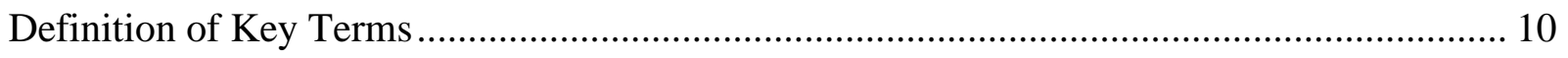

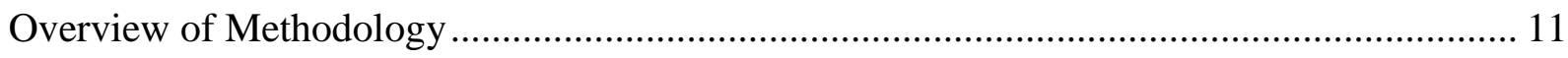

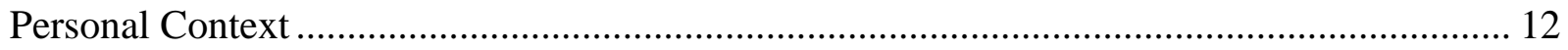

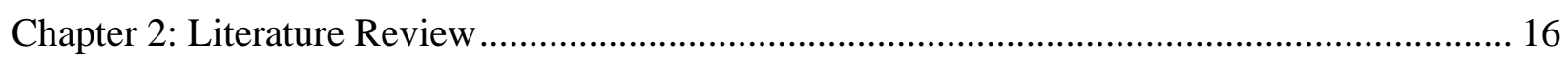

Persistence and Retention Theoretical Models .............................................................. 16

Rural, First-Generation, STEM Students’ Persistence ..................................................... 17

General persistence factors of Appalachian first-generation students. ............................ 18

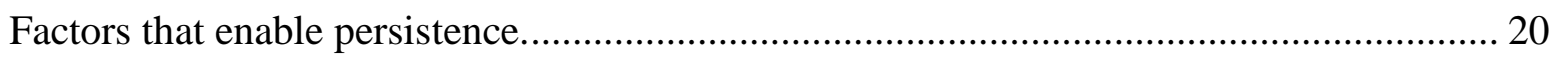

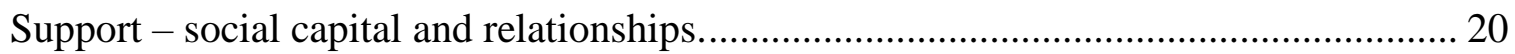

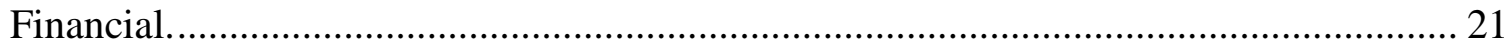

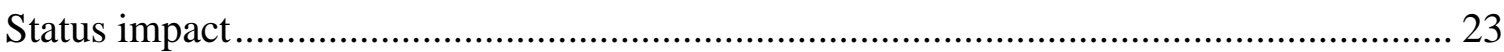

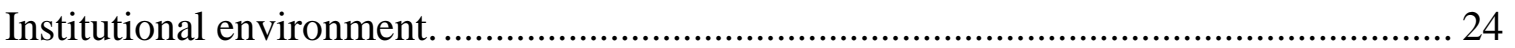

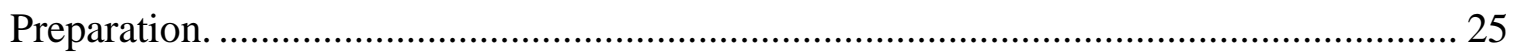

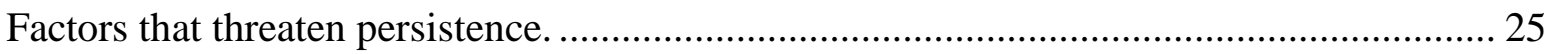

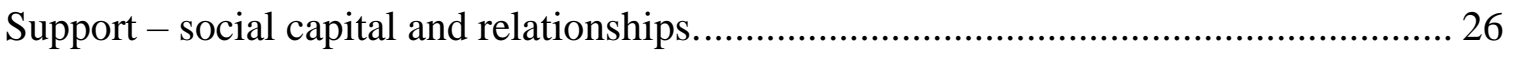

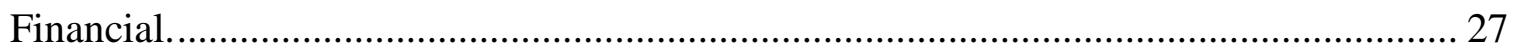

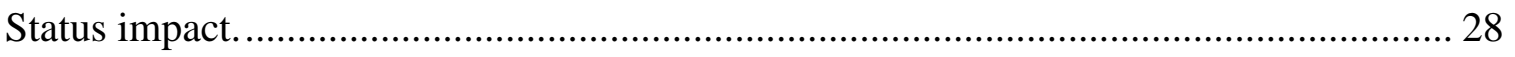

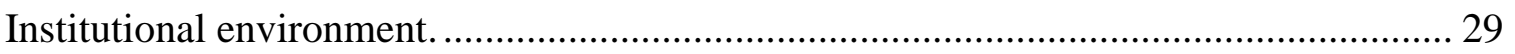

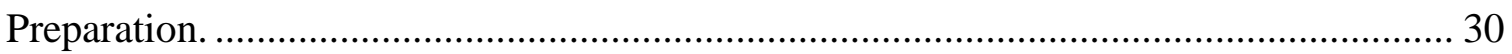

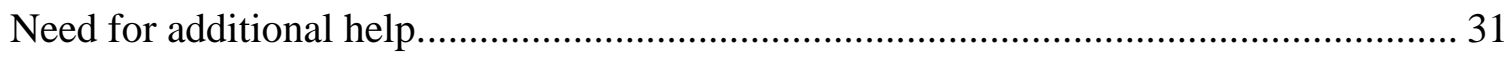

Faculty view of STEM student's persistence........................................................... 32

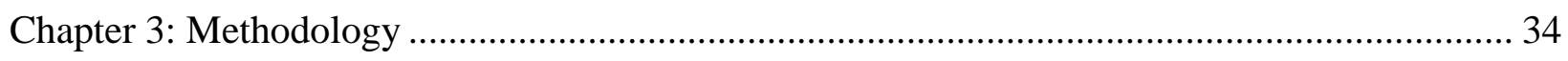




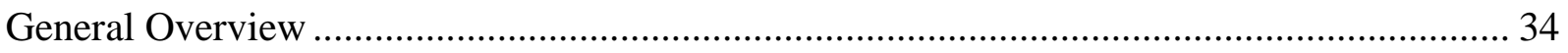

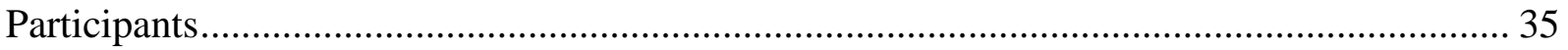

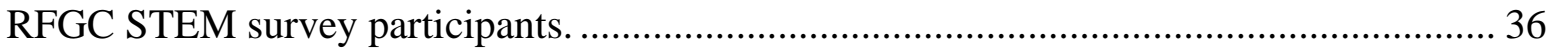

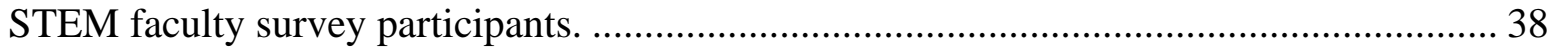

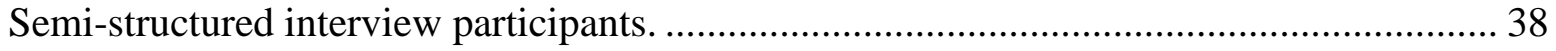

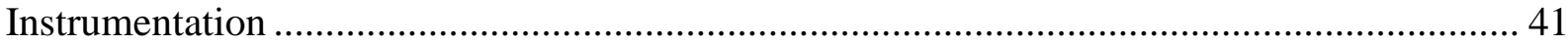

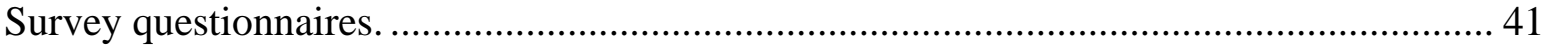

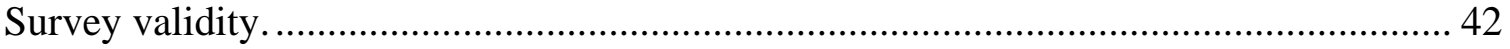

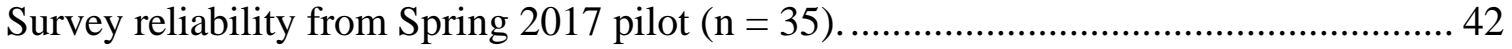

Semi-structured interviews (face-to-face or phone). ........................................................ 43

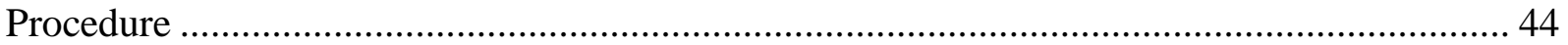

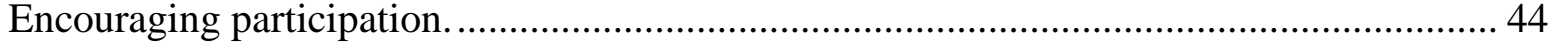

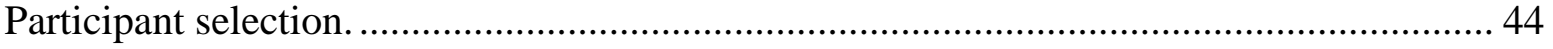

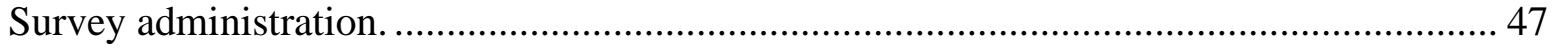

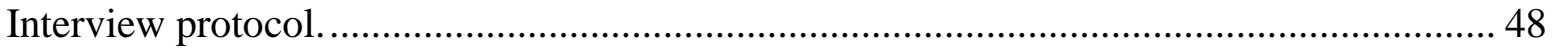

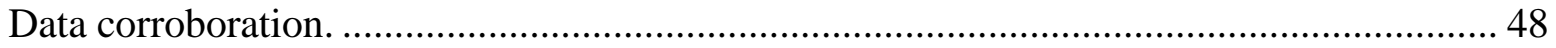

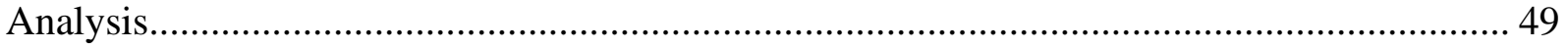

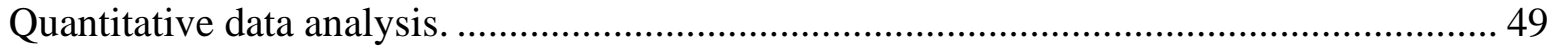

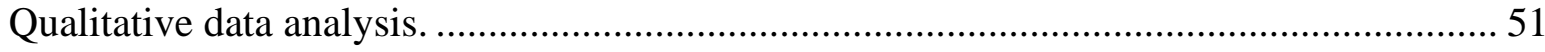

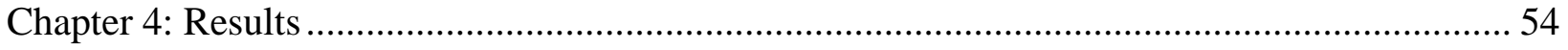

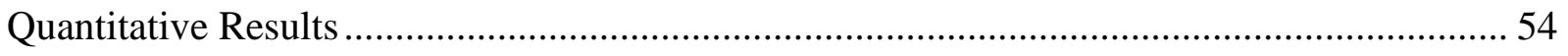

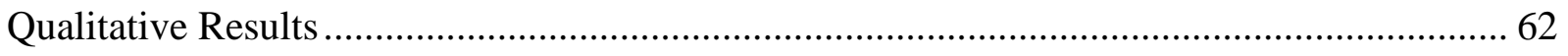

What factors enable the persistence of RFGC students in STEM majors?........................... 66

What do RFGC STEM majors perceive as factors that enable them to persist? .............. 67

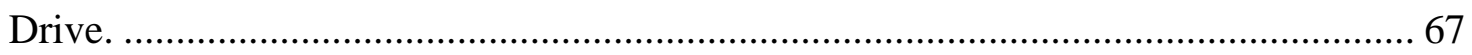

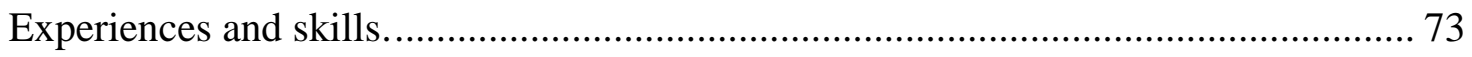

Resources and support. .................................................................................. 79

What do faculty view as the factors that enable RFGC STEM students to persist? ......... 88

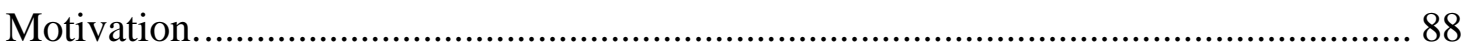

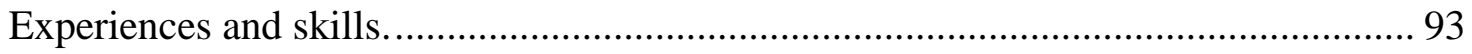

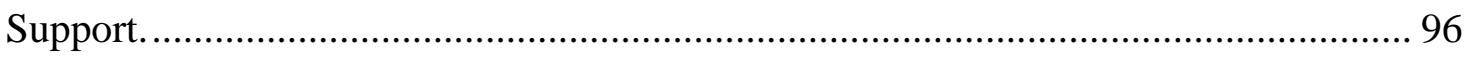

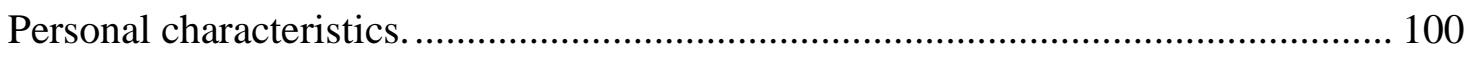

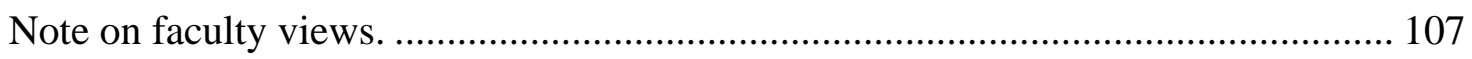

What factors threaten the persistence of RFGC students in STEM majors? ...................... 108 
What do RFGC STEM majors perceive as the factors that threaten their persistence? . 108

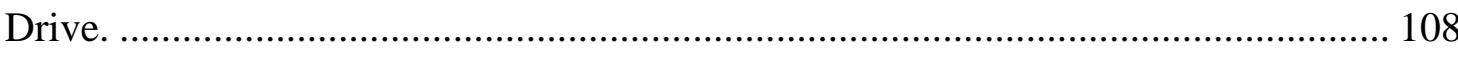

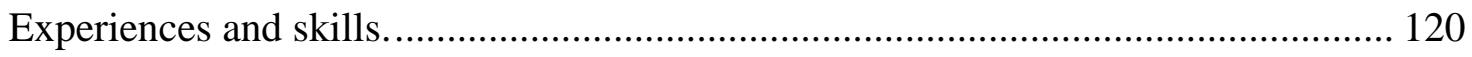

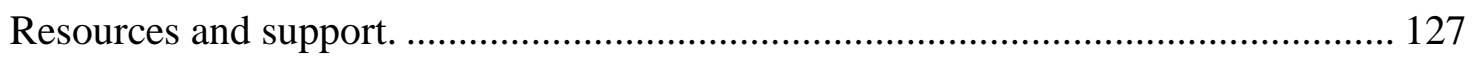

How do RFGC STEM majors handle or deal with the challenges they face?............... 135

What are their successful means to adapting to these challenges? ........................... 136

How do these challenges change over time as a STEM major? .............................. 140

What do faculty view as the factors that threaten RFGC STEM students' persistence? 143

Institutional environment and faculty. .......................................................... 143

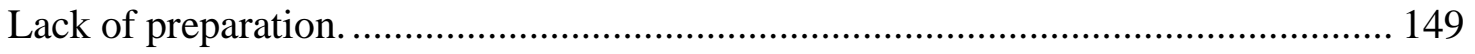

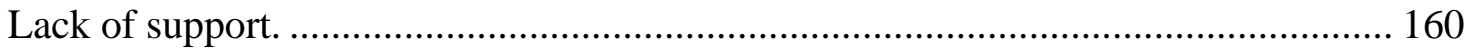

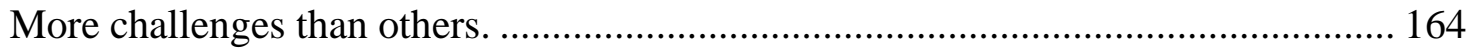

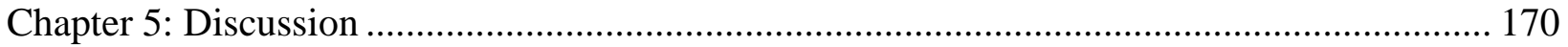

What Factors Enable the Persistence of RFGC Students in STEM Majors?........................ 170

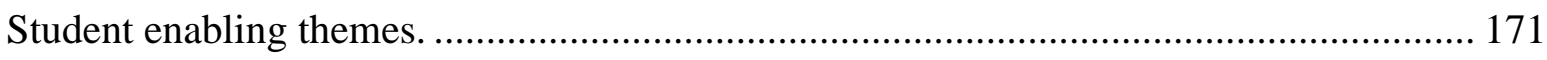

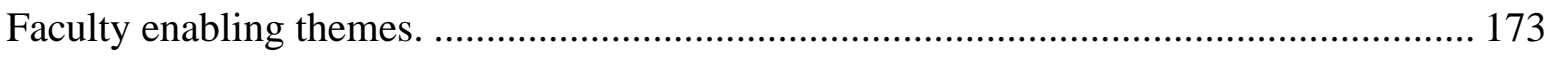

What Factors Threaten the Persistence of RFGC Students in STEM Majors?..................... 177

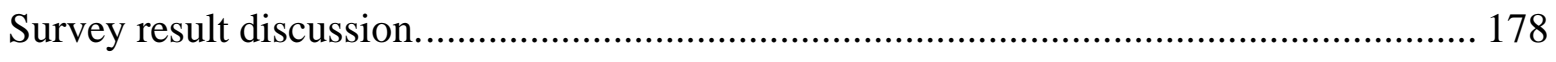

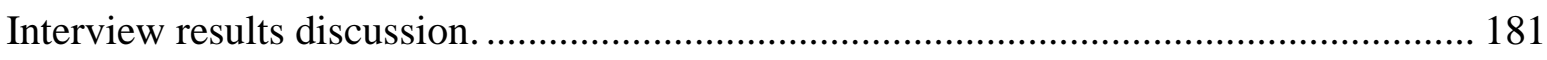

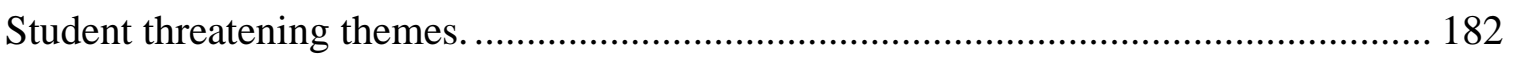

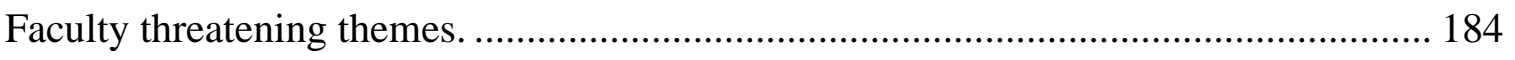

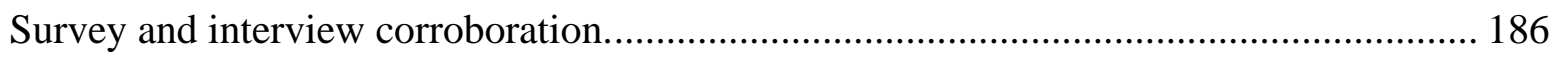

Comparison to Opatz's Persistence Pyramid............................................................... 187

How do RFGC STEM Majors Handle or Deal with the Challenges they Face? ................... 189

What are their successful means to adapting to these challenges? ................................. 190

How do these challenges change over time as a STEM major? ................................... 191

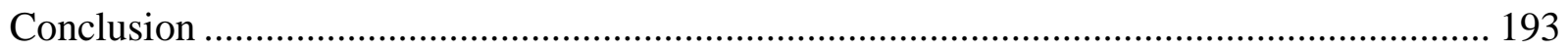

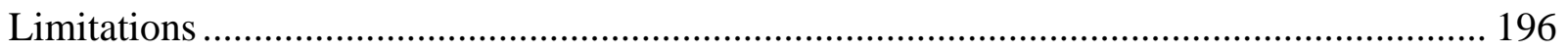

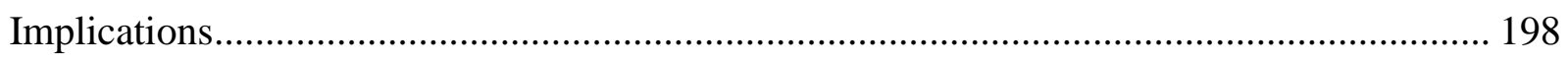

Recommendations for Future Research .............................................................. 201

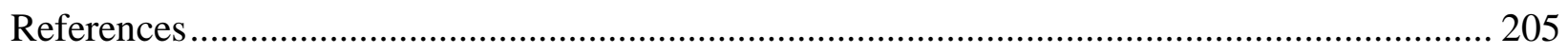

Appendix A Projected Job Openings in STEM Occupations, 2008-2018 …......................... 210

Appendix B Appendix B National Science Foundation Approved STEM Fields .................... 211

Appendix C Instrument Timeline .............................................................................. 216

Appendix D RFGC STEM Student Survey .................................................................. 217 
ENABLING AND THREATENING FACTORS AFFECTING PERSISTENCE

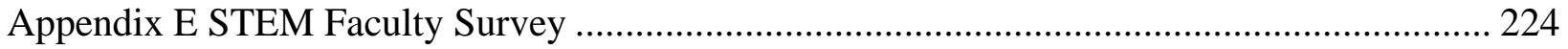

Appendix F RFGC STEM Student Interview Questions .................................................. 231

Appendix G STEM Faculty Interview Questions .......................................................... 232

Appendix H Exodus Interview Questions......................................................................... 233 


\section{List of Tables}

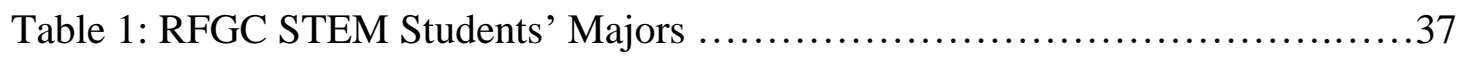

Table 2: RFGC STEM Students' Background ................................. 37

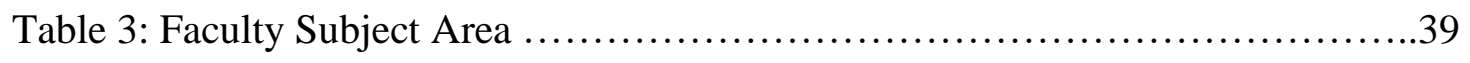

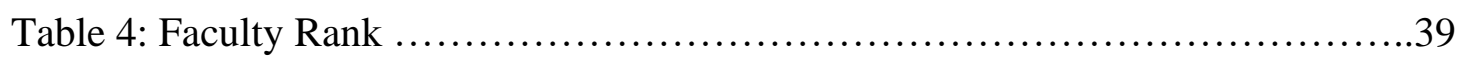

Table 5: Interview Demographics, RFGC STEM Students ......................40

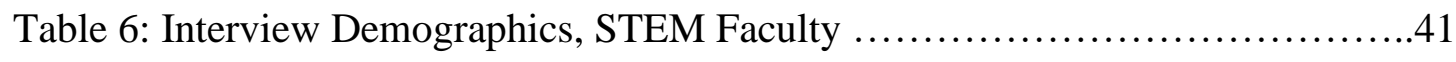

Table 7: Instrumentation-Related Appendices ................................44

Table 8: Student and Faculty Survey Summary ...............................55

Table 9: Student Survey Responses in Order ..............................57

Table 10: Faculty Survey Responses in Order ..............................58

Table 11: Kruskal-Wallis H Test Results ................................60

Table 12: RFGC STEM Coding - Enabling Factors ..........................63

Table 13: RFGC STEM Coding - Threatening Factors .........................64

Table 14: STEM Faculty Coding - Enabling Factors ..........................65

Table 15: STEM Faculty Coding - Threatening Factors .......................66

Table 16: Most Concerning Student Survey Items .......................... 178

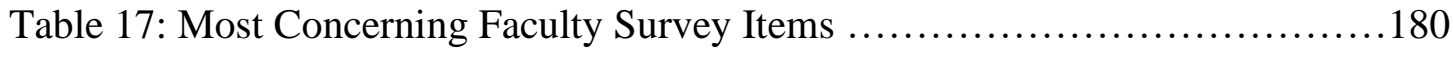


ENABLING AND THREATENING FACTORS AFFECTING PERSISTENCE

\section{List of Figures}

Figure 1: Persistence Pyramid: Student Factors ............................... 9

Figure 2: Persistence Pyramid: Campus Factors $\ldots \ldots \ldots \ldots \ldots \ldots \ldots \ldots \ldots \ldots \ldots$ 
ENABLING AND THREATENING FACTORS AFFECTING PERSISTENCE

\section{List of Appendices}

Appendix A Projected Job Openings in STEM Occupations, 2008-2018 ............................. 210

Appendix B Appendix B National Science Foundation Approved STEM Fields ................... 211

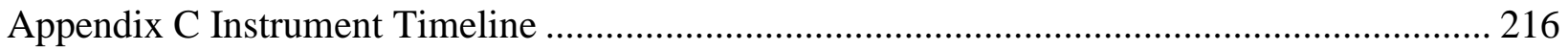

Appendix D RFGC STEM Student Survey ............................................................... 217

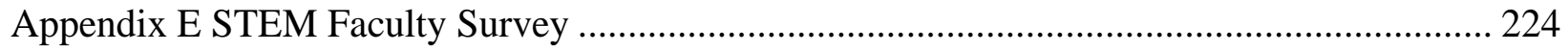

Appendix F RFGC STEM Student Interview Questions ................................................. 231

Appendix G STEM Faculty Interview Questions ......................................................... 232

Appendix H Exodus Interview Questions...................................................................... 233 


\section{Chapter 1: Introduction}

Multiple reports, such as those from the President's Council of Advisors on Science and Technology (2012), U.S. Department of Education (2017), and West Virginia Council on STEM (2014) proclaim a need to increase the number of science, technology, engineering, and mathematics (STEM) degrees in the United States. Even with an influx of international students into U.S. higher education programs, there is still an estimated shortage of STEM majors. Two means for increasing STEM graduates are: (a) recruitment and eventual enrollment of more students and (b) to increase the retention and persistence of those who do enroll in STEM majors.

The President's Council of Advisors on Science and Technology (2012) state that between 2012 and 2022, approximately one million additional STEM degrees will be needed (see Appendix A for a graphic). The advisory council desires this increase so that a diverse STEM workforce is attained. Degree completion is key to producing an increase in the STEM workforce. If there is a $10 \%$ increase in retaining STEM majors, from $40 \%$ to $50 \%$ in overall retention, this increase will equate to an additional 72,500 degrees (President's Council of Advisors on Science and Technology, 2012). To meet the goal of one million additional STEM degrees, an average of 100,000 degrees would be needed each year over the next ten years. Even if the proposed $10 \%$ increases retention efforts, there will still be a shortfall to the council's declaration. A $10 \%$ increase in retention can be a daunting task, given the fact that less than $40 \%$ of students who enter STEM majors will complete a STEM degree. This is a drastic difference as compared to the overall college completion rate of 59\% (U.S. Department of Education, 2017).

In West Virginia, there is a substantial call for additional STEM workers. Those who decide to go into a STEM field can also benefit financially with this career move. In 2014, the 


\section{ENABLING AND THREATENING FACTORS AFFECTING PERSISTENCE}

West Virginia Governor created the West Virginia Council on STEM to address the need for a qualified STEM workforce over the next ten years. The STEM Council Report (2014) desired an increase of 25,000 STEM jobs by 2018, but employers in West Virginia have difficulty finding the talent they need (West Virginia Council on STEM, 2014). STEM Council recommendations focused on improving K-12 STEM education through the establishment of regional hubs, engaging students in STEM opportunities, and improving public awareness of STEM and STEM jobs in the state. The state's focus is on enrolling more students in the STEM fields to increase the number of degrees produced. While this is one way to increase STEM degrees, additional increases can be attained by focusing efforts on those that are already in an undergraduate STEM degree with retention/persistence efforts, such as the efforts proposed by the Expanding the First2 STEM Success Network NSF INCLUDES Alliance.

Persistence is described as the continued enrollment in an institution of higher education until degree completion (Hicks, 2012; Opatz 2013). Even though persistence and retention are used synonymously and are relatively similar, some education personnel distinctly differentiate them. This distinction is not known or understood by many. Still, organizations like the National Center for Education Statistics have distinguished the two, "retention is an institutional measure and persistence is a student measure" (Hagedorn, 2006, p. 6). Hagedorn aimed at defining retention in terms of measurement for institutions, but found this task complex, “...student retention is complicated, confusing, and context dependent" (p. 2). For simplicity, this dissertation will focus on persistence as a continuation in higher education from the student's perspective.

Persistence is an ongoing student endeavor that ends with a degree completion or when the student has decided not to continue. Though persistence is an ongoing venture, authors report 


\section{ENABLING AND THREATENING FACTORS AFFECTING PERSISTENCE}

that persistence concerns are most significant in a student's early college years. "It is during the student's first two years of college that most students drop out of their desired STEM field" (President's Council of Advisors on Science and Technology, 2012, p. 6). These first couple of years are even more crucial to at-risk student groups; first-generation students are more likely to drop out during their first two years as compared to non-first-generation students (Chen \& Soldner, 2013; Choy, 2001). A report on rural STEM students found that rural status was not a factor affecting persistence as compared to non-rural students if they made it to the end of their first year (Wilson, Lyons, \& Quinn, 2013).

Even though the percentage of the U.S. rural population has changed drastically, there is still a large significant portion of rural students attending higher education, "54.4 percent in 1910 to 19.3 percent in 2010” (Ratcliffe, Burd, Holder, \& Fields, 2016, p. 1). The number of rural students at an institution can be significantly higher if the institution is in a predominantly rural region and is a substantial distance from an urban district. As with any institution, maintaining a steady student population, or even increasing enrollment, is an essential goal for rural institutions.

The number of rural students at a given institution varies considerably, given the location of the institution and the local factors affecting the student population. These factors can include regional population density and the competitiveness of other regional institutions. In the Spring of 2017 , a pilot study was conducted by the researcher in collaboration with the First 2 Network. The study was conducted at a WV university with approximately 4,500 students. The survey was administered to the institution's freshmen and sophomore students that were majoring in a STEM field. Out of the 313 freshmen and sophomores, 225 students (71.9\%) were identified as rural, and 88 students $(21.8 \%)$ were labeled as non-rural. Overwhelmingly, the majority of this 


\section{ENABLING AND THREATENING FACTORS AFFECTING PERSISTENCE}

population is from a rural background, which means that this institution should see significant retention increases with retention efforts focused on this group.

No matter an institution's situation, there is still reason to be concerned with increasing the persistence of rural first-generation students. West Virginia's Higher Education Policy Commission (WV HEPC) is a few years into its statewide goal of "Double the Degrees." This initiative's goal is to roughly double the degrees from 18,000 (a state record in 2014) to 40,000 by the year 2025 (2015). Currently, only 30\% of the WV population holds an associate degree or higher. It is predicted that $50 \%$ of the population will need an associate degree or higher to fill the state's workforce need (Commission, 2015).

WV HEPC lists numerous benefits of attaining an undergraduate degree: higher earnings, steady employment, and greater likelihood to be active with civic and community activities. Individuals and their families can drastically benefit from an increase in family income; "Workers with a bachelor's degrees earn 60 percent more than those without a degree. Students with an associate degree earn 25 percent more" (Trachtenberg, 2014). Sixty percent is a drastic difference and Baum, Ma, and Payea describe this wage difference in monetary terms. As of 2011, bachelor's degree recipients earned $\$ 21,100$ more than those with a high school degree considering yearly salaries (2013). This shows that individuals and families can drastically benefit from the attainment of a post-secondary degree. Individuals earning a degree is also essential for institutions and state agencies as this improves the states workforce and economic development.

\section{Statement of the Problem}

As there is limited empirical data focused on the persistence of rural first-generation college (RFGC) STEM students, this dissertation will aim to add to the knowledge of this topic. 


\section{ENABLING AND THREATENING FACTORS AFFECTING PERSISTENCE}

Persistence and retention have been long-studied topics that have significant roots in the work of Vincent Tinto. Tinto (1975) developed a theoretical model of persistence that relates three primary areas: individual attributes, institution's academics, and social impact. Numerous professionals, including Tinto, see this model as limited and, therefore, an area in which there is a need for additional research. One critic of Tinto's model, Leslie Joseph Opatz, conducted a study that utilized Tinto's model along with other research to develop the Persistence Pyramid (Opatz, 2013). The pyramid is made of two main groups of factors, the individual student factors and the campus-based environmental factors (Opatz, 2013).

More relevant persistence studies have been completed on students who are firstgeneration, or from rural areas, or majoring in a STEM field. The more relevant resources contained some combination of these three descriptors, but none were found to have all three: rural, first-generation, and STEM. Phillips (2015) looked at successful first-generation, lowincome students from a rural region. Schutz (2003) focused on the first semester of firstgeneration students who were from a rural area and came from an agricultural family. Beasley (2011) studied the success of first-generation rural students considering their access to and pathways of college. Hand and Miller-Payne (2008) determined factors that affected the persistence of first-generation students in an Appalachian region. Wilson, Lyons, and Quinn (2013) conducted a study in Australia that looked at the first-year experiences of rural students in a STEM course ${ }^{1}$. These sources have common factors that affect persistence and formed the framework of this study's literature review. The literature review is broken into two main categories; enabling factors and threatening factors. The sub-sections of the enabling factors that affect persistence are: student support, financial, status impact (rural or first-generation), institutional environment, and preparation. Sub-sections of the threatening factors that affect 


\section{ENABLING AND THREATENING FACTORS AFFECTING PERSISTENCE}

persistence are the same as the enabling categories with a supplementary section on the need for additional guidance. While these sources provide a basis on the factors affecting persistence, none of the sources focused directly on RFGC STEM students in the first two years of higher education. Primarily these sources have focused on successful students and have only gathered factors that are enabling.

Currently the research is missing what factors enable and threaten rural first-generation students from persisting. Previous research has found factors affecting persistence for rural or first-generation students but not for students that are both rural and first-generation. In order to retain and recruit more RFGC STEM students, we should understand the enabling and threatening factors affecting persistence of RFGC STEM students. Thus, there is a need to determine what enables and threatens RFGC STEM majors from persisting within their first two years of higher education. The first two years are the most crucial to a student's success in attaining a degree. Understanding what enables and threatens these students' persistence will be invaluable in providing appropriate help for students. In addition to understanding the challenges that students face, it is also essential to know how students have overcome these challenges. Determining student strengths or the factors that enable students to persist will also help professionals to develop solutions to persistence issues.

\section{Theoretical Framework}

Previous literature provides the basis of the theoretical perspective of this study: a framework related to persistence factors. One of the most influential resources is Opatz's (2013) case study on low-income student's persistence. The Persistence Pyramid was developed and tested in this study (see figures 1 and 2). The pyramid is made of two main categories, individual student factors, and campus-based environmental factors. Each of these categories contains four 


\section{ENABLING AND THREATENING FACTORS AFFECTING PERSISTENCE}

sub-groups. The student factor sub-groups are: economic, social, psychological, and academic. The campus factor sub-groups are: educational and curricular support, support for diversity and community, involvement opportunities, and a caring culture. Opatz believes that his model applies to an array of "demographic groups and institutions" (p. 19).

One limitation concerning Opatz's report was that he studied successful low-income students and their perceived factors affecting persistence. Studying successful students, especially those at the end of their bachelor's degree, has limitations. Determining the enabling factors of successful students does not mean that others will become successful if they mimic those that are successful. Understanding the struggles that unsuccessful or struggling students experience in their first semesters would enhance Opatz's findings. Opatz derived his Pyramid from Tinto's Theoretical Model of Dropout, and his own experiences along with additional research by others. Tinto (2006) suggested that more qualitative research could help to gain a better understanding of the reasoning behind students' persistence and emphasized the need for more research to be done on persistence for low-income students. Both Tinto and Opatz emphasize the need for additional qualitative studies to test their models and further advance our knowledge of student persistence or retention.

Even though the literature has revealed some factors affecting persistence (Beasley, 2011; Phillips, 2015; Schutz, 2003) and provided persistence or retention models (Opatz, 2013; Tinto, 1975), these findings were developed with a population that did not include RFGC STEM students. This study used content and thematic analysis based upon grounded theory principles to uncover themes in an attempt to fill this void related to RFGC STEM students. Creswell describes how grounded theory is an appropriate qualitative method for developing a theory, "The literature may have models available, but they were developed and tested on samples and 
ENABLING AND THREATENING FACTORS AFFECTING PERSISTENCE

populations other than those of interest to the qualitative researcher" (2007, p. 66). Though a theory will not be developed from this study, themes produced from grounded theory constructs will help to understand the views of the RFGC STEM population.

Semi-structured interviews were conducted with RFGC freshmen and sophomore students as they experience what it is like to be a STEM major. This qualitative data collection aligns with Patton's grounded theory views, “...grounded theory depends on methods that take the researcher into and close to the real world so that the results and findings are grounded in the empirical world" (2002, p. 125). In addition to student interviews, STEM faculty also participated in semi-structured interviews.

\section{Purpose}

The purpose of this study is to develop an understanding of the factors that affect the persistence of RFGC STEM students. Some of these factors enable students to persist and can be thought of as strengths that are based upon student characteristics or their background. This is a peculiar aspect of this study, as there is limited research that focused on the strengths or enabling factors of RFGC STEM majors. Other factors affecting persistence are described as threatening and are based upon weaknesses or lacking attributes of the student. This study is designed to not only determine which factors are enabling and threatening to persistence but will also determine how students have successfully navigated through challenging events. 
Figure 1

\section{Persistence Pyramid \\ Student Factors}

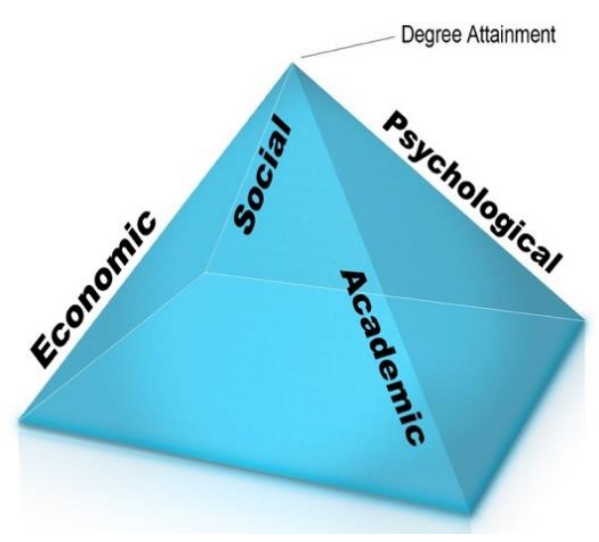

Figure 1. Student Factors of the Persistence Pyramid. Reprinted with permission from Leslie Joseph Opatz.

Figure 2

\section{Persistence Pyramid \\ Campus Factors}

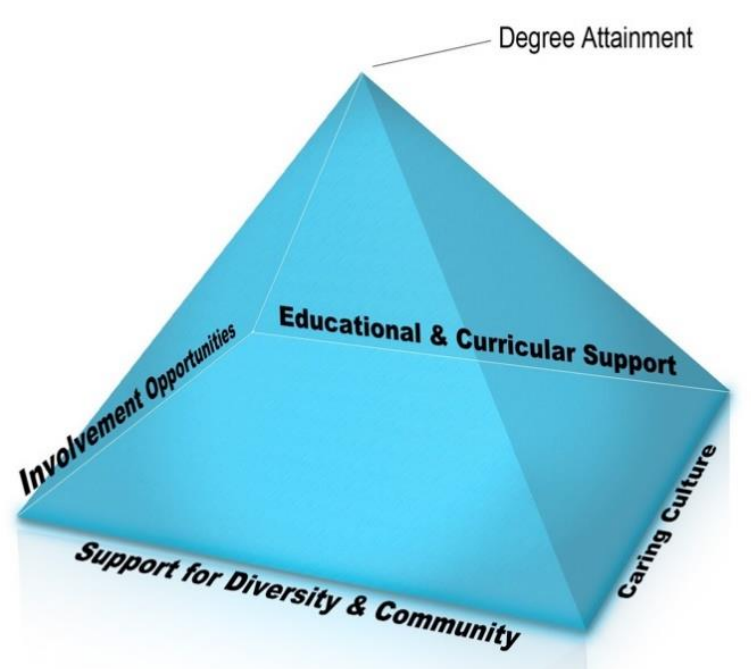

Figure 2. Campus Factors of the Persistence Pyramid. Reprinted with permission from Leslie Joseph Opatz. 
ENABLING AND THREATENING FACTORS AFFECTING PERSISTENCE

To accomplish this, quantitative and qualitative methods are used to acquire an understanding of these persistence factors. These factors are developed by the views of WV RFGC STEM students and WV STEM faculty. Upon analysis of the data and the corroboration between the two forms of data, themes were derived. A comparison of this study's themes with Opatz's Persistence Pyramid determined the relevance of Opatz's model with RFGC STEM students. The new themes supported and added to the persistence model. The purpose of this study is to add to the persistence knowledge base so that up to date retention efforts can be developed to assist these students in accomplishing their goal of attaining a STEM degree.

\section{Research Questions}

RQ1: What factors enable the persistence of RFGC students in STEM majors?

a. What do RFGC STEM majors perceive as factors that enable them to persist?

b. What do faculty view as the factors that enable RFGC STEM students to persist?

RQ2: What factors threaten the persistence of RFGC students in STEM majors?

a. What do RFGC STEM majors perceive as the factors that threaten their persistence?

b. How do RFGC STEM majors handle or deal with the challenges they face?

i. What are their successful means to adapting to these challenges?

ii. How do these challenges change over time as a STEM major?

c. What do faculty view as the factors that threaten RFGC STEM students' persistence?

\section{Definition of Key Terms}

The following is a summary of the major terms used in this study.

- First-generation - neither parent(s) nor guardian(s) graduated from an institution of higher education and therefore have not attained a bachelor's or associate degree.

Although some studies view first-generation as those students whom neither parent had 
ENABLING AND THREATENING FACTORS AFFECTING PERSISTENCE

ever enrolled in college, this study will use the former definition as it aligns with most of the studies in the literature (Childs, 2015; Geier, 2016; Dika \& D'Amico, 2016).

- Persistence - the continuation in higher education from the student's perspective, continued enrollment in an institution of higher education. "Persistence is defined as students staying in college until they get a degree" (Hicks, 2012, p. 20). "Persistence generally refers to an individual student's ongoing enrollment in higher education to the point of graduation" (Opatz, 2013, p. 5).

- Rural - The determination of a student's rural status is determined by the student's high school zip code and name. These two items will be cross-referenced with locale codes (Rural, Town, Suburban, City) generated from the National Center for Education Statistics-Common Core of Data (NCES-CCD) website, https://nces.ed.gov/ccd/rural_locales.asp. NCES locale codes are based upon the U.S. Census Bureau's definition of urban and rural. For additional information on these locale boundaries, got to https://nces.ed.gov/programs/edge/Geographic/LocaleBoundaries. The searchable database that was used for this study has been updated. The updated database can be found at https://nces.ed.gov/ccd/elsi/tableGenerator.aspx.

- STEM major - see Appendix B for the National Science Foundation (NSF) approved Science, Technology, Engineering, and Mathematics (STEM) fields as identified by the Big Ten Academic Alliance (Big Ten Academic Alliance, 2014)

\section{Overview of Methodology}

This study employed surveys and interviews to determine the factors affecting RFGC STEM persistence. Surveys were distributed in the spring of 2018 and fall of 2018 to RFGC STEM majors. In each round of the survey, potential interview candidates were self-identified by 


\section{ENABLING AND THREATENING FACTORS AFFECTING PERSISTENCE}

their responses to the survey. STEM faculty were surveyed and interviewed between the spring and fall of 2018. The RFGC STEM survey instrument identified students who decided to leave STEM or school altogether and those students were asked to be interviewed. These combined sources gave the researcher multiple viewpoints as to the factors that enable and threaten RFGC STEM major's persistence. Survey data were analyzed with descriptive and inferential statistics to determine group themes and to determine any differences among the groups. The groups of interest are RFGC STEM students and STEM faculty that are at a West Virginia institution of higher education. Statistical analysis was also conducted between the freshmen and sophomore sub-groups of the RFGC STEM students to determine any differences that occur over time. Content and thematic analysis were used to analyze the interview data to identify themes of enabling and threatening factors affecting persistence.

\section{Personal Context}

With qualitative research, it is essential to identify the background of a qualitative researcher as his/her background is the basis of his/her Qualitative Lens. Qualitative researcher's lived experiences transform their opinions and beliefs. This can affect a researcher's ability to interpret data and conduct research using qualitative methods appropriately. The researcher needs to reflect upon their past experiences and the research topic to account for human bias in qualitative research.

My lens is formed by my background as a rural student who majored in a STEM field. I attended a very small K-12, rural school district. I graduated with 72 students. Though the school offered limited academic options, I still feel that I benefitted from the learning environment. Though the number of upper-level courses was limited, I was able to get individual help and attention from my teachers. One very impactful teacher made me retake Algebra II, as I barely 


\section{ENABLING AND THREATENING FACTORS AFFECTING PERSISTENCE}

passed the course. Even though I wanted to continue to a higher level of mathematics as my brother did, the teacher insisted that it would be in my best interest to retake Algebra II. That was the starting point of my transformation from a passive learner to a proactive and focused learner. I was determined to make an A in my second round of Algebra II, so that I could continue in the mathematics series of courses. This gave me the strong foundation I needed to be successful in pre-calculus-trigonometry and physics. This one event propelled me academically, as I went from an average student to an almost straight-A student. I would go on to start my college career as a secondary mathematics education major. I struggled with my first calculus class in college, and I decided to switch to a different STEM education degree. My new major was still in education but with specializations in general science (5-adult) and mathematics (5-9 grades). Attaining this degree made me the first in my immediate family to accomplish this level.

I grew up on the family farm, where I was introduced to many STEM concepts at an early age. This STEM primer was not an intentional education by my family, as it was just part of our daily activities. Growing up in this environment, I was not mindful of this informal STEM training. I only realized this opportunity when I reviewed the literature on RFGC students. I started to realize that my upbringing may have had a positive impact on my ability to attain a STEM degree.

I also started to realize that my rural upbringing, along with being a first-generation college student, had harmful effects on my academic progress. As I progressed through my study, I realized that my background not only gave me some abilities to persist in my degrees, but it also created challenges that I had to overcome. Listening to what others perceived as strengths and weaknesses, I was enlightened to even more factors that may have impacted me as 
ENABLING AND THREATENING FACTORS AFFECTING PERSISTENCE

an RFGC student. These positive and negative factors related to my background still influence me today.

My experiences have caused me to form the assumption that a rural upbringing has a favorable effect on a future STEM student. I have the belief that rural people generally have a solid work ethic and tend to possess problem-solving skills, even at a young age. Rural students, especially those who were raised on a farm, have firsthand experience of STEM topics in action. This can give a STEM student an advantage when formally learning STEM topics as they have prior experience with which they can connect new information. I now realize how lucky I was growing up using a tape measure, observing nature every day, and having the freedom to play with random broken items (or maybe I broke them, oops!). At the time, I did not think that performing daily chores was beneficial to my development, but I now know that my chores were the basis of my work ethic and grit (drive to succeed).

As a researcher, I must be careful that my lens does not influence my research by forming preconceived categories (answers) or let my background influence data interpretation. I also found it hard to abstain from offering advice during interviews. I found myself wanting to help participants with their struggles, but I focused on staying on track with the semi-structured questions.

Though I have a very similar background to the participants of this study, I am still twenty-some years removed from being an entry-level college student. When I started college, email was in its preliminary stages, cell phones were referred to as flip phones, as they were made of two pieces and had to be closed together when not in use. The cellphones were not "smart"-phones, so the internet was not at my fingertips, nor was it in my life except for the occasional use in a school computer lab. 
ENABLING AND THREATENING FACTORS AFFECTING PERSISTENCE

My passion for this dissertation topic is based upon my desire to enhance my understanding of the factors that affect persistence so that I may increase the success of rural first-generation STEM majors and students in general. My overall goal is to increase the awareness of underrepresented student's persistence. I hope that studies like this can help develop support mechanisms or interventions that increase student success. 
ENABLING AND THREATENING FACTORS AFFECTING PERSISTENCE

\section{Chapter 2: Literature Review}

\section{Persistence and Retention Theoretical Models}

Tinto (1975), author of the Theoretical Model of Dropout, was the first to relate individual attributes (family background and pre-college schooling) with the institution's academics (grade performance and intellectual development) and social systems (peer-group interactions and faculty interactions). In Tinto's 2006 article, he states:

We have learned much about the complex character of student persistence and have become more sophisticated in our thinking about how to promote persistence for different students and in different settings. But, as the data reveal, it is a journey that has only begun. (p.14)

Tinto acknowledges the vast knowledge that the field has gained, but realizes that retention and persistence is a "complex web" that needs further investigation (p.2).

Opatz (2013) and others see flaws in Tinto’s model, as it "lacks empirical support, has poorly defined terms that are difficult to measure, contains constructs that lack internal validity, and is only appropriate for certain types of students" (p. 13). Building upon what Tinto put together, Opatz developed his model of persistence, the Persistence Pyramid. His model is not solely based upon Tinto's model, but it was a significant influence. Tinto's work has been a historical component in the evolution of the retention and persistence field, impacting many researchers. Opatz relied upon the findings of numerous other authors: Astin (1977, 1993b), Bean (1985), Collins (1986), and Frye (1983), and combined his own practitioner knowledge to form the pyramid.

The pyramid is made of two main factors, the individual student factors and the campusbased environmental factors. The campus-based environmental factors form the base of the 


\section{ENABLING AND THREATENING FACTORS AFFECTING PERSISTENCE}

pyramid as they are foundational to student success, but a student needs less of this support as they get further through their program. The individual student factors make the edges of the pyramid going from the base to the apex. These student factors are the characteristics that they maintain through their process of degree attainment. These two significant factors do not work independently of each other, but are intertwined. Each of these main groups contains four subgroups. The student factors are: economic, social, psychological, and academic. The campus factors are educational and curricular support, support for diversity and community, involvement opportunities, and caring culture. Though Opatz (2013) used this model with low-income students, he believes that his model "...can be applied appropriately to a variety of demographic groups and institutions" (p. 19). Though the work of Tinto and Opatz is very informative, their work did not focus directly on RFGC STEM student's persistence. Therefore, further investigation of persistence factors related to this group is needed.

Tinto and Opatz's models set the groundwork for persistence studies, but they will not be used to direct this dissertation's methodology. Tinto's research is notated for historical and background purposes. Opatz's model is relatively new, and he suggests that the model can be used with varying demographics and institutions. Opatz's model will be used as a comparison in the conclusion of this study.

\section{Rural, First-Generation, STEM Students’' Persistence}

Research that explores the persistence of RFGC students in STEM undergraduate programs is limited. However, some studies have focused on one or multiple aspects of RFGC STEM persistence. These scarce studies focus on rural and/or first-generation and/or STEM, but not rural and first-generation and STEM (all three criteria combined). The following sections are organized according to the subsequent themes; general persistence factors for Appalachian first- 


\section{ENABLING AND THREATENING FACTORS AFFECTING PERSISTENCE}

generation college students, factors that enable persistence, and the factors that threaten

persistence. The sub-sections that compose the enabling factors affecting persistence are support, financial, status impact (rural or first-generation), institutional environment, and preparation. Sub-sections of the threatening factors affecting persistence are the same as the enabling ones, but with one additional section, the need for additional help. Due to the complexity of persistence elements, some factors can be found overlapping from one section to another. Several factors relate to other elements of persistence, and this makes it difficult to isolate them into specific categories.

\section{General persistence factors of Appalachian first-generation students.}

Studies in this section discuss factors affecting persistence, but they do not provide considerable details. Even though they lack extensive persistence details, they provide adequate information to form an overview of the general factors affecting persistence. The authors do not refer to the participants as rural residents, but they are from the Appalachian region, which is mostly rural. Another relation to this study is that the authors also focus on first-generation students' persistence.

Hunley (2015) describes two main categories of persistence as Participant Influences and Participant Experiences. He eventually breaks participant influences into two sub-categories: Family Influences (home expectations and challenges, and first-generation status) and Cultural Influences (rural upbringing and poverty, and Appalachian stereotypes). He sub-divides participant experiences into Social Experiences (campus connections, financial challenges, commuting experiences) and Educational Experiences (educational self-efficacy and teacher and staff relationships). Hunley went beyond just listing the factors as his research lead to the rank of these factors. His ranking from the most important to the least important factor affecting 


\section{ENABLING AND THREATENING FACTORS AFFECTING PERSISTENCE}

persistence is: family influences, cultural influences, social experiences, and academic experiences. He did not list these factors as enabling or threatening as the students had differing experiences and views toward these factors.

Hand and Miller-Payne (2008) list five factors that affect persistence and though the authors do not directly state whether the factors are enabling or threatening, they did offer details on the effect the factors have on students. Hand and Miller-Payne (2008) discuss similar points compared to Hunley's (2015) list, Importance of home and family; wish to stay close to home, emotional support from family, desire to have a better life, or accomplishing what their parents did not. They also mention Financial concerns; need for financial aid and retain what monetary awards they earned. Even if students have scholarships, there was still the need to work, but having to work reduces school involvement and study time. These students are concerned with losing their scholarships, and this adds to the students' determination to persist, as they must maintain a specific grade point average. Internal locus of control was another persistence factor by Hand and Miller-Payne. This is where students have a sense of responsibility for their own success (focus, determination, motivation, set goals, strategies to attain goals, monitor progress). They also do not blame their shortcomings on others or external factors such as luck, teachers, or lack of resources. Relationships and emotional support were also found to be important, as all participants made use of Student Support Services (SSS). SSS provides the students with emotional support and school personnel as mentors. Students with an internal locus of control, are more likely to reach out to faculty to get to know them or to get help with class topics. Communication of information was another common element in Hand and Miller -Payne's study. Most of the student comments were related to the lack of financial knowledge, but information on tutoring, career advice, and general issues was also desired. 
ENABLING AND THREATENING FACTORS AFFECTING PERSISTENCE

The previous studies provided a sufficient framework on persistence, but more specific information was needed to fully understand the variables related to RFGC STEM students' persistence. As this study focuses on participants that are from a rural region, are first-generation college students, and are majoring in a STEM field, the following sections only include those resources that investigated one of these criteria or a combination of the three.

\section{Factors that enable persistence.}

To fully understand a phenomenon, researchers need to take a holistic approach to the problem. If researchers only look at one side of an event, their understanding will be limited to that one view. Current research predicts if a student will be successful, but we need to have a better understanding as to why these predictors lead to success. For example, Medrano (2015) found that a student's college STEM course GPA in their first-year correlates to success in attaining a STEM certificate or degree. While this correlation is informative, it does not provide any means to increase the success of other students. We need to understand how students successfully navigate the first two years of higher education. We need to know how students overcome challenges and deficits to attain a degree. A few studies describe persistence factors that helped students in achieving their goals; these factors are considered enabling factors.

\section{Support - social capital and relationships.}

Studies report that students who have existing support networks consisting of family, peers, school personnel, and/or the community, were found to be successful (Beasley, 2011; Geier, 2016; Hand \& Miller-Payne, 2008; Phillips, 2015). These specific support networks enable students because they are encouraging positive influences on the student and align with their desire to attain a degree. In addition to the positive psychological effects, these relationships can lead to numerous beneficial opportunities (career, school involvement, academic success) 


\section{ENABLING AND THREATENING FACTORS AFFECTING PERSISTENCE}

(Beasley, 2011; Geier, 2016).

Some students do not have such support networks when they enroll in college, but develop them over time. Some students build their network from college personnel, fellow students (including study groups), faculty, and community members (Geier, 2016; Phillips, 2015; Uche, 2015). Some of these relationships lead to additional opportunities, such as internships and undergraduate research (Geier, 2016), which may accelerate one's career. Some of these networks were made possible due to the students' campus involvement as they befriended peers and community members that were of assistance in some manner (Uche, 2015; Phillips, 2015). The peer networks were especially beneficial if they served as an accountability group, and it did not matter if the students had similar backgrounds or not (Phillips, 2015). Some institutions and programs are proactive in providing support groups, as was the case for a research project for incoming STEM freshmen designed to match these students with STEM research mentors. This project not only increased the course success but also increased the number of students who desired to attain a four-year science degree (Ward, et al., 2014). Hand \& Miller-Payne (2008) interviewed students that were members of a program that assisted low-income first-generation students. They reported that "...our greatest attribute is that we are able to build one-on-one relationships with our students.... they can get a lot of these services someplace else on campus — tutoring, academic advising — but they don't get personalized attention" (Hand \& Miller-Payne, 2008, p. 10). While these studies described human support that enabled students to persist, financial support is an even more significant concern.

\section{Financial.}

Low-income status has been traditionally associated with rural and first-generation status. This is especially the case within the Appalachian region (Hand \& Miller-Payne, 2008). 


\section{ENABLING AND THREATENING FACTORS AFFECTING PERSISTENCE}

Obtaining financial assistance for these groups is essential as living expenses consume their individual and family income. Also, this group has very few, if any, additional financial resources. Not only is financial aid needed to enroll in higher education, but it must persist so that students can finish their degrees (Beasley, 2011; Geier, 2016; Phillips, 2015; Uche, 2015). In a rare case, Beasley reported that most of her participants did not have to work and received financial support from their parents, such as being able to live at home, transportation (car), and spending money.

Students are resourceful when it comes to funding unresolved financial need by securing jobs (on and off-campus) and by being frugal with school and everyday expenses (Hand \& Miller-Payne, 2008; Phillips, 2015; Schutz, 2003; Uche, 2015). Campus jobs, such as workstudy, may not fully cover financial need, and, therefore, students must secure additional employment (Hand \& Miller-Payne, 2008). Uche (2015) discussed one student's ability to focus on other needs due to institutional support that was in the form of two job opportunities. One job was related to the student's major, working in a chemistry laboratory. The combined school jobs enabled the student to purchase a car, which was a major need.

Attaining financial support can have a positive effect on persistence factors, such as reducing the need to work, which increases the time available for school and campus activities (Hand \& Miller-Payne, 2008). If students work less, they have more time for studying, meeting tutors and peers, and participating in both academic and extra-curricular activities. Being more active in school activities can lead to beneficial relationships with peers and school personnel, or even community members. These new relationships not only help with academics, but can open doors to career opportunities.

Students that receive academic scholarships have additional motivation, as they are afraid 


\section{ENABLING AND THREATENING FACTORS AFFECTING PERSISTENCE}

of losing this financial aid if their grades drop too low (Hand \& Miller-Payne, 2008). Students also worked harder on their academics because they did not want to disappoint those that contributed to their financial assistance (Uche, 2015).

\section{Status impact.}

For this section, status refers to being from a rural area and/or a first-generation college student. Being from a rural area, or being the first to go to college, is mostly thought of as a threatening factor to persistence, but it can also serve as motivation to attain a degree. Some students are driven to be successful in college because they view their potential degree as a means to a better life (Geier, 2016; Hunley, 2015). Other students are inspired to prove subjective people wrong because they have been stereotyped as not worthy or capable of attaining a degree because of their background (Beasley, 2011; Phillips, 2015). First-generation students have a sense of pride in themselves for being in college and for their family, as it is an accomplishment that is valued and supported by their family (Phillips, 2015; Schutz, 2004). These students strive to be successful, as they do not want to disappoint their family or miss out on the opportunity to attain a degree.

Students' experiences and their background can be advantageous to a college student, particularly in cases in which they have attained valuable skills or developed studious characteristics. Geier (2016) found that her participants drew from their previous experiences, which helped them to be successful. Students described these enabling abilities as work ethic, discipline, goal setting, ability to deal with adversity, and determination to not fold under challenging times. Phillips (2015) found that these students had specific strengths that enabled them to be successful. Two significant themes evolved as a result of these strengths of rural and first-generation students. The first theme was labeled as rural social skills, and students made 


\section{ENABLING AND THREATENING FACTORS AFFECTING PERSISTENCE}

comments related to being friendly, being unbiased, and having developed social skills due to their rural upbringing. These social skills enabled students to develop beneficial relationships with students and staff. The second theme, statuses serving as impetuses for success, includes work ethic, self-sufficiency, internal motivation or drive, not feeling entitled, being frugal, and having money management skills.

Schutz's (2003) findings correlate to those of Geier and Phillips, as he found that rural first-generation students have experience dealing with complex tasks and successfully overcome challenges. Many students with a rural or first-generation status found themselves in positions or situations (work, home responsibilities, etc.) that helped form their self-efficacy and pride.

\section{Institutional environment.}

An institution's environment or atmosphere can be a catalyst for developing a student's support network. Phillips (2015) states explicitly that the positive environment of the campus, along with available resources and opportunities, can assist students in persisting. Several successful participants were found to be actively involved with campus activities (Geier, 2016; Hunley, 2015; Phillips, 2015; Tinto, 1975). Rural first-generation students and parents are unaware of the opportunities and resources that an institution provides. They are also oblivious to the importance of a campus support network for a student to be successful. Students that are involved with campus activities tend to develop relationships that lead to support networks or assist students in utilizing institutional resources (Geier, 2016). Some students are proactive in connecting to campus personnel, such as faculty. Those students who have had positive experiences with high school teachers or those who realize the benefit of developing faculty relationships take the initiative to meet their professors (Beasley, 2011; Hand \& Miller-Payne, 2008). 
ENABLING AND THREATENING FACTORS AFFECTING PERSISTENCE

\section{Preparation.}

Though one's status or upbringing can be thought of as preparation, this section will mainly focus on academics. Regarding persistence indicators, Uche (2015) found that higher GPA, higher levels of mathematics and science in high school correlated with successful STEM majors. Upper-level high school courses were found to be strengths, as those who took AP or honors classes felt that their school prepared them for college-level courses (Beasley, 2011). Specific teachers were mentioned as reasons that students felt prepared for their higher education courses. These teachers did not teach advanced courses, but students felt that the content that was and the teacher's expectations made them more prepared for college (Beasley, 2011; Uche, 2015).

Additional items that students felt benefitted them were not a result of a specific course or teacher. How the student adapted or developed over their academic career was found to be beneficial. Students emphasized that they were good students in high school, loved to learn, acquired excellent study skills, or developed a strong work ethic (Hunley, 2015). In an all-female study, extra-curricular activities were found to generate confidence and a healthy competitive nature in and out of the classroom (Geier, 2016).

\section{Factors that threaten persistence.}

The previous sections discussed items that were believed to be factors that enable persistence. The following sections are elements that are thought of as threatening factors or those items considered to be challenges, issues, or even weaknesses. Due to the complexity of persistence, some elements that were stated as enabling may also be considered threatening factors. For example, relationships were shown to be impactful on student success; this is especially true with peers. Some friends help students through tough times, while others may be 
ENABLING AND THREATENING FACTORS AFFECTING PERSISTENCE

the cause of troubles or issues. Peers are an enabling factor, if they are encouraging and supportive of a student's scholastic objectives. If peers are not supportive or understanding, they can then be threats to a student's persistence.

\section{Support - social capital and relationships.}

If a student's social interactions are not supportive or encouraging to completing a degree, this interaction may have a catastrophic effect on his/her persistence. Beasley (2011) found that significant others (boyfriends, girlfriends, spouses) can persuade students into quitting school or not even enrolling, even if an athletic scholarship is available. Phillips (2015) found family and community to be enabling factors, but they have also discouraged students from college. One of Phillips' participants cited, "My mother was very upset with me. She told me if I went there, she would disown me, so I didn’t go there” (p. 145). One girl said, “I think some people- -some parents I think around here tell 'em that it's pointless, that college is pointless" (Beasley, 2011, p. 180). Beasley also found that students were hesitant to leave their hometown; "I love it here, so it's where you're born and raised. There is an attachment to the place, but it is the attachment to family that creates or strengthens this attachment to place" (p. 110). Family is another important aspect of a student's support network. Wilson and Kittleson (2013) report that when family expectations and student academic goals did not align, tension grew between the student and family. Students must decide between schoolwork and family desires, which adds to their stress level.

Students may experience a lack of a STEM role model and, because of this, they may have lower STEM career expectations (Versypt \& Ford-Versypt, 2013). Those students without a STEM mentor had less desire to attain a bachelor's degree in STEM, let alone a higher-level degree. If students do not have this support, or do not adjust and create an enabling support 


\section{ENABLING AND THREATENING FACTORS AFFECTING PERSISTENCE}

network, they may be at a disadvantage compared to those who do. Some students wished that they had someone to guide them with their college decisions (Phillips, 2015; Uche, 2015). These students reported that they were unaware or uninformed about college or their chosen major or both. Students in this situation may drop out as they realize that the major or school that they wanted is not for them.

Geier (2016) found that social integration was a product of time. Some students did not have the time for socializing and campus involvement because their home or work responsibilities, or both, required most of their time. Some of the students that Geier studied eventually had time to socialize and partake in campus activities. They realized the benefit of social capital, peers, faculty, and other campus personnel (2016).

\section{Financial.}

It comes as no surprise that finances were found as a challenge to students' continuation of their education (Beasley, 2011; Geier, 2016; Hunley, 2015; Phillips, 2015; Uche, 2015; Versypt \& Ford-Versypt, 2013). In general, people compare the cost of attaining a bachelor's degree with a home mortgage. This vast expense can be a significant burden to individuals or their families or both. Some students specifically mentioned that the lack of family financial support might cause them to drop out (Hand \& Miller-Payne, 2008; Uche, 2015). But the cost of tuition is not the only way that finances impact student persistence. Some college costs came as a surprise to students (Schutz, 2004) as they found that there are additional costs to participate in certain activities (athletics, sorority, study abroad) (Phillips, 2015). Specific majors carry additional fees, such as program fees, additional test fees, higher book costs, and lab fees (Hunley, 2015; Hand \& Miller-Payne, 2008). These additional costs can limit the student's educational experiences and even drive them out of their desired major. 


\section{ENABLING AND THREATENING FACTORS AFFECTING PERSISTENCE}

Because most of these students need to work, many of them struggle to find a balance between home life, work, and school (Geier, 2016; Phillips, 2015; Wilson, Lyons, \& Quinn, 2013). Students outside of the RFGC status may not struggle with this home, work, and school conflict as more finances may be available to them; "My roommate from first year, she's kind of like a rich girl from Chicago and she doesn't understand why I have to have a job." (Hand \& Miller-Payne, p. 8). While maintaining a set GPA, for financial aid purposes, was previously found to be a positive factor, other students stated that this was added pressure and threatened their persistence (Beasley, 2011). Because of the financial burden of higher education, some students spend vast amounts of time researching, applying for, and making themselves better candidates (volunteer work, etc.) for scholarship opportunities (Geier, 2016). Even before enrolling in a school, students feel this pressure as they need to make decisions that are impacted by financial considerations. If an institution has a drastic price difference, or if their desired program has additional costs, the student may need to make a decision that contrasts their desires as their top choice may cost more than they can afford or are willing to pay (Geier, 2016).

\section{Status impact.}

Student status (rural or first-generation) was found to be an enabling factor, but it can also serve as a threat or weakness to persistence. Numerous first-generation students talked about their feeling of being lost or that they lacked direction because the student and family members were unaware of college proceedings. Common themes related to feeling lost were: the financial aid process, various other institutional forms, educational opportunities (study abroad, tutoring, etc.) or even what to do when faced with an issue or challenge (where to get help) (Beasley, 2011; Schutz, 2003; Phillips, 2015). Some students were missing the drive or interest in their field as they were unsure of their college path; they just thought they needed to go to college 
ENABLING AND THREATENING FACTORS AFFECTING PERSISTENCE

(Phillips, 2015).

Students felt uncomfortable on campus because they were different from most others on campus. Students felt inferior due to their clothing and lack of technological skills or devices (Phillips, 2015; Schutz, 2003). These students also experienced social awkwardness with having to work and with differences in work ethic and entitlement. Beasley (2011) found that negative stereotypes impacted the student's confidence and expectations, as some of her participants were made fun of for their accents and clothing. This tension was so high that some students felt the need to fit in and changed their style or who they were to acclimatize to the campus environment (Schutz, 2004; Phillips, 2015). Schutz (2004) found that the lack of a rural setting adversely impacted the student's view of college and their continuance in their career path.

\section{Institutional environment.}

Some authors grouped threatening factors according to institutional context, either by the environment or atmosphere. Most of these factors have already been reported under the persistence headings of financial or status impact, so they will not be repeated here. Numerous elements of persistence are intertwined and some even have a cause and effect relationship; one such factor is time. Time can be an issue for anyone as they balance work, family (home responsibilities and relationship building), the need for rest, and other obligations. Students have additional time requirements with classes, studying, and other school activities. Rural firstgeneration students may need extra time to travel to school (Wilson, Lyons, \& Quinn, 2013), as many cannot afford to live on or near campus. Additional time is frequently needed with home responsibilities, such as caring for family members, tending to the family business or farm, and with general chores (Phillips, 2015; Wilson, Lyons, \& Quinn, 2013). Wilson and Kittleson (2013) found that female, first-generation science majors struggled with managing their time 


\section{ENABLING AND THREATENING FACTORS AFFECTING PERSISTENCE}

with the need to study, work, and maintain personal relationships. The competitive nature of STEM classes made for a high-pressure environment as students referred to some courses as "weed out classes" (Wilson \& Kittleson, 2013; Geier, 2016). In addition to the competitiveness of STEM courses, Geier (2016) also states that students found it challenging to adjust to college as students experienced distinctly different expectations from college faculty compared to high school. Some students felt that college was more rigorous, and they had to work harder to maintain scholarships (Beasley, 2011; Geier).

\section{Preparation.}

To minimize the number of threatening categories, those items related to a student's previous education (formal or informal), life experiences, and self-efficacy will be summarized in this section.

Students that have successful high school experiences with mathematics and science courses are more likely to be successful in college STEM courses (Uche, 2015). Other students were found to be absent of these enriching experiences in mathematics and science and, therefore, these courses are viewed as barriers to their success. This is especially true for students that experience lower quality mathematics and science classes or had no advanced STEM course options (Beasley, 2011; Uche, 2015; Versypt \& Ford-Versypt, 2013). Students were concerned about possible failure as they felt unprepared for college-level classes, especially mathematics (Beasley, 2011). Participants described their mathematics courses as low-quality, given that they rarely had a steady teacher or teachers were not certified (Beasley, 2011). Low-quality educational experiences can impact a student's college entry scores to the point that students need to take remedial courses (Beasley, 2011). If a student is interested in a STEM field, and they are required to take remedial mathematics, they are already behind with mathematics 


\section{ENABLING AND THREATENING FACTORS AFFECTING PERSISTENCE}

requirements. Such studnets may also be limited in taking other classes as mathematics is a prerequisite to specific STEM courses. Student's early high school experiences may have deterred them from taking STEM college-prep courses on time. One student described that her first high school science course was unfavorable, especially with the lack of laboratory activities. This led to the student not taking chemistry until her senior year, and she regretted not taking it earlier (Uche, 2015). Uncertified teachers, quality of classes, and access to upper-level courses are not the only cause of poor preparation, as students realized that they were not very good students in high school (Hunley, 2015). Students that are aware of their deficiencies, such as not being studious, is a benefit to them. If students are aware of their weaknesses, they can adjust or reach out for help if they desire.

\section{Need for additional help.}

Researchers suggest that institutions need to be more aware of the needs and challenges that rural first-generation students face (Phillips, 2015). Rural and first-generation students need to be recognized as an underrepresented group in higher education (Versypt \& Ford-Versypt, 2013). Student unawareness or inexperience is a significant reason for institutions to provide additional and more focused guidance for rural first-generation students. Schutz (2004) and Beasley (2011) explicitly state areas in which students are more likely to be ill-informed: higher education costs, benefits of relationship building, the rigor of college courses, course structure, and professor expectations. Phillips recommended several ways that the institution can support these students. Colleges can increase communication efforts and information sharing, especially with how college works. Institutions need to make sure that students are aware of the available institutional resources along with offering information sessions on academic success tips, budgeting skills, and career advice. Phillips also states that the institutions can create a more 
ENABLING AND THREATENING FACTORS AFFECTING PERSISTENCE

empathetic environment by increasing faculty and campus personnel's awareness of rural firstgeneration issues.

Advising and career counseling can be a beneficial resource for these students, as some of these students are uncertain of their career choices. A study on first-year rural students in Australia found that students had numerous reasons why they were thinking about withdrawing from school. The most common reasons were changing their major or uncertainty about their major or wavering interest (Wilson, Lyons, \& Quinn, 2013). Uche (2015) and Ward, et al. (2014) found similar student experiences and feelings. Uche found that students wished that they had more guidance in choosing a school and major. Appropriate support networks can help guide students with academic decisions making them more successful and giving them greater desire and determination. Ward and others studied the effect of research mentors with Cheyenne freshmen and sophomores. They found these relationships to be beneficial to academic success along with an increase in a students' desire to continue to a higher degree.

\section{Faculty view of STEM student's persistence.}

Research that reports on faculty or staff views on factors that enable and threaten students to persist are very minimal. Gandhi-Lee, Skaza, Marti, Schrader, and Orgill (2015) investigated faculty views on the barriers to STEM student success and their perceptions of what makes a successful STEM student. The authors found that the faculty believed that students have specific characteristics that are key to student success. These characteristics involve curiosity and engagement in their STEM field. They also tend to have excellent problem-solving capabilities, the ability to synthesize information, good communication skills, strong work ethic, and positive attitudes. All 27 of the faculty interviewed viewed mathematics (knowledge and skills) as a threatening factor to persistence. In addition to a lack of mathematics ability, they also stated that 
ENABLING AND THREATENING FACTORS AFFECTING PERSISTENCE

the students' fear of mathematics limited their ability to be successful. Only a handful of the faculty (six of the 27) believed that high school content knowledge was a critical factor to success. Five of the 27 faculty thought that students who had general STEM skills and studious characteristics could be successful in learning STEM content, no matter their previous knowledge attainment. 
ENABLING AND THREATENING FACTORS AFFECTING PERSISTENCE

\section{Chapter 3: Methodology}

\section{General Overview}

This chapter discusses the participants, study instruments, procedures, and data analysis. West Virginia University's Institutional Review Board (IRB) has reviewed and approved this human subject study, IRB Number 1705589537. The purpose of this study is to determine the factors that enable and threaten RFGC STEM students' persistence. RFGC STEM students and STEM faculty from five West Virginia (WV) institutions were surveyed and interviewed. The students were from a rural area, first-generation college students, and have freshmen or sophomore status, majoring in a STEM field. Additional details on participant selection can be found in the procedures section. Instruments used in this study include survey instruments and semi-structured interviews for both RFGC STEM students and STEM faculty. The instrumentation section will discuss the development of the survey instruments and the semistructured interview questions. The procedure section describes how participants were selected and how the instruments were administered. See Appendix $C$ for a timeline visual of when the surveys and interviews were administered. The last section of this chapter is data analysis, which includes both quantitative and qualitative data. Quantitative data was analyzed with descriptive and inferential statistics to determine the factors affecting persistence based on the survey data. Content and thematic procedures were the basis of the qualitative analysis to determine themes derived from the interviews. All the data collected was used to answer the following questions: RQ1: What factors enable the persistence of RFGC students in STEM majors?

a. What do RFGC STEM majors perceive as factors that enable them to persist?

b. What do faculty view as the factors that enable RFGC STEM students to persist?

RQ2: What factors threaten the persistence of RFGC students in STEM majors? 
ENABLING AND THREATENING FACTORS AFFECTING PERSISTENCE

a. What do RFGC STEM majors perceive as the factors that threaten their persistence?

b. How do RFGC STEM majors handle or deal with the challenges they face?

i. What are their successful means to adapting to these challenges?

ii. How do these challenges change over time as a STEM major?

c. What do faculty view as the factors that threaten RFGC STEM students' persistence?

\section{Participants}

The previous literature related to RFGC STEM persistence is not only limited in quantity, but is also limited in the diversity of samples. Most of the previous studies were conducted at a single institution and, therefore, had a limited sample size. This limited the participant diversity of these studies. This study involves participants from five WV institutions that vary in Carnegie Classification from Doctoral Universities, Very High Research Activity to Baccalaureate Colleges: Diverse Fields (The Carnegie Classification of Institutions of Higher Education, n.d.) and included both private and public schools. This expanded sample size produced a more robust and diverse group of participants as compared to previous studies.

Student and faculty participants were self-selected when they accessed the survey. The survey was accessed by clicking on the link that was contained within in the email that advertised the study. Interview participants were identified when they answered "Yes" to the survey question concerning their willingness to be interviewed. A sub-group of the RFGC STEM group is made of students who decided to withdraw from their chosen STEM degree. These students decided to either pursue a non-STEM degree or decided to withdraw from higher education altogether. This group will be referred to as the Exodus group. 
ENABLING AND THREATENING FACTORS AFFECTING PERSISTENCE

\section{RFGC STEM survey participants.}

The RFGC STEM group were either freshmen or sophomore students attending a WV institution of higher education. They possessed the following characteristics: (a) from a rural area (R) as defined by NCES-CCD coding, (b) first-generation college (FGC) students, and (c) are enrolled in a National Science Foundation approved STEM field. See Appendix B for the list of approved STEM fields. The survey was administered at two different periods, in the Spring of 2018 and the Fall of 2018. Given that the survey was administered at two different points, each survey had its own set of participants. Some participants were in both samples if the institution included them in both STEM student lists, and the student decides to take both surveys.

The students who participated in this study were initially identified as a STEM major by their home institution. The student survey was sent out to nearly 6,800 freshmen and sophomore STEM majors across WV. There were over nine hundred people that responded to the email invite. Of those who accessed the survey, 321 students self-identified as a first-generation college student. These respondents were sorted to determine their rural status, and 125 participants were identified as RFGC STEM students. Table 1 shows a breakdown of the students' STEM majors. The number of majors and student backgrounds does not equal the number of participants because participants were not forced to answer demographic questions, and students were given the option to choose multiple answers for those with diverse backgrounds and multiple majors. The females $(n=67)$ outnumbered the males $(n=43)$, and no participants selected "Other" as a gender option. The participants represent typical freshmen and sophomores, as the average age of the participants was 19.75 , with a range of 18 to 38 . This group is academically above average, considering their self-reported overall GPA was 3.29. Student backgrounds are summarized in Table 2. 
ENABLING AND THREATENING FACTORS AFFECTING PERSISTENCE

Table 1

RFGC STEM Students' Majors

\begin{tabular}{cc}
\hline STEM Major & $n$ \\
\hline Biology & 18 \\
Biochemistry & 3 \\
Chemistry & 13 \\
Computer Science & 8 \\
Engineering & 30 \\
Geoscience & 2 \\
Mathematics & 2 \\
Mathematics Education & 3 \\
Physics/Astronomy & 2 \\
Psychology & 5 \\
Science Education & 3 \\
Social Science & 9 \\
Other & 7
\end{tabular}

Table 2

RFGC STEM Students' Background

\begin{tabular}{cc}
\hline Background & $n$ \\
\hline American Indian/Alaska Native & 3 \\
Appalachian & 36 \\
Asian & 1 \\
Black/African American & 4 \\
Hispanic/Latino & 1 \\
Native Hawaiian/Pacific Islander & 1 \\
White & 105 \\
\hline
\end{tabular}


ENABLING AND THREATENING FACTORS AFFECTING PERSISTENCE

\section{STEM faculty survey participants.}

This group is made of faculty who teach a STEM course at a West Virginia (WV) institution. Each institution's list of available STEM majors and the NSF approved STEM fields were cross-referenced to ascertain corresponding STEM faculty.

Invitations to the survey were sent out to 706 WV STEM faculty, and 122 faculty accessed the survey and gave their consent. Though there were 122 faculty that consented to the survey, the number of responses for each survey question was between 60 and 70 . Basic demographic information was collected from the survey instrument. Table 3 shows a distribution of the faculty's subject area. The group's identified gender was mostly female $(n=34)$ followed closely by the male faculty $(n=33)$ and one participant chose "Other" as their gender. The demographic background of the faculty participants was largely White $(n=65)$, with one participant each choosing American Indian/Alaska Native and "Other" Group. Table 4 lists the distribution of the Faculty Rank for this group. The faculty come from a range of urban-rural areas, as most reported that they grew up in a Rural area $(n=27)$, followed by Town $(n=20)$, and the same number of faculty listed City and Urban $(n=11)$.

\section{Semi-structured interview participants.}

Within the survey questionnaire, RFGC STEM students and STEM faculty were asked if they would be willing to volunteer for an interview. Participants indicated their willingness to be interviewed by answering yes or no to this survey question. If they answered yes, the survey instrument asked for the participant's preferred email so that an interview could be scheduled. As mentioned above, a sub-group of the RFGC STEM students are those who decide to leave their chosen STEM field or higher education altogether (Exodus group). This group was determined 
ENABLING AND THREATENING FACTORS AFFECTING PERSISTENCE

by a set of survey questions that asked about their intentions on continuing in a STEM major and returning to school the next semester.

Table 3

Faculty Subject Area

\begin{tabular}{ccc}
\hline Subject & $n$ & Percentage \\
\hline Chemistry & 4 & $5.88 \%$ \\
Computer Science & 2 & $2.94 \%$ \\
Engineering & 6 & $8.82 \%$ \\
Geosciences & 2 & $2.94 \%$ \\
Life Sciences (Non-medical) & 15 & $22.06 \%$ \\
Materials Research & 0 & $0.0 \%$ \\
Mathematics & 14 & $20.59 \%$ \\
Physics or Astronomy & 7 & $10.29 \%$ \\
Psychology & 10 & $14.71 \%$ \\
Social Science & 4 & $5.88 \%$ \\
STEM Education & 2 & $2.94 \%$ \\
Other & 2 & $2.94 \%$ \\
\hline
\end{tabular}

Table 4

Faculty Rank

\begin{tabular}{ccc}
\hline Faculty Rank & $n$ & Percentage \\
\hline Emeritus Professor & 1 & $1.43 \%$ \\
Full Professor & 23 & $32.86 \%$ \\
Associate Professor & 18 & $25.71 \%$ \\
Assistant Professor & 16 & $22.86 \%$ \\
Instructor/Lecturer & 5 & $7.14 \%$ \\
Part-time & 7 & $10.00 \%$
\end{tabular}

This question was included on both rounds of the survey instrument for RFGC STEM students. If a participant responded that they were not returning to school or was not continuing 
ENABLING AND THREATENING FACTORS AFFECTING PERSISTENCE

in a STEM field, the survey asked them to volunteer for an interview and those who agreed were asked to provide their preferred email address. Demographic information for student interviews can be found in Table 5 and for faculty in Table 6. One Exodus student agreed to an interview, Chris, and his demographic information is included with the other RFGC STEM students.

Table 5

Interview Demographics, RFGC STEM Students

\begin{tabular}{|c|c|c|c|c|c|}
\hline Name & Major & School & Year & $\underline{\text { Background }}$ & Age \\
\hline Ariel & Engineering & $\begin{array}{c}\text { Doctoral Universities, } \\
\text { Very High Research }\end{array}$ & FR & White & 18 \\
\hline Misty & $\begin{array}{l}\text { Computer Science \& } \\
\text { Math (was Business) }\end{array}$ & $\begin{array}{l}\text { Master's Colleges \& } \\
\text { Universities: Small }\end{array}$ & $\mathrm{SO}$ & White & 32 \\
\hline Brenda & $\begin{array}{c}\text { Sociology/Criminolog } \\
\text { y (was Biology) }\end{array}$ & $\begin{array}{l}\text { Master's Colleges \& } \\
\text { Universities: Medium }\end{array}$ & $\mathrm{SO}$ & $\begin{array}{c}\text { White, } \\
\text { Hispanic, } \\
\text { Black }\end{array}$ & 19 \\
\hline Michael & Mechanical Engineer & $\begin{array}{c}\text { Master's Colleges \& } \\
\text { Universities: Small }\end{array}$ & FR & White & 19 \\
\hline Courtney & Biology & $\begin{array}{l}\text { Master's Colleges \& } \\
\text { Universities: Small }\end{array}$ & SO & White & 19 \\
\hline Don & $\begin{array}{l}\text { Computer Science } \\
\text { and Computer } \\
\text { Engineer (was } \\
\text { Biology, Pre-med) }\end{array}$ & $\begin{array}{c}\text { Doctoral Universities, } \\
\text { Very High Research }\end{array}$ & SO & White & 20 \\
\hline Abigail & Mechanical Engineer & $\begin{array}{c}\text { Master's Colleges \& } \\
\text { Universities: Small }\end{array}$ & $\mathrm{SO}$ & $\begin{array}{c}\text { Appalachian, } \\
\text { American } \\
\text { Indian, } \\
\text { Alaska } \\
\text { Native }\end{array}$ & 32 \\
\hline Brandy & Computer Science & $\begin{array}{c}\text { Doctoral Universities, } \\
\text { Very High Research }\end{array}$ & $\mathrm{SO}$ & White & 20 \\
\hline Devin & $\begin{array}{l}\text { Electrical Engineer } \\
\text { Technology }\end{array}$ & $\begin{array}{c}\text { Master's Colleges \& } \\
\text { Universities: Small }\end{array}$ & FR & White & 19 \\
\hline Kerri & Biology, Pre-med & $\begin{array}{c}\text { Master's Colleges \& } \\
\text { Universities: Small }\end{array}$ & FR & White & 18 \\
\hline $\begin{array}{c}\text { Chris } \\
\text { (exodus) }\end{array}$ & $\begin{array}{l}\text { Bio Preprof - now } \\
\text { Music Educ }\end{array}$ & $\begin{array}{l}\text { Master's Colleges \& } \\
\text { Universities: Medium }\end{array}$ & FR & White & 18 \\
\hline
\end{tabular}


ENABLING AND THREATENING FACTORS AFFECTING PERSISTENCE

Table 6

Interview Demographics, STEM Faculty

\begin{tabular}{cccc} 
Name & STEM Field & School & $\underline{\text { Years of }}$ \\
Deb & Mathematics & & Doctoral Universities, Very High Research \\
Will & Physics & Doctoral Universities, Very High Research & $20+$ \\
Amy & Biology & Doctoral Universities, Very High Research & 18 \\
Lydia & Mathematics & Master's Colleges \& Universities: Small & 17 \\
Josh & Political Science & Master's Colleges \& Universities: Medium & 20 \\
Margo & Psychology & Master's Colleges \& Universities: Small & 17 \\
Nik & Chemistry & Master's Colleges \& Universities: Small & $20+$ \\
Robert & Chemistry & Master's Colleges \& Universities: Small & 18 \\
Paige & Astronomy & Doctoral Universities, Very High Research & 4 \\
Mike & Engineering & Master's Colleges \& Universities: Small & 11 \\
\hline
\end{tabular}

\section{Instrumentation}

\section{Survey questionnaires.}

Survey questionnaires for RFGC STEM students and the faculty were developed and administered in the spring of 2017, as a pilot study. The pilot instrument was developed from two previously used instruments. For the RFGC STEM student survey, the section on STEM barriers, survey Question 11, was developed from the 2016 Your First College Year Survey (Higher Education Research Institute, 2016). This question was also included in the STEM faculty survey as Question 2. No reliability information was found for the original survey instrument for this survey question. Following the piloting of this adapted survey instrument, changes and additions were made based upon feedback from the participants and STEM education professionals. 
ENABLING AND THREATENING FACTORS AFFECTING PERSISTENCE

\section{Survey validity.}

Modifications were made to clarify questions based upon the pilot participants' feedback. Additional questions or statements were added to the demographic section to collect additional information or for clarification purposes. For example, one demographic question asked if the student was employed; there was confusion as to what would count as "employment." Additional demographic questions were added to aid in determining the student's status, such as home address zip code, first-generation college status, academic status, and sibling college status. Outside of the demographic adjustments, survey items were adjusted as described in the reliability section.

\section{Survey reliability from Spring 2017 pilot $(n=35)$.}

The STEM Barriers items, Question 11 of the RFGC STEM survey and Question 2 of the STEM faculty survey contain 18 items and were found to be acceptably reliable $(\alpha=0.86)$ using Cronbach's alpha. To gain a more accurate view of participants' views, participants were given the option to add additional comments after each of these Likert type scale items. One additional open-ended question was added at the end of this survey question: "What other challenges make staying in your STEM classes/major difficult?”

After each Likert type scale item, participants are given the option to add additional comments. One open-ended item was added to this question: "Do you have anything else to add in regard to your rural background and relation to college?" The final version of the RFGC STEM survey can be seen in Appendix D.

As mentioned above, Question 2 of the STEM faculty survey was found to be reliable. The rest of the STEM faculty survey is composed of items that inquire about demographics, faculty development experiences, and characteristics concerning the courses that the faculty 
ENABLING AND THREATENING FACTORS AFFECTING PERSISTENCE

teach. Pilot participants were asked about the understandability and clarity of the survey, and it was determined that no necessary adjustments were needed. To make sure that faculty views were understood, participants were given the option to add additional comments for each Likert type item in the faculty survey. The final version of the faculty instrument can be found in Appendix E.

\section{Semi-structured interviews (face-to-face or phone).}

In addition to the survey questionnaire, RFGC STEM students were asked to participate in semi-structured interviews. Semi-structured interview questions were created to conduct individual interviews. The questions were made by the researcher with feedback from STEM education professionals and students who piloted the interview questions. Students who piloted the July 2017 interview protocol stated that they did not have any issues understanding the questions. In addition to the pilot feedback, a cross-reference was made with Aaron Phillips' dissertation interview protocol (Phillips, 2015). Phillips' study was based on rural firstgeneration students' strategies related to persistence. Given the close relationship to this study, Phillips' interview questions made for a quality reference. A comparison of the interview protocol confirmed that the RFGC STEM interview questions were appropriately worded to derive participant's views related to their persistence. With the review of Phillips' questions and procedures, it was determined that a ranking of the enabling and threatening factors would be beneficial for this study. Additional details of this process can be found in the procedures section.

Semi-structured interview questions are slightly different for the Exodus group as compared to the RFGC STEM students that remain in their chosen STEM major. The Exodus students were asked additional questions to determine their rationale for why they are leaving a 
ENABLING AND THREATENING FACTORS AFFECTING PERSISTENCE

STEM major or higher education altogether. It is vital to individually ask Exodus students what their rationale is for leaving their desired STEM path as this group's experiences and perceptions were not found in the literature.

Semi-structured interview questions were designed to help understand the views of the STEM faculty as to what threatens and what enables RFGC STEM students' persistence.

Interview questions and related instrumentation items can be found in the appendices section and the following table summarizes these items.

Table 7

Instrumentation Related Appendices

\begin{tabular}{cc}
\hline Instrumentation Item & Appendix \\
\hline Instrument Timeline & $\mathrm{C}$ \\
RFGC STEM Student Survey & $\mathrm{D}$ \\
STEM Faculty Survey & $\mathrm{E}$ \\
RFGC STEM Student Interview Questions & $\mathrm{F}$ \\
STEM Faculty Interview Questions & $\mathrm{G}$ \\
Exodus Interview Questions & $\mathrm{H}$ \\
\hline
\end{tabular}

\section{Procedure}

\section{Encouraging participation.}

To urge RFGC STEM students to complete the survey instruments, each survey participant was eligible for a 25-dollar gift card. Each round that the survey was administered, a gift card was given to a randomly chosen student participant. For each round of the student survey and for the one round of the faculty survey, two reminder emails for each round were sent out to maximize response rates.

\section{Participant selection.}




\section{ENABLING AND THREATENING FACTORS AFFECTING PERSISTENCE}

The selection of student participants was a multiple-step process. This process involved merging institutional data and survey data to identify potential participants. The first step for participant selection was to attain a list from each institution consisting of all STEM majors according to the institution. This initial list was cross-referenced with the approved NSF STEM fields to select appropriate majors. Some institutions were able to sort their STEM majors once they were given a list of NSF approved STEM fields. If an institution's STEM list was not sorted by freshmen or sophomore status, this was completed by the researcher. The majority of the institutions do not track a student's first-generation status. Even if this information was available, the definition of first-generation typically varies from school to school. For this study, a student's first-generation status is defined as neither parent(s) nor guardian(s) graduated from an institution of higher education, and, therefore, have not attained a bachelor's or associate degree (Childs, 2015; Geier, 2016; Dika \& D'Amico, 2016). Institutional data did not provide students' high school zip codes, which were needed to identify a student's rural status. First-generation and rural status would need to be obtained from the survey instrument.

The survey instrument was sent to all Freshmen and Sophomores that were in an NSF approved STEM major. The survey instrument included questions that identified participants as first-generation and collected the student's high school name and zip code. Survey data and institutional data were cross-referenced to develop a list of students that were Freshmen or Sophomores, NSF approved STEM majors, and self-identified first-generation. This list was sorted for rural status by utilizing a student's high school zip code, and if needed, the high school name. The zip code provided by the student was compared to a national database of schools' urban-rural status. The National Center for Education Statistics [NCES] Common Core of Data 
ENABLING AND THREATENING FACTORS AFFECTING PERSISTENCE

(CCD) provides access to an elementary and secondary school database, ElSi

(Elementary/Secondary Information System).

The online access tool for this database is called the Data Query Tool. One of the searchable school characteristics is Urban-centric Locale. An Urban-centric Locale code lists each school as either city, suburban, town, or rural. A school's overall Locale code is based upon the majority of its students and the locale that they reside in. For example, if a school was located in a suburban location, but the majority of its students were from a rural area, that school's Urban-centric Locale code would be rural. Using the Data Query Tool, a spreadsheet was downloaded that included: school name, zip code, and locale code. The student's high school name and zip code were cross-referenced (Excel's VLOOKUP) with the spreadsheet to identify rural participants. These steps led to a list of potential participants that were rural, firstgeneration, STEM majors who were in either their Freshmen or Sophomore year. This process was completed twice, once in the spring of 2018, and again in the fall of 2018. This enabled the researcher to gather data from a fall semester and a spring semester to help determine changes that students may experience over time. Some students were participants in both rounds of the survey, fall and spring.

Institutional data was also used to identify WV faculty who teach NSF-identified STEM courses. The researcher provided each institution with a list of programs that match the approved NSF STEM fields. Institutions then used this information to sort their faculty population to produce a list of potential STEM faculty participants. For a few institutions, the published school directory was sorted to develop the faculty list.

Potential participants' information was stored in a group (student or faculty) spreadsheet for organization and communication purposes. An initial email advertisement, which included a 


\section{ENABLING AND THREATENING FACTORS AFFECTING PERSISTENCE}

link to the survey, was sent to all potential participants. The first question of the survey determined consent and appropriate age, which was considered 18 years of age or older. If a respondent did not consent, they were not allowed to view the rest of the survey. Those that consented became official participants of this study.

Participants for interviews were selected from the survey results. One of the survey questions asked for interview volunteers. If respondents agreed to volunteer for an interview, their contact information was collected to set up an interview.

Exodus students, those who dropped out of college or switched to a non-STEM major, were identified by the survey. The survey asked each person their current major and their intent to continue in that major. If a person responded that they are no longer enrolled or switched majors, their contact information was collected to set up an interview.

\section{Survey administration.}

This study collected initial data from RFGC STEM students and STEM faculty by a corresponding survey. These surveys were identical except for the wording of the questions. The faculty survey was adjusted so that the questions made sense to a faculty member answering questions about RFGC STEM students. The RFGC STEM student survey was administered twice. The first round of the survey was administered in the spring of 2018 and was first available on February $9^{\text {th }}$ and closed on March $12^{\text {th }}$. The second round of the RFGC STEM survey was administered in the fall of 2018 , and it started on November $15^{\text {th }}$ and closed on December $22^{\text {nd }}$. The STEM faculty survey was administered once in the spring of 2018 and was open from March $29^{\text {th }}$ until May $6^{\text {th }}$. An overview of the survey and the interview timeline can be found in Appendix C 
ENABLING AND THREATENING FACTORS AFFECTING PERSISTENCE

\section{Interview protocol.}

All participants that volunteered for interviews were contacted for interviews. All student volunteers were interviewed, including the one Exodus student. Most of the faculty volunteers were interviewed, except for two faculty, who stopped responding to emails.

All semi-structured interviews, RFGC STEM, RFGC STEM Exodus, and STEM faculty were conducted face-to-face or by phone. Interviews were audio-recorded to ensure that accurate data was collected. Transcription of interviews was initiated using audio-to-text technology to produce a draft transcription. The draft transcription was then reviewed and edited by the researcher by replaying the interview recording until the transcription was deemed accurate. The transcription was then forwarded to each corresponding interview participant for member checking. Content and thematic analysis utilizing grounded theory concepts were applied to develop themes for group's interviews. Further details on member checking and analysis are found in the Analysis section.

\section{Data corroboration.}

This study did not employ a mixed-methods analysis, even though quantitative and qualitative data were collected. Qualitative and quantitative data were used in corroboration to inform the researcher as to what factors impact RFGC STEM student persistence.

Survey instruments enabled the researcher to sample a large portion of WV students and faculty. This quantitative data gave the researcher a general understanding of survey participants' opinions as to what are the factors affecting persistence. Semi-structured interviews were able to shed light on any additional factors affecting persistence as the interview questions are openended as compared to the prescribed factors listed in the surveys. During semi-structured interviews, the researcher was able to ask follow-up questions so that the researcher could 
ENABLING AND THREATENING FACTORS AFFECTING PERSISTENCE

develop a deeper understanding. The interviews also informed the researcher as to how students adjusted to or coped with the challenges that they faced. These items were not found in the surveys. The corroboration of the multiple forms of data is a form of triangulation.

\section{Analysis}

Descriptive and inferential statistics, along with content and thematic analysis, formed the foundation of the analysis process. This study employed quantitative and qualitative methods to answer the following research questions:

RQ1: What factors enable the persistence of RFGC students in STEM majors?

a. What do RFGC STEM majors perceive as factors that enable them to persist?

b. What do faculty view as the factors that enable RFGC STEM students to persist?

RQ2: What factors threaten the persistence of RFGC students in STEM majors?

a. What do RFGC STEM majors perceive as the factors that threaten their persistence?

b. How do RFGC STEM majors handle or deal with the challenges they face?

i. What are their successful means to adapting to these challenges?

ii. How do these challenges change over time as a STEM major?

c. What do faculty view as the factors that threaten RFGC STEM students' persistence?

\section{Quantitative data analysis.}

Demographic information was collected from the survey instrument and was used to describe the sample population and to assist in the analysis of data. The quantitative analysis involved both descriptive and inferential statistics. Descriptive statistics were utilized to rank the threating factors affecting persistence found in the survey instrument. Inferential Statistics were completed on the survey data to determine any significant differences between any of the RFGC STEM groups, freshmen, sophomore, or upperclassmen. 


\section{ENABLING AND THREATENING FACTORS AFFECTING PERSISTENCE}

Students and faculty were asked to complete a Likert-like survey that listed items that may make finishing a STEM degree difficult. The possible responses were: $1=$ Untrue, $2=$ Somewhat untrue, $3=$ Somewhat true, and $4=$ True. The faculty survey included a fifth response option of N/A, and this response was used if the faculty felt that they were unaware of having taught rural first-generation students. The N/A response was not part of the mean calculation for the faculty. Numerous faculty participants used N/A for many of the survey items, and, as such, this reduced the sample size. The mean for each survey item was calculated for the students and the faculty to make general comparisons.

To fully understand the challenges that RFGC STEM students face, it is important to determine any differences that exist between the sub-groups of RFGC STEM students. One of the research questions in this study is how do RFGC STEM student's challenges change over time. To help answer this question, the survey responses of Freshmen, Sophomores, and those that labeled themselves as "Other" were compared. A Kruskal Wallis H test, also known as a one-way ANOVA on ranks, was used to compare these means. This is a nonparametric test to determine if a significant difference exists between 3 levels of an independent variable. In this case, the three levels are the student's year in school: freshmen, sophomore, or other. Since the dependent variable is ordinal data (Likert-like), a one-way ANOVA is not suitable, but the Kruskal Wallis $\mathrm{H}$ is appropriate.

The Kruskal Wallis $\mathrm{H}$ can only determine if there is a significant difference between three different groups (FR., SO., and other). To determine where the significant difference is between the groups, a Mann Whitney U test was conducted between the groups. To reduce the effect of a Type I Error, the traditional alpha of 0.05 is divided by the number of groups (3) to determine the adjusted alpha level of 0.015 . 


\section{ENABLING AND THREATENING FACTORS AFFECTING PERSISTENCE}

\section{Qualitative data analysis.}

Qualitative data was derived from the RFGC STEM majors and STEM faculty interviews. Once an interview was conducted, transcriptions were made from the audio recordings and confirmed by the process of member checking. Once the interview transcriptions were checked for accuracy, the study used content and thematic analysis to uncover themes.

The general constructs of grounded theory were used to complete thematic analysis on each group's qualitative data, RFGC STEM student interviews and STEM faculty interviews. Just as constant-comparative analysis is foundational to deriving a theory utilizing grounded theory methodology (Patton, 2002), it was also fundamental in this study's thematic analysis. This constant comparison occurs while the researcher pilots the interview protocol, administers each interview, transcribes interview responses, and ends with the analysis of the data. This process is confirmed by Corbin and Strauss: "As the researcher moves along with the analysis, each incident in the data is compared with other incidents for similarities and differences" (2008, p. 73). As the researcher reviews and studies the transcriptions, the researcher starts to recognize patterns that are based upon similarities and differences of the participants' responses. This is an essential process in [coding] as "...it allows the researcher to differentiate one category/theme from another and to identify properties and dimensions specific to that category/theme" (p. 73).

Building off of constant-comparison analysis, grounded theory procedures were utilized to develop themes. These steps include: (a) open coding, (b) axial coding, and (c) selective coding (Creswell, 2007). Open coding starts with the review of interview transcripts in which broad groups (categories) are recognized within the data (2007). A researcher needs to immerse him/herself in the data by reading the interview transcripts multiple times before categories are recognized. Through the constant comparison of data, like and unlike, characteristics are 


\section{ENABLING AND THREATENING FACTORS AFFECTING PERSISTENCE}

revealed to the researcher. These characteristics are vital in the process of combining responses to further derive categories. This process is described as axial coding, "the investigator assembles the data in new ways" and eventually "identifies a central phenomenon" (p. 67). Previous theories or models that describe factors affecting persistence can inform the researcher as to what can be expected, but the researcher cannot let this sway their analysis process. The researcher's categories and the further development of codes must be derived from the researcher's observations, in this case, the interview transcripts. In the end, further sorting results in the fine-tuning of the codes into themes (selective coding). Coding tables for the students and faculty can be found in Tables 12-15.

Qualitative researchers desire a high degree of accuracy, credibility, and reliability in their work. This can be accomplished through the triangulation of data or analytics (Patton 2002). Patton declares that the goal of triangulation is not to have the data come to an agreement, but to test for such agreement. Patton describes the different types of triangulation as [methods triangulation, triangulation of sources, analyst triangulation, and theory/perspective triangulation] (p.556). Regarding Patton's modes of triangulation, this study incorporated methods triangulation and triangulation of sources. Methods triangulation involves "checking out the consistency of findings generated by different data collection methods" (p. 556). Though this study did not employ a mixed-methods approach, surveys and interviews where utilized to determine factors affecting persistence for RFGC STEM students. Integrating quantitative and qualitative methods is a common practice with methods triangulation (2002). Persistence factors were derived from two groups, RFGC STEM students and STEM faculty. Comparison of the RFGC STEM students' and STEM faculty's interviews and survey responses are each a form of 
ENABLING AND THREATENING FACTORS AFFECTING PERSISTENCE

triangulation of sources as the sources are observed using the same methods (interview or survey) (2002). 
ENABLING AND THREATENING FACTORS AFFECTING PERSISTENCE

\section{Chapter 4: Results}

\section{Quantitative Results}

RFGC STEM students and faculty who taught STEM courses were asked to complete a Likert-type survey, Q5.1_1-18 for students; Q3_1-16 for faculty. Each survey question is a statement of a potential difficulty that a student may face as they go through their major. The survey results will help to answer the research questions as to what are the factors that threaten students (RQ2) and how do challenges change over time (RQ2.b.ii). Participants ranked each item (question) according to the following response options: $1=$ Untrue, $2=$ Somewhat untrue, $3=$ Somewhat true, and 4= True. Each item listed in the survey is a threatening factor, or, as the survey described them, reasons that might make staying in a STEM program difficult. The faculty survey included a fifth response option, "N/A," and this response was used if the faculty felt that they were unaware of having taught rural first-generation students. The N/A response was not part of the mean calculation for the faculty. Numerous faculty respondents used N/A for multiple survey items and, as such, reduced the number of responses $(n)$ significantly.

The total number of faculty surveys that were submitted was 122. A total of 125 RFGC STEM student surveys were submitted. Five students were removed because they did not provide any responses to Questions 5.1_1-18. Another student was removed because their class status could not be identified. Table 8 summarizes the number $(n)$ of students and faculty who rated (1, 2, 3, or 4) each "difficulty" item and the corresponding Mean. The difficulties that were listed in the faculty survey were reworded for survey clarity. Student questions, Q5.1_14 and Q5.1_15 were not included in the faculty survey, as they were believed to be irrelevant questions to ask the faculty. 
ENABLING AND THREATENING FACTORS AFFECTING PERSISTENCE

Table 8

Student and Faculty Survey Summary

\begin{tabular}{|c|c|c|c|c|c|}
\hline RFGC STEM Students & $n$ & Mean & STEM Faculty & $n$ & Mean \\
\hline $\begin{array}{l}\text { Q5.1_1 It is difficult to adjust to the } \\
\text { academic demands of my STEM } \\
\text { classes. }\end{array}$ & 119 & 2.56 & $\begin{array}{l}\text { Q3_1 Difficulty adjusting to the } \\
\text { academic demands of STEM classes }\end{array}$ & 70 & 3.43 \\
\hline $\begin{array}{l}\text { Q5.1_2 I am having a hard time } \\
\text { developing study skills that enable me } \\
\text { to pass my STEM classes. }\end{array}$ & 119 & 2.29 & $\begin{array}{l}\text { Q3_2 Difficulty developing study } \\
\text { skills. }\end{array}$ & 69 & 3.43 \\
\hline $\begin{array}{l}\text { Q5.1_3 I do not understand what my } \\
\text { professors expect of me academically. }\end{array}$ & 119 & 1.65 & $\begin{array}{l}\text { Q3_3 Difficulty understanding what } \\
\text { professors expect academically }\end{array}$ & 69 & 3.23 \\
\hline $\begin{array}{l}\text { Q5.1_4 I am intimidated by my } \\
\text { professors. }\end{array}$ & 119 & 1.93 & $\begin{array}{l}\text { Q3_4 Feeling intimidated by } \\
\text { professors. }\end{array}$ & 68 & 3.15 \\
\hline $\begin{array}{l}\text { Q5.1_5 The math I have to do in my } \\
\text { STEM classes is too hard. }\end{array}$ & 118 & 1.97 & $\begin{array}{l}\text { Q3 5 Finding the math they have to } \\
\text { do in in their STEM classes too hard. }\end{array}$ & 67 & 3.27 \\
\hline $\begin{array}{l}\text { Q5.1_6 My STEM classes have too } \\
\text { many students in them, so I do not get } \\
\text { individual support from my } \\
\text { professors. }\end{array}$ & 118 & 1.73 & $\begin{array}{l}\text { Q3_6 Finding that STEM classes have } \\
\text { too many students in them, limiting } \\
\text { individual support from professors. }\end{array}$ & 64 & 2.44 \\
\hline $\begin{array}{l}\text { Q5.1_7 Professors in my STEM } \\
\text { classes tend to lecture a lot. }\end{array}$ & 119 & 2.91 & Q3_7 Disliking lectures & 60 & 2.18 \\
\hline $\begin{array}{l}\text { Q5.1_8 STEM classes are more } \\
\text { boring than I expected. }\end{array}$ & 119 & 1.95 & $\begin{array}{l}\text { Q3_8 Finding STEM classes to be } \\
\text { more boring than expected. }\end{array}$ & 61 & 2.23 \\
\hline $\begin{array}{l}\text { Q5.1_9 I do not have friendships with } \\
\text { people in my STEM classes. }\end{array}$ & 117 & 2.07 & $\begin{array}{l}\text { Q3_9 Lack of connection to other } \\
\text { STEM students outside of classes. }\end{array}$ & 60 & 2.63 \\
\hline $\begin{array}{l}\text { Q5.1_10 My social life interferes with } \\
\text { studying. }\end{array}$ & 119 & 1.89 & $\begin{array}{l}\text { Q3_10 Interference of social life with } \\
\text { studying. }\end{array}$ & 63 & 3.25 \\
\hline $\begin{array}{l}\text { Q5.1_11 Because I have a job, I do } \\
\text { not have as much time as I need for } \\
\text { studying. }\end{array}$ & 119 & 2.01 & $\begin{array}{l}\text { Q3_11 Not having as much time as } \\
\text { needed for studying because they have } \\
\text { jobs. }\end{array}$ & 64 & 3.5 \\
\hline $\begin{array}{l}\text { Q5.1_12 I might not be able to afford } \\
\text { finishing my degree. }\end{array}$ & 119 & 2.09 & $\begin{array}{l}\text { Q3_12 Being unable to afford } \\
\text { finishing their degree. }\end{array}$ & 64 & 3.3 \\
\hline $\begin{array}{l}\text { Q5.1_13 Because I have } \\
\text { responsibilities at home, I do not have } \\
\text { as much time as I need for studying. }\end{array}$ & 119 & 1.93 & $\begin{array}{l}\text { Q3_13 Not having as much time as } \\
\text { needed for studying because they need } \\
\text { to help their family. }\end{array}$ & 62 & 3.27 \\
\hline Q5.1_16 I am lonely or homesick. & 119 & 1.92 & Q3_14 Feeling lonely or homesick. & 57 & 2.95 \\
\hline Q5.1_17 I do not feel safe on campus. & 119 & 1.19 & Q3_15 Feeling unsafe on campus. & 53 & 1.68 \\
\hline $\begin{array}{l}\text { Q5.1_18 I do not feel that I belong in } \\
\text { college. }\end{array}$ & 119 & 1.55 & $\begin{array}{l}\text { Q3_16 Feeling that they do not belong } \\
\text { in college. }\end{array}$ & 62 & 2.35 \\
\hline $\begin{array}{l}\text { Q5.1_14 I don't know where to get } \\
\text { help with my coursework. }\end{array}$ & 119 & 1.57 & & & \\
\hline $\begin{array}{l}\text { Q5.1_15 I don't know where to get } \\
\text { help if I feel depressed or worried. }\end{array}$ & 119 & 1.71 & & & \\
\hline
\end{tabular}


ENABLING AND THREATENING FACTORS AFFECTING PERSISTENCE

Determining what students and faculty perceive as factors threatening persistence of RFGC STEM students is one of the main questions of this study. This Likert-type survey was one source used to answer this inquiry. Below are the students' rankings of the survey items. The table is in order of lowest ranking, or those items that are of lesser concern to students $(1=$ untrue), to the highest-ranking, or those items that are most concerning to them $(4=$ true $)$. The students did not seem too concerned about any of the items. Q5.1_7 Professors in my STEM classes tend to lecture a lot, had an average rank of 2.91. This item was the students' most concerning possible difficulty, but this ranking is between the response of "Somewhat untrue" (2) and "Somewhat true" (3). The students only ranked six of the eighteen survey items above a two, "Somewhat untrue."

The faculty rankings of the possible difficulties that RFGC students may face are summarized in Table 10. The table is in order of those items that faculty rated as being of least concern to students to the most concerning to students. Overall the faculty ranked all items higher than the students. The faculty ranked all but one survey item as a 2, "Somewhat untrue" or higher. The students did not rank any of the survey items above a three, but the faculty ranked nine of the sixteen items as a 3 or above.

One of this study's research questions is: "Do RFGC STEM student's challenges change over time?" To answer this question, a comparison analysis was made between the survey responses of the freshmen, sophomores and those that labeled themselves as "Other." This "Other" group was a surprise group, as only freshmen and sophomores were invited to participate in the survey. This other group was made of those that did not provide their class status, stated that they were upperclassmen, or that they were one status based upon hours, but another based upon years. For this study, the year in school was used to distinguish a student's 
ENABLING AND THREATENING FACTORS AFFECTING PERSISTENCE

Table 9

Student Survey Responses in Order

\begin{tabular}{|c|c|c|}
\hline RFGC STEM Student Survey Item & $n$ & Mean \\
\hline Q5.1_17 I do not feel safe on campus. & 119 & 1.19 \\
\hline Q5.1_18 I do not feel that I belong in college. & 119 & 1.55 \\
\hline Q5.1_14 I don't know where to get help with my coursework. & 119 & 1.57 \\
\hline Q5.1_3 I do not understand what my professors expect of me academically. & 119 & 1.65 \\
\hline Q5.1_15 I don't know where to get help if I feel depressed or worried. & 119 & 1.71 \\
\hline \multicolumn{3}{|l|}{ Q5.1_6 My STEM classes have too many students in them, so I do not get } \\
\hline individual support from my professors. & 118 & 1.73 \\
\hline Q5.1_10 My social life interferes with studying. & 119 & 1.89 \\
\hline Q5.1_16 I am lonely or homesick. & 119 & 1.92 \\
\hline Q5.1_4 I am intimidated by my professors. & 119 & 1.93 \\
\hline \multicolumn{3}{|l|}{ Q5.1_13 Because I have responsibilities at home, I do not have as much time } \\
\hline as I need for studying. & 119 & 1.93 \\
\hline Q5.1_8 STEM classes are more boring than I expected. & 119 & 1.95 \\
\hline Q5.1_5 The math I have to do in my STEM classes is too hard. & 118 & 1.97 \\
\hline \multicolumn{3}{|l|}{ Q5.1_11 Because I have a job, I do not have as much time as I need for } \\
\hline studying. & 119 & 2.01 \\
\hline Q5.1_9 I do not have friendships with people in my STEM classes. & 117 & 2.07 \\
\hline Q5.1_12 I might not be able to afford finishing my degree. & 119 & 2.09 \\
\hline \multicolumn{3}{|l|}{ Q5.1_2 I am having a hard time developing study skills that enable me to pass } \\
\hline my STEM classes. & 119 & 2.29 \\
\hline Q5.1_1 It is difficult to adjust to the academic demands of my STEM classes. & 119 & 2.56 \\
\hline Q5.1_7 Professors in my STEM classes tend to lecture a lot. & 119 & 2.91 \\
\hline
\end{tabular}


ENABLING AND THREATENING FACTORS AFFECTING PERSISTENCE

Table 10

Faculty Survey Responses in Order

\begin{tabular}{lcc}
\multicolumn{1}{c}{ STEM Faculty Survey Item } & $n$ & Mean \\
\hline Q3_15 Feeling unsafe on campus. & 53 & 1.68 \\
Q3_7 Disliking lectures & 60 & 2.18 \\
Q3_8 Finding STEM classes to be more boring than expected. & 61 & 2.23 \\
Q3_16 Feeling that they do not belong in college. & 62 & 2.35 \\
Q3_6 Finding that STEM classes have too many students in them, limiting & 64 & 2.44 \\
individual support from professors. & & 60 \\
Q3_9 Lack of connection to other STEM students outside of classes. & 57 & 2.95 \\
Q3_14 Feeling lonely or homesick. & 68 & 3.15 \\
Q3_4 Feeling intimidated by professors. & 69 & 3.23 \\
Q3_3 Difficulty understanding what professors expect academically & 63 & 3.25 \\
Q3_10 Interference of social life with studying. & 67 & 3.27 \\
Q3_5 Finding the math they have to do in in their STEM classes too hard. & 62 & 3.27 \\
Q3_13 Not having as much time as needed for studying because they need to & 64 \\
help their family. & & 64 \\
Q3_12 Being unable to afford finishing their degree. & 3.50 \\
Q3_1 Difficulty adjusting to the academic demands of STEM classes & 69 \\
Q3_2 Difficulty developing study skills. & 3.43 \\
Q3_11 Not having as much time as needed for studying because they have & 64 \\
jobs. & 63
\end{tabular}

class status. Those students that did not provide a class status on the survey were crossreferenced with the original institution's list according to their email. The class status found on the institutional list was used to classify those that did not provide a status. One student's class status was not identified, and they were removed from the study. With these alterations, the "Other" group is made of only upperclassmen (juniors and seniors) and will be referred to as such. 
ENABLING AND THREATENING FACTORS AFFECTING PERSISTENCE

A Kruskal-Wallis H test was chosen to complete the comparison of these three groups. A Kruskal-Wallis $\mathrm{H}$ test provided evidence of a significant difference $(\mathrm{p}=0.05)$ between at least one pair of groups in five of the eighteen survey questions. Questions Q5.1_6, Q5.1_7, Q5.1_9, Q5.1_17 and Q5.1_18 were identified as having a potentially significant difference between the freshmen or sophomores or the upperclassman. See Table 11 for a summary of the KruskalWallis H test.

For survey question Q5.1_6, a Kruskal-Wallis H test showed that there was a statistically significant difference in Likert-type scores between the different class statuses, $\chi^{2}(2)=6.918, p=$ 0.031, with a mean score of 1.84 for freshmen, 1.51 for sophomore and 2.06 for upperclassman.

For survey question Q5.1_7, a Kruskal-Wallis H test showed that there was a statistically significant difference in Likert-type scores between the different class statuses, $\chi^{2}(2)=8.483, p=$ 0.014, with a mean score of 3.02 for freshmen, 2.67 for sophomore and 3.31 for upperclassman.

For survey question Q5.1_9, a Kruskal-Wallis H test showed that there was a statistically significant difference in Likert-type scores between the different class statuses, $\chi^{2}(2)=6.208, p=$ 0.045, with a mean score of 2.35 for freshmen, 1.92 for sophomore and 1.62 for upperclassman.

For survey question Q5.1_17, a Kruskal-Wallis H test showed that there was a statistically significant difference in Likert-type scores between the different class statuses, $\chi^{2}(2)$ $=7.036, p=0.026$, with a mean score of 1.27 for freshmen, 1.06 for sophomore and 1.38 for upperclassman.

For survey question Q5.1_18, a Kruskal-Wallis H test showed that there was a statistically significant difference in Likert-type scores between the different class statuses, $\chi^{2}(2)$ $=7.112, p=0.029$, with a mean score of 1.80 for freshmen, 1.31 for sophomore and 1.50 for upperclassman. 
ENABLING AND THREATENING FACTORS AFFECTING PERSISTENCE

Table 11

Kruskal-Wallis H Test Results

\begin{tabular}{ccc}
\hline Survey Question & $\mathrm{n}$ & Significance \\
\hline Q5.1_1 It is difficult to adjust to the academic demands of my STEM & 119 & .652
\end{tabular}
classes.

Q5.1_2 I am having a hard time developing study skills that enable me to 119 pass my STEM classes.

Q5.1_3 I do not understand what my professors expect of me academically. $119 \quad$.236

Q5.1_4 I am intimidated by my professors. $\quad 119 \quad 063$

Q5.1_5 The math I have to do in my STEM classes is too hard. $\quad 118 \quad .210$

Q5.1_6 My STEM classes have too many students in them, so I do not get $118 \quad .031 *$ individual support from my professors.

Q5.1_7 Professors in my STEM classes tend to lecture a lot. $119 \quad .014^{*}$

Q5.1_8 STEM classes are more boring than I expected. $119 \quad .542$

Q5.1_9 I do not have friendships with people in my STEM classes. $\quad 117 \quad$.045*

Q5.1_10 My social life interferes with studying. $\quad 119 \quad .118$

Q5.1_11 Because I have a job, I do not have as much time as I need for $\quad 119 \quad$.191 studying.

Q5.1_12 I might not be able to afford finishing my degree. $\quad 119 \quad .457$

Q5.1_13 Because I have responsibilities at home, I do not have as much $\quad 119 \quad 496$ time as I need for studying.

Q5.1_14 I don't know where to get help with my coursework. $\quad 119 \quad 483$

Q5.1_15 I don't know where to get help if I feel depressed or worried. $\quad 119 \quad .504$

Q5.1_16 I am lonely or homesick. $119 \quad .514$

Q5.1_17 I do not feel safe on campus. $119 \quad .026^{*}$

Q5.1_18 I do not feel that I belong in college. $119 \quad .029 *$

*Significant at alpha $<0.05$.

The Kruskal-Wallis H test can only determine if there is a significant difference between different groups. A post hoc test (Dunn's) was conducted to determine where the significant 


\section{ENABLING AND THREATENING FACTORS AFFECTING PERSISTENCE}

difference is between the groups for each of the five questions. Pairwise comparisons were performed using Dunn's (1964) procedure with a Bonferroni correction for multiple comparisons. Adjusted p-values are presented. This post hoc analysis revealed statistically significant differences in four of the five questions, Q5.1_6, Q5.1_7, Q5.1_17 and Q5.1_18.

For question, Q5.1_6, a post hoc analysis revealed statistically significant difference in Likert-type scores between the sophomores (mean rank $=51.85)$ and upperclassman (mean rank $=72.88)(p=.049)$, but not between the freshmen (mean rank =62.95) and any other group combination. What this means is that the Upperclassman group ranked the statement, "My STEM classes have too many students in them, so I do not get individual support from my professors" higher than the Sophomore group. The Upperclassman group feels that this statement is more accurate to them than the Sophomore group.

Question, Q5.1_7, a post hoc analysis revealed statistically significant difference in Likert-type scores between the sophomores (mean rank $=51.43$ ) and upperclassman (mean rank $=76.09)(p=.021)$, but not between the freshmen (mean rank $=63.69)$ and any other group combination. The Upperclassman group ranked the statement, "Professors in my STEM classes tend to lecture a lot" higher than the Sophomore group. This statement more accurately represents the Upperclassman's feelings compared to the Sophomores.

Question, Q5.1_17, a post hoc analysis revealed statistically significant difference in Likert-type scores between the freshmen (mean rank $=64.50)$ and sophomores (mean rank $=$ 53.85) $(p=.041)$, but not between the upperclassman (mean rank =65.66) and any other group combination. The Freshmen group felt that the statement, "I do not feel safe on campus" reflects their views more accurately than the Sophomore group. 


\section{ENABLING AND THREATENING FACTORS AFFECTING PERSISTENCE}

The last statement that was found to have a significant difference is survey question Q5.1_18. A post hoc analysis revealed statistically significant differences in Likert-type scores between the freshmen (mean rank $=68.00)$ and sophomores (mean rank $=52.69)(p=.024)$, but not between the upperclassman (mean rank $=58.25$ ) and any other group combination. The Freshmen group feels that the statement, "I do not feel that I belong in college" reflects their view more than the Sophomore group.

\section{Qualitative Results}

The qualitative portion of this study utilized qualitative methods to determine themes from student and faculty interview data. The Methodology chapter (Chapter 3) lists demographic information of the students and faculty that were interviewed. Pseudonyms are used to ensure the anonymity of interview participants. The following chapter sections are organized according to the dissertation's research questions. The study's research questions are as follows:

RQ1: What factors enable the persistence of RFGC students in STEM majors?

a. What do RFGC STEM majors perceive as factors that enable them to persist?

b. What do faculty view as the factors that enable RFGC STEM students to persist?

RQ2: What factors threaten the persistence of RFGC students in STEM majors?

a. What do RFGC STEM majors perceive as the factors that threaten their persistence?

b. How do RFGC STEM majors handle or deal with the challenges they face?

i. What are their successful means to adapting to these challenges?

ii. How do these challenges change over time as a RFGC STEM major?

c. What do faculty view as the factors that threaten RFGC STEM students' persistence?

This chapter was also organized according to the codes and subsequent themes developed by the researcher. The major sections of this chapter are the research question and the responses 
ENABLING AND THREATENING FACTORS AFFECTING PERSISTENCE

under each question are organized according to the coding tables. These coding tables will help the reader to understand the development the interviews quotes into categories (open coding), then into codes (axial coding), and finally into a theme (selective coding). Refer to Tables 12 -

15.

Table 12

RFGC STEM Coding - Enabling Factors

\begin{tabular}{|c|c|c|}
\hline Open Coding & Axial Coding & Selective Coding \\
\hline $\begin{array}{l}\text { Drive and confidence } \\
\text { Determination }\end{array}$ & Drive, confidence, and determination & \multirow{3}{*}{ Drive } \\
\hline $\begin{array}{l}\text { Interest in STEM subjects } \\
\text { Hobbies (experiences) - like to } \\
\text { do STEM like things }\end{array}$ & Interest & \\
\hline $\begin{array}{l}\text { STEM degree (valuable career) } \\
\text { Better life }\end{array}$ & Making a better life/no other choices & \\
\hline $\begin{array}{l}\text { Family influence skills and } \\
\text { abilities } \\
\text { Hobbies and jobs }\end{array}$ & Background - experiences and skills & \multirow[t]{2}{*}{ Experiences and skills } \\
\hline $\begin{array}{l}\text { Teachers and classes } \\
\text { Extra-curricular benefits }\end{array}$ & High school preparation & \\
\hline $\begin{array}{l}\text { Environment and peers } \\
\text { (emotional) }\end{array}$ & \multirow{4}{*}{ Institutional support and resources } & \multirow{6}{*}{ Resources and support } \\
\hline Professors and course design & & \\
\hline $\begin{array}{l}\text { Other institutional personnel } \\
\text { Institutional financial support }\end{array}$ & & \\
\hline School programs and resources & & \\
\hline $\begin{array}{l}\text { Parents or siblings } \\
\text { Support financial }\end{array}$ & \multirow[t]{2}{*}{ Support - family and community } & \\
\hline Other emotional support & & \\
\hline
\end{tabular}


ENABLING AND THREATENING FACTORS AFFECTING PERSISTENCE

Table 13

RFGC STEM Coding - Threatening Factors

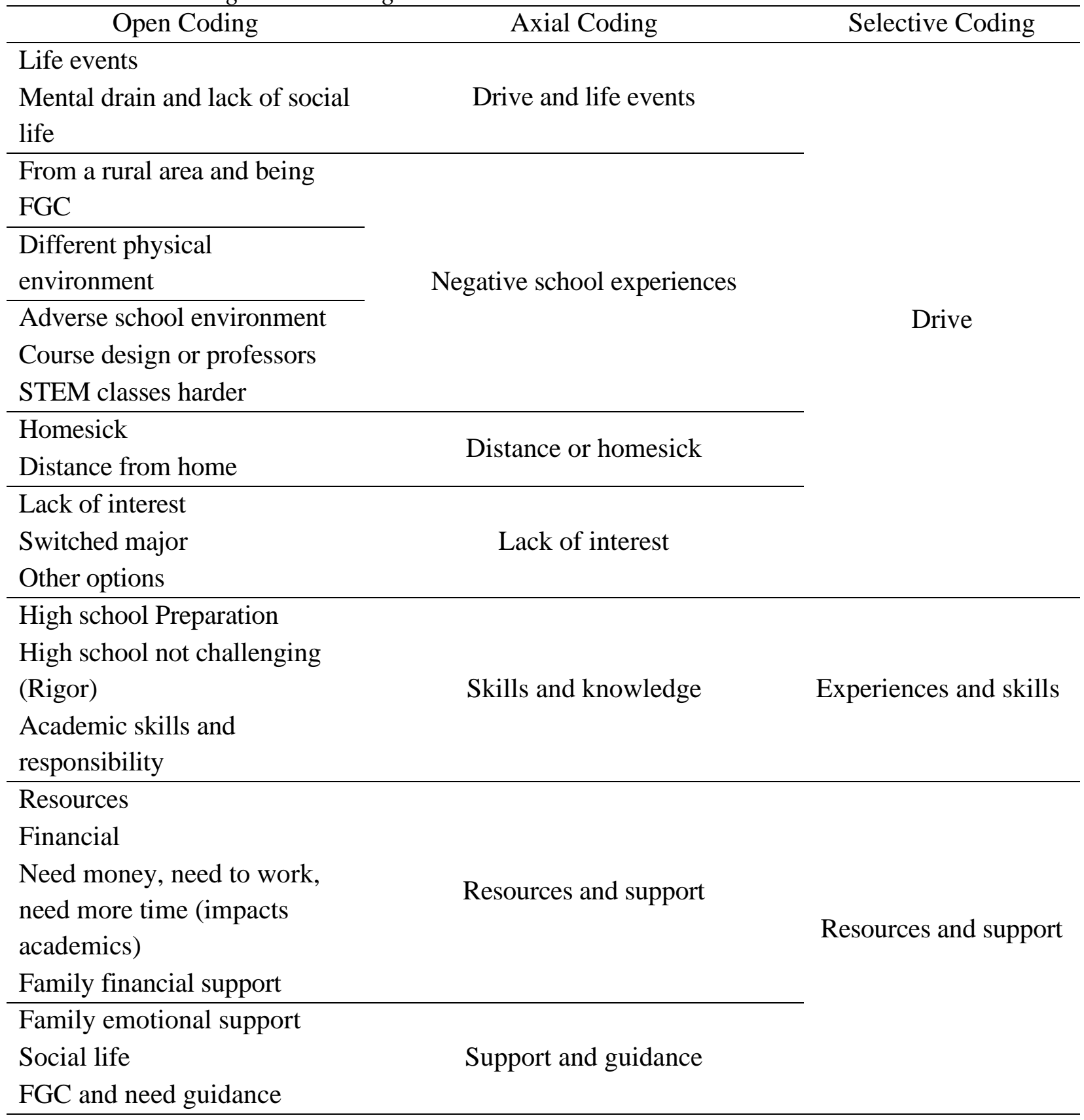


ENABLING AND THREATENING FACTORS AFFECTING PERSISTENCE

Table 14

STEM Faculty Coding - Enabling Factors

\begin{tabular}{lcc}
\multicolumn{1}{c}{ Open Coding } & Axial Coding & Selective Coding \\
\hline STEM Career & & \\
$\begin{array}{l}\text { Better life } \\
\text { Reason in college - Know what they }\end{array}$ & End in sight & \\
want & & Motivation \\
$\begin{array}{l}\text { See benefit of education } \\
\text { Give back to community - Doctor }\end{array}$ & \\
\hline $\begin{array}{l}\text { Initiative Interest } \\
\text { Something to prove }\end{array}$ & Student interest & \\
\hline Realize they can do it & Realize they can do it & \\
\hline
\end{tabular}

Fixing things

Environment -nature, mechanics, etc.

Experiences

Skills associated with working (blue-

collar)

Skills

Flexibility and creativity

Family

Scholarships

Financial

Institutional

Family

Friends Peers

Emotional

Support

Safe place and school environment

Tutoring

Peers

Academic

Someone to answer non-class questions

\begin{tabular}{|c|c|c|}
\hline $\begin{array}{l}\text { Background - rural and workers } \\
\text { Independence } \\
\text { Intrinsic blame }\end{array}$ & $\begin{array}{l}\text { Responsibility and } \\
\text { independence }\end{array}$ & \\
\hline $\begin{array}{l}\text { Obedient - Do what they are told } \\
\text { Take constructive criticism better }\end{array}$ & Acquiescence & \\
\hline $\begin{array}{l}\text { Gone thru adversity } \\
\text { Not rattled/frustrated easily }\end{array}$ & & Personal characteristics \\
\hline $\begin{array}{l}\text { Outgoing and confident } \\
\text { Resourceful creative flexible } \\
\text { Tenacious and stubborn }\end{array}$ & Resilience & \\
\hline Work ethic & Work ethic & \\
\hline
\end{tabular}

Table 15 
ENABLING AND THREATENING FACTORS AFFECTING PERSISTENCE

STEM Faculty Coding - Threatening Factors

\begin{tabular}{|c|c|c|}
\hline Open Coding & Axial Coding & Selective Coding \\
\hline $\begin{array}{l}\text { Homesick } \\
\text { New environment } \\
\text { Fitting-in }\end{array}$ & $\begin{array}{l}\text { Homesick new } \\
\text { environment }\end{array}$ & \multirow{2}{*}{$\begin{array}{l}\text { Institutional environment } \\
\text { and faculty }\end{array}$} \\
\hline $\begin{array}{l}\text { Harder classes } \\
\text { Faculty }\end{array}$ & Faculty influences & \\
\hline $\begin{array}{l}\text { Academic prep., rigor, and teachers } \\
\text { Did well in high school but struggling } \\
\text { Have to catch up } \\
\text { Less prepared more time and money }\end{array}$ & $\begin{array}{l}\text { Academic content } \\
\text { preparation }\end{array}$ & \multirow{3}{*}{ Lack of preparation } \\
\hline $\begin{array}{l}\text { Career aspirations } \\
\text { Not knowing their major } \\
\text { Told college or major } \\
\text { Wrong major chosen }\end{array}$ & $\begin{array}{l}\text { Knowledge of major } \\
\text { career school }\end{array}$ & \\
\hline $\begin{array}{l}\text { Critical thinking and use of technology } \\
\text { Study skills }\end{array}$ & Academic skills & \\
\hline
\end{tabular}

Lack of family friend support

Family community pressure

Home family responsibilities

Emotional support

Lack of support

Limited due to rural FGC

Financial

Financial support

Mental or drug issues

Extreme independence, un-willingness

to get help

Personal items

Beliefs, lack desire and confidence

Un-aware of resources

Finances

More challenges than

others

Lack of technology

Less prepared causes more time and

Limited access to

money needed

resources

Transportation and expenses (long

commutes)

What factors enable the persistence of RFGC students in STEM majors? 
ENABLING AND THREATENING FACTORS AFFECTING PERSISTENCE

Factors that enable student persistence were not found in previous studies related to rural first-generation STEM majors. One of the goals of this study is to determine what factors enable this group. Specific interview questions were asked of both RFGC STEM students and STEM faculty to ascertain what they feel are strengths or enabling factors to persist.

\section{What do RFGC STEM majors perceive as factors that enable them to persist?}

Semi-structured interviews were conducted with eleven RFGC STEM students. Three major themes were found to be enabling factors: Drive, Experiences and skills, and Support.

Drive.

Numerous comments were made by RFGC students concerning their desire to attain a STEM degree. Don discusses the importance of drive; "my biggest asset is my drive... I see kids who just don't care about their opportunity to get this awesome degree and make a successful life for themselves." He later goes on to say, "That drive can get you anywhere, even if you suck at something." Ariel discusses how outside factors, like family, create her drive, "I have a lot of drive that I know my parents haven't done this before me, so I really want this. I don't know if that is specific to STEM, but it is specific to first-generation."

Students made additional "drive" comments, and these remarks fall into one of the following categories: confidence, determination, interest in their STEM field, or trying to make a better life. Brandy believes that confidence is a vital component to being successful in college. Students that didn't excel in high school; I feel like college is harder for them because they don't have that confidence in themselves. I had a lot of confidence in myself because I did well in high school, and I did well on my ACT, and I feel that some students don't have the confidence in themselves to know that they can succeed in college. 


\section{ENABLING AND THREATENING FACTORS AFFECTING PERSISTENCE}

Courtney offers a little different viewpoint about confidence; she mentions the importance of being confident in her choice of major.

I was very confident that this was the right major, and I purposely took a few general studies [courses to see if] I wanted to change my major to like psychology maybe. I was like, no, I definitely like biology.

Don describes the importance of confidence and how that can impact students continuing in their program of study.

That's the biggest thing that would probably stop me is maybe hitting a pothole and just getting down on myself and getting in one of those mental downward spirals of just lack of confidence. You have to know that you have no doubt in your mind that you're prepared. And that confidence is almost more important than the studying itself. It's important to stay confident, important to stay humble at the same time. You just have to ride that line as best you can and stay positive. And that's the biggest strength really, is being able to approach those challenges and not be overwhelmed like so many classmates of mine in engineering; they just get overwhelmed from course material and want to drop out of a class or drop out of school.

It is no surprise that determination was a popular topic of RFGC student's interviews. Drive and determination are very similar, but determination is an individual and internal factor; whereas, drive can come from multiple sources. Brandy talks about the importance of determination, especially for first-generation students.

Kids that are first-generation, if they don't have that determination, they just give up because they don't expect it to be that hard. If you're determined and keep your head on track, even if you did awful in high school, you can still succeed in college. I feel if you 


\section{ENABLING AND THREATENING FACTORS AFFECTING PERSISTENCE}

are determined, especially a STEM major, you can get through tough classes and tough obstacles.

Misty describes how her determination is not just with individual studying, but includes seeking help.

I will seek outside resources from the classroom. So many times, I see people complaining that they're not getting it and yet they don't seem to be making any effort.

You know, they are not the ones that you see waiting outside the teacher's office.

Chris, who is an Exodus RFGC STEM major, described why he is leaving his STEM major and how he lacked determination.

It's doable, but you've got to have a lot of grit for that. Just a lot to keep up with. It's just a lot really. In every aspect. A lot of work, a lot of business to take care of, a lot of time spent, a lot of knowledge consumed. If you're not really committed, it's not going to happen. I wasn't committed enough.

Having an interest in one's major is a powerful driving mechanism. Brenda mentioned, "I just find it really interesting, and I really like the professors. When you're interested in something, you just naturally pay more attention, and you're more involved." Brandy talked about her general interest in learning and a crucial component of her major, problem-solving.

If you like to learn, for me, I like listening to the professor teach for an hour. If you don't like to do that, sometimes it's difficult to want to learn. I just knew that I wanted to work with engineering because I knew it had a lot of math and science and problem-solving. And I really like the problem-solving aspect of it.

Devin goes a step above just liking or having an interest in his chosen field. He explains; 


\section{ENABLING AND THREATENING FACTORS AFFECTING PERSISTENCE}

And I always loved working on things. I've always loved fixing problems. I love working on vehicles, [and other things], and I just thought electrical would be perfect. So, just a love for what I'm doing has helped me get to where I am today and is going to help me get through it all the way through.

Chris, exodus student, discussed how he was interested in his major classes, but not the other courses that were required for the degree, general studies courses.

I definitely enjoyed it. It was very intriguing. What was intriguing was the biology classes themselves. I thoroughly enjoyed the biology. However, with the major, I needed everything. So, all the other things that I needed to fully understand biology and to achieve the goal just were not interesting enough to devote all my time to it. I 've always been interested in the sciences. I'm still very interested in the sciences, just cannot devote my entire life to it.

General studies courses can require a significant amount of time, which is on top of an already time-consuming STEM major's course load. Chris mentioned that he decided to leave the STEM fields because of the time required for studying and completing course work. This was a life choice that he made, as he was not willing to study for a few hard years to attain a STEM degree.

Drive can be fueled by a number of sources. One such source is having an end in sight, such as a favorable career. RFGGC STEM students see the value of their education as their desire for a better life drives them. Devin describes his rationale for pursuing a STEM degree, Making more money, maybe not. But a less stressful job and maybe something that I'm not working my butt off every day, yeah. Because I wouldn't mind working a lot now, like in the oil fields or something, that wouldn't bother me right now, but in 30-40 years I don't want to be doing that. 


\section{ENABLING AND THREATENING FACTORS AFFECTING PERSISTENCE}

Don was probably the most outspoken student concerning his need for the degree to make a better life. "I knew that a STEM major would be the best option if I wanted to secure my future. I wanted to make sure that no matter what, I would have a foot in the door." Don's childhood was not a pleasant one and his past fuels his desire to attain a better life.

I know what the alternatives are. I know what your own personal hell, you can say, is about. I know what being poor, being on the street, or being in a tough situation is like, and I want to avoid that for me and whatever children I [have].

A lack of alternative career routes (no other choices) also fuels Don's drive for a better life.

I can't not study, because I have no choice. I don't have any family members that work for a company that I can get a job from. I don’t have any skills outside of [my] major. This is my only plan, and I'm putting all my chips in one basket.

Like Don, many people feel that a STEM career is a good career, as it can be profitable and is a high demand field. Misty shares this view, "The STEM major more than any other because, in general, the number of jobs and the kind of pay and the job outlook... maybe not a huge difference, but enough."

Even though Michael has a very lucrative summer job, which can turn into a great career, he is animated about attaining his STEM degree. Michael works the summers in the natural gas industry as a welder's helper, which could lead to a job as a pipeline welder making 2-3 times what he makes as a welder's helper.

I make $\$ 1800$ a week, and that sounds phenomenal, but then whenever you truly think about it, I work 60 hours a week, so I work 20 overtime hours a week. I work six 10’s six days a week, 10 hours a day, and my day would start at about 4:30, so whenever I would get out of bed, I would get up, pack my lunch, drive an hour to work, work from 7-5. 


\section{ENABLING AND THREATENING FACTORS AFFECTING PERSISTENCE}

Even though Michael has this lucrative opportunity, he knows that a better career awaits with his degree, "I don't want to work in the middle of winter or in extreme temperatures, hot or cold, and it's also hard on your body. I just have to keep in mind that I'll make money in the end." Before Abigail tried college, she pursued careers that did not require higher education, and she sees her degree as a better occupation route.

I've kind of exhausted most things, being 32. I spent a lot of time trying to find a good job, and it just didn't happen. So, yeah, it's kind of essential to the future to do this, and I don’t want to give up on it. I really like the idea of mechanical engineering.

Having experienced other career routes, Abigail is driven by her desire to attain a degree that leads to a more profitable and favorable career.

The theme Drive, developed from RFGC STEM student comments that fell within one of the following codes: confidence, determination, interest in their STEM field, or trying to make a better life. The number of students that made comments relevant to the codes are as follows: confidence (4 out of 11 students), determination ( 7 out of 11 students), interest (11 out of 11 students), and better life (6 out of 11 students). Each of the eleven RFGC STEM students made at least one comment that related to drive.

A student's confidence in their STEM abilities or their choice of major can help students to stay in their field of study when times get tough. When troubling times do arise, RFGC STEM students have enough confidence in their abilities or their career track that they keep fighting through the tough times to overcome challenges. Students that do not have this confidence, and experience challenging times may feel that they do not belong and lose their desire to stay in their chosen STEM major or school altogether. Determination is synonymous to drive, and a number of students described the importance of their determination or the lack of it. Like 


\section{ENABLING AND THREATENING FACTORS AFFECTING PERSISTENCE}

confidence, when times get tough for a student, determination is what keeps a student from giving up. Chris, exodus student, discussed how his desire to attain a degree was not great enough to continue on in the degree. He did not have enough determination to overcome the fear of the extensive time that he felt it would require to be successful in a STEM course.

A student's interest in a STEM topic can also help students push through the tough times as they are interested in learning the topic at hand or have a "love" for the field they are pursuing. This interest or love is what keeps them from finding another career when they experience challenges. Rural first-generation students that grew up in Appalachia may come from lower-income families, and attaining a degree can be viewed as a means to a better life. This better life is accomplished by securing lucrative employment. This type of employment or career can give a person and their family benefits and stability that they did not previously have. Some of these students have seen their parents struggle, or they themselves struggled, to make ends meet, and a favorable career was viewed as a means to a better life.

These factors are grouped together under drive because students that do not demonstrate confidence, determination, interest or a desire for a better life, are more likely to move on to other ventures when challenging times arise.

\section{Experiences and skills.}

In the previous section on drive, some students discussed how their experiences gave them their interest or determination to be a STEM major. Similarly, a student's experiences gave them skills or knowledge that they believe are enabling factors to persist in their STEM major. Abigail talked about growing up around mechanics and how rural folks tend to be more resourceful. These experiences gave her some knowledge related to engineering. 


\section{ENABLING AND THREATENING FACTORS AFFECTING PERSISTENCE}

My dad was a mechanic all of his life and used to build hot rods, 1938 Chevy Coupe, 1938 Chevy truck and a 1968 Camaro. I always got to spend time out in the shop watching him do work and stuff like that. It's always been something that's around me since I was a kid. Technical-mechanical stuff. I like it. The majority of people around here have grown up in some form of poverty and rural living, and we're all pretty resourceful in that nature. Your car breaks down, you're more likely to go out and fix it, or you know somebody who can help fix it. More shade tree mechanics and hitching rides with people.

Devin discusses how his hobby has given him foundational knowledge and skills for his chosen major.

I think my strength would be, like I said, with having somewhat of a background in what I'm doing. I love working on vehicles, even though most of the car isn't electrical, there's a lot of it that is. And going through a lot of electrical issues, I've learned simple wiring. And when I look at diagrams and stuff, I have some sort of a background in it. I understand a lot of what I'm seeing on the paper when they give it to me, so I have that strong foundation to start with.

Growing up in certain physical environments or within specific family environments can shape a student. Courtney describes how her background not only developed her interest in STEM but also gave her some foundational knowledge.

There were definitely some childhood aspects of where my parents were very outdoorsy. The family I grew up in had a passion for the outdoors and for animals. My Dad was even able to name [different] kind of trees. That was because he cut and delivered wood. He knew that like maple was a good burning wood. I remember a key moment when I 


\section{ENABLING AND THREATENING FACTORS AFFECTING PERSISTENCE}

lived in Florida; we were out on the water on a boat, and wild dolphins came up to the boat. I remember being this little kid, and it was so fascinating and I [can] pinpoint that moment where animals really fascinated me. So, it's definitely something from my past and how I grew up in a family that we appreciated the outdoors and animals and stuff like that.

A person's work ethic is derived from their past experiences and gives them this characteristic. When Misty was asked if she contributes any of her strengths due to being rural and firstgeneration, she said, "I think so... being a hard worker...you really have to apply yourself and work harder than some of the easier majors." Several others made comments related to their work ethic and willingness to work hard in their courses. Ariel said, "Probably I would say like a work ethic and just like studying and paying attention in classes. I work really hard for the most part. and that's just the thing that keeps me going."

RFGC student's schooling was found to be enabling factors with the classes that they took and their teacher's warnings about college rigor. Brenda discussed how her small, rural school still had good options, "My school is smaller, but I feel like they accommodated pretty well and made sure that everyone knew what they had to know for college. ... it still had plenty of college [prep] classes that you could take.” Kerri also discussed how her school provided quality STEM courses, "I think I had a good background in high school with my science classes, as far as biology and anatomy go. So, I think that helped me.” Misty mentions differences between her school and other schools with the type of course offerings.

I think I had a decent high school. I know some high schools don't even have advanced programs or anything, and we did have that. We didn't have some of the stuff the others had. Some of them have all kinds of computer science classes and stuff. We didn't have 


\section{ENABLING AND THREATENING FACTORS AFFECTING PERSISTENCE}

anything like that. But we had advanced math and sciences, actually...that definitely helped... just more prepared for [college].

A number of the student's schools are connected to technical centers, which is very common with WV rural schools. The technical centers were able to provide students with unique opportunities, as Abigail discussed, "Being connected to the tech center definitely made it a little more promising than some of the other schools in the county." When asked why being beside the tech center was beneficial, Abigail said, "The aviation course I took, working in the shop, building an airplane and making it fly and all; that was very satisfying." Abigail would also discuss how experiences like this course lead her to major in Mechanical Engineering. Devin also took a technical course in high school and viewed this as beneficial. When asked where he got a specific skill, outside of school or in school, he said: "A little bit of both because in high school, I took diesel mechanics class."

Teachers were also viewed as enabling factors for RFGC persistence. Abigail mentions a specific math teacher that was very beneficial.

The few good teachers I had that really made me understand math were so invaluable. They didn't teach from the book, they taught us how to do it and then we'd do some practice problems from the book. So, it was real good. Geometry I understood perfectly, and it was a lot on the teachers.

Like Misty, other students credited their high school teachers for the preparation or warnings they gave about how college would be.

They would, in general, talk about being prepared for college and how you'll be responsible for stuff. The teachers aren't going to walk you through everything. And 


\section{ENABLING AND THREATENING FACTORS AFFECTING PERSISTENCE}

they're not going to wait for you. It's not like high school in that respect. I feel like in high school they prepared me for no hand holding, and there's still a lot of it.

Ariel also made similar comments, "My high school [teachers], they were all like, just expect that you're going to have a lot more work, and it's going to be pretty much non-stop."

Rural schools typically have smaller student bodies, and, as such, most of the students participate in multiple extracurricular activities. Michael discussed how his sports background gave him specific skills or developed his character, "Being a three-sport athlete, I had some idea of time management... accountability, responsibility, stuff like that. Working as a team.” Ariel also described how extracurricular activities developed her, "I've always done marching band. That enabled me because it taught me a lot about discipline. And I continue to do that, so that's helping me with time management as well.” Devin also credited sports for his never-give-up mentality, "One of the biggest things that has helped with my persistence and stuff is sports. No matter how hard it got, quitting was never the option." Courtney believes that participating in extracurricular activities at a smaller (rural) school was an advantage for attaining scholarships.

We had good sports, and that could increase your chances of being scouted and getting an athletic scholarship. I could see that being something. I was in a lot of clubs too. College applications, they asked about extracurricular activities. So, I had a lot to put down on paper. I would say that enabled [me].

Even though students feel that their school prepared them for college, this does not mean that those students will persist. Chris, exodus student, felt that he was prepared for his biology courses, but this alone was not enough for him to persist. "I had AP biology in high school, so that definitely helped. It's probably the reason I wasn't bad in biology. [Just the biology course by itself] was still way too much work." Students' past experiences have given them beneficial 


\section{ENABLING AND THREATENING FACTORS AFFECTING PERSISTENCE}

skills and knowledge, but this may not be enough to continue through their degree. When preparation is not enough to get students through a tough time, they need to rely on other resources. One of the possible resources is other people to help RFGC students to get through some tough times by giving words of wisdom or helping to explain content. There are other times that the resource they need is not a person but monetary or physical resources.

Experiences and skills were found to be an enabling theme derived from RFGC STEM students' comments. This theme was developed from three codes. The number of students that made comments relevant to the codes are as follows: background/experiences ( 8 out of 11 students), skills (10 out of 11 students), and high school preparation (10 out of 11 students). Some type of experience or skill comment was made by all 11 students.

Students made comments about their hobbies or family activities (background) that gave them beneficial experiences. These informative activities helped the students to gain knowledge and interest in topics that related to a STEM degree. These informal educational experiences provide foundational knowledge along with real world references when they are officially trained in their STEM courses. These informal experiences range from fixing items at home, like a car's mechanical or electrical parts, to spending time in nature, where they learn names of organisms and how to distinguish them.

Students credited their background and experiences for their work ethic which helped the students to adjust to the challenges that they have faced. Their work ethic helped them put in the required time to read and complete the homework that was assigned. Students with lesser work ethics may not be willing to spend the time on these assignments. Students' high school experiences were described as beneficial in persisting in their STEM degrees. These experiences 


\section{ENABLING AND THREATENING FACTORS AFFECTING PERSISTENCE}

either gave RFGC STEM students content knowledge, skills, or psychological preparation that enabled them to adjust to the rigors of college.

The comments used to identify this section's theme were all related to skills or experiences that students felt had enabled them by giving them foundational knowledge, beneficial skills, or experiences that they can build off of while in their STEM courses.

Even though students feel that their school prepared them for college, this does not mean that those students will persist. Chris, exodus student, felt that he was prepared for his biology courses, but this alone was not enough for him to persist. "I had AP biology in high school, so that definitely helped. It's probably the reason I wasn't bad in biology. [Just the biology course by itself] was still way too much work." Students' past experiences have given them beneficial skills and knowledge, but this may not be enough to continue through their degree. If a student's experiences or skills are not enough to get through the tough times that they experience, RFGC STEM students need to rely on other resources. One of the possible resources is other people to help RFGC students to get through some tough times by giving words of wisdom or helping to explain content. There are other times that the resource they need is not a person but monetary or physical resources.

\section{Resources and support.}

Varying forms of support were found to be enabling agents for RFGC students. Students felt that social capital was a benefit to their academic pursuits. Michael viewed his support network as a positive influence, "It's definitely helpful to have someone encouraging there. They'll point you in the right direction and give you positivity." Abigail also understands this benefit; "Having people that you know are there to try to help you succeed is definitely a bonus." Brenda discussed how she utilized more than one resource for support. 


\section{ENABLING AND THREATENING FACTORS AFFECTING PERSISTENCE}

I go to my Mom a lot, and I talk to professors, and I talk with my friends a lot. I ask them for advice a lot. And I think, once or twice, I asked people at Student Support Services, and I just ask them about any challenges I have, and they can usually help me out. The enabling forms of support fall into two categories: institutional, and family and community. Institutional personnel were found in various supporting roles: faculty, peers, tutors, and other school personnel. Don talked about the benefit of caring faculty, "You've got some really awesome, caring teachers here who want you to pass and understand... and that you become a good engineer. That definitely helps my drive. It has definitely been a huge benefit to my ability to keep going."

Courtney also discussed faculty and how they produced a positive atmosphere.

The fact that you can have more of an intimate relationship with your professors. I walk past [my instructor] and [he] says, "How are you?" It's more intimate and more personal and more of like a trusted relationship with the professors to where they are more approachable, and you know you can ask them questions if needed.

Abigail made similar comments about her peers. "I get along with most of my classmates. We get together and study. That's definitely an asset. It would be difficult if I didn't get along with the people that I deal with on a daily basis." Brandy also mentioned how peers helped with scheduling issues.

[Peers] helped me figure out what I wanted, like how I wanted to map [my classes]. You have your advisor, but they're not always able to help you because they have like tons of students. I feel like it helps to have people... friends tell you, like, "Yeah, that class was actually hard. If you want to save that for an easier semester, you should do that." Stuff like that will help you. 


\section{ENABLING AND THREATENING FACTORS AFFECTING PERSISTENCE}

Devin discussed how a college summer program helped him develop peer relationships that were beneficial to his academics.

Some of the people in the [First2 Network] that I became close with, I asked them, "Hey, will you go to the library and help me with this or look over my essay?" They have been helping me a lot. And especially having an on-line chemistry class this semester, which I've been scared to death of. But a few of them were chemistry majors, and I already told them, "We're going to be going to the library every once in a while."

Brenda also discussed how the atmosphere at her institution was attractive to her as an RFGC student. "The staff [at my school] were all really friendly, and I just liked the positive energy that was on campus, and it was like in the mountains, and I liked that." Brandy's comments are a good representation of the overall responses of the RFGC STEM group.

The financial aid is nice... And the professors are really helpful... I went to her like every other couple days just to ask her questions about class. I took a class freshman year that pretty much we just learned how to take notes and how to like study for STEM major classes... what you needed to do in class to really retain the information, but it also taught you how to calculate your GPA, and it taught me more about my loans and financial aid and how to make sure that I was in the percentage I needed to be to continue with your scholarships.

She also stated how a student organization would be beneficial for a student's career aspirations. If you're involved in the STEM organizations, a lot of those work with communities to help fix problems and it gives you experience [with] problem-solving...Sometimes some of the groups go to like conferences, and it helps you see what's out there, opportunities with jobs ... you go to a conference, and then you see like people are working for a 


\section{ENABLING AND THREATENING FACTORS AFFECTING PERSISTENCE}

company, and they say, "I also minored in this," or. "I would've done this in college; I would've like been better prepared for this." So, I feel like those organizations can also help you like throughout school by just deciding if that's like your right career path and like if you need to add any classes to your major.

One of the major hurdles that students needed to overcome was the rigor of college classes. RFGC students referenced different means that they utilized to assist in attaining course content knowledge. Brandy discussed how tutoring and content help was readily available at her institution.

I know that [my school] is always like we have so much tutoring. I feel like they really do. They always have somebody to help you. A lot of their TAs are very helpful, like they do pick their TAs very well. I don't think I've ever had a TA that was just like there just to get their job done. They actually wanted to help you like learn it.

Devin mentioned an alternative resource to tutoring, peer mentoring, that was beneficial. "The upper-classmen who have gone through that program came and kind of like guided us and told us if you screw up during college or whatever, call us. We can help you; we've been there.” Abigail also discussed the benefit of peer mentors along with tutors.

This semester, I've gotten a perfect score on every quiz up to the mid-term, so it's working, and I'm happy for that. But I've pursued other tutoring services and things like that, and I've accessed the [peer mentor] last semester and this semester a little bit. I've had to ask for help a lot more, but it's worked.

Institutions also provide student support for non-academic topics such as what Abigail mentioned. 


\section{ENABLING AND THREATENING FACTORS AFFECTING PERSISTENCE}

They've got people for like a rehab thing going on now on campus. They have people who are recovering addicts and stuff. I think that's a big thing around here, too. I know a lot of students who have parents who have been opiate addicts, or they are themselves. And it's definitely a factor socially here.

Don talked about how beneficial his STEM peers were to him.

STEM friends, especially because they're all in the same ballpark as me, we can all have good intelligent conversations and feel like we're intellectually stimulating each other. I definitely could not survive without my friends, and I definitely couldn't do it by myself without the moral support and the encouragement that I receive, as well as what I give to my friends.

Brenda discussed how those that do not have institutional support would be at a disadvantage, "For someone who wasn't in Student Support Services; I'm in there and they always help with stuff. I guess someone who wasn't in [this type of program] would be really confused as to what to do."

While social support was prevalent in the student responses, additional provisions were also discussed. Misty described the benefit of online access to software, "The technology or software that we have access to at the school has helped. There are nights that I can come home and remotely access the software on the computers at school." Brandy stated how course design was also beneficial.

I took the two-semester calc, it was like two-semester calc 1 where you learn like half of the semester in the first semester, instead of like learning it all at once, you do it over a year cause ... Which it benefited me because I only took college trig in high school, like up to college trig so I didn't have any calculus...they do a good job separating it so that 


\section{ENABLING AND THREATENING FACTORS AFFECTING PERSISTENCE}

you get like a solid base with calc before you take like calc $2 \ldots$ [my school] also helps a lot of their freshman, there are a lot of reminders from your professors. They help you transition from high school where your teacher told you everything to do.

Devin had similar remarks to Brandy's.

Most of my teachers will put the slides from the notes up on Blackboard. I go through and look at those. And then I add to my notes what I missed... I expected to come in here and they'd expect me to know a lot of things before we started, and we actually started out at like the ground level and built up.

Financial support was a common topic as an enabling factor to RFGC student persistence.

Brenda talked about the benefit of this assistance. "[School cost] is not that big of an issue because [my school] is really good with scholarships and stuff, so I know that I'm not going to leave college being entirely in debt." Kerri discussed all of the various financial support she attained. "I have the PROMISE. I have the PELL Grant, the West Virginia Higher Education Grant, and then I think I have the Presidential Scholarship at [my school].” Don states how impactful financial aid is for an RFGC student:

[Financial aid], I'm extremely grateful for. The opportunity to go to college for free is so monumental. That's how you change lives, man, that's how you better the world, just giving people the opportunity to show them that they're worth something. Especially somebody in a rural situation.

Chris, exodus student, describes how his RFGC status qualifies him for financial aid, "Where I'm from qualifies me for a few and then, again, low income, first-generation, all that qualifies me." Not only does financial assistance cover school costs, it can also help students to focus more on their academics. Courtney described how institutional work-study was an advantage, "I 


\section{ENABLING AND THREATENING FACTORS AFFECTING PERSISTENCE}

don't have a job off-campus. I was a hall monitor, but I only worked weekends. I was able to just do my homework during the four-hour shift."

A student's family or friends were also found to be an enabling support mechanism.

When Aerial was asked to describe assets or strengths of other RFGC students, she said, "A lot of us have a lot of support from our families. They want us to succeed, and they're very emotionally supportive. Not necessarily financially...trying to motivate us to do what we need to do and do our best.” Devin said,

My greatest strength would probably be my family... It's just mostly my family helping push me through. Even when I say I don't like this anymore, or I'm tired of this, or I'm homesick, if I call them and talk to them about it, I get, "Well, I don't care, you're staying. You're doing it!"

When Kerri was asked what enables her, she mentioned family support, "I have a good support system; my parents are very supportive of me getting a degree in what I'm getting a degree in and just me going to college in general." Kerri went on to discuss how her first-generation status impacted her parental support.

I think that's a big reason why my mom pushed me to go because she regretted not ... well, she went, but she didn't finish. She went for a semester, so ... She had a lot of regrets and didn't want me to have the same regrets. I think just seeing her own struggles and regrets, it makes me realize that I should do this.

Even though these RFGC students do not have parents that attained a college degree, some students were able to rely on other family members with college degrees. When Chris, exodus student, was asked about his assets or strengths, he responded, "My stepfather is a pharmacist; he had knowledge about [college] pretty well." RFGC students that have family 


\section{ENABLING AND THREATENING FACTORS AFFECTING PERSISTENCE}

members with college degrees may be a loophole of sorts with being labeled as first-generation. Brandy stated, “[My sister and I are] twins. That's why it's always awkward when people are like, are you first-generation? We're both going to college, but we're like the first people to go to college at the same time." Brandy went on to discuss how her sister and another family member were beneficial to her navigating financial issues. "I talked to like my uncle. He knew a lot about it, so we talked to him...Plus my sister has taken out loans. So, I kind of knew from her how to do it."

RFGC students also found social support outside of their families. Kerri discussed how her relationship with her psychologist was a huge factor, "She has a son in medical school, so she tells me all the things I need to know about college..." Kerri goes on to discuss how this relationship complements her drive, "She definitely pushed me into the medical field. I definitely feel the need to... I want to make her proud. I really want to push through it because I feel like if I didn't, I would let her down.”

Outside of emotional support, family and friends provided other means to help RFGC students to persist. Abigail's parents were able to live with her and her daughter, providing various forms of support.

I'm really lucky with my family. I've got a lot of people backing me up and supporting me to kind of cover all the bases of it, so I can concentrate on learning. They help with my daughter, taking care of her. I own my home, and my mom and her husband came and moved up here with us, so we could all still be together. So, my mom works from home and my stepdad's retired, so they'll watch [my daughter] when I have classes and for studying and all that kind of stuff. So, it helps out a lot. Helps pay the bills and all of that. 


\section{ENABLING AND THREATENING FACTORS AFFECTING PERSISTENCE}

Some students mentioned how their families were able to fund some of their college expenses. Brenda discussed a few ways that her parents were able to financially support her.

My family had savings bonds and then by the time I graduated and went off to college, they had some money saved up for me so that I didn't have to work my first year, and it was really helpful. They also paid for my car, which was really helpful. I needed a car. Devin also had family financial support, "My grandfather, instead of giving Christmas presents and stuff like that, he opened up a stock account for us. He put money in there for everything. So, that's basically paid for my first year." Additional students mentioned that they received financial funds from local sources. Courtney was lucky enough to have two full-ride scholarships from her rural region, "I think, my county...It's [a married couple] Memorial Scholarship. I got that one and [another county scholarship]. That was a big deal."

Resources and support were found to be an enabling theme derived from RFGC STEM students' comments. Each student made at least one comment that related to this theme. The codes revolved around either institutional or family and community. Both of these were devised of two categories, social capital and financial support. The number of students that made comments relevant to the codes are as follows: institutional social capital (9 out of 11 students), institutional financial (8 out of 11 students), family social capital (10 out of 11 students), and family financial (6 out of 11 students).

Institutional social capital came in the form of faculty, staff, and peers. Students discussed how these sources of support were utilized when they experienced challenges that they were struggling to overcome. Students utilized these resources because they were unsure of how to overcome the challenge or they needed emotional support to help them trudge through the hard times. Faculty, peers, and tutoring services helped students get through content-specific 


\section{ENABLING AND THREATENING FACTORS AFFECTING PERSISTENCE}

hardships. Emotional support and answers to non-content issues came from faculty, staff, and peers. Non-content issues include, but are not limited to, adjusting to college life, financial issues, and major specific issues. Students also reached out to family, friends and other community members for emotional support and to help them get through non-content problems. Students also stated how institutional and family and community financial assistance was needed to overcome their school financial needs. Without this assistance, the students said that they would not be able to afford finishing their schooling.

This section answered the research question of, what do RFGC STEM majors perceive as factors that enable them to persist? The three enabling themes developed from the student interviews answered this question: Drive, Experiences and skills, and Resources and support.

\section{What do faculty view as the factors that enable RFGC STEM students to persist?}

Based on the faculty interview responses, four main themes were found as to what enables RFGC STEM students to persist: Motivation, Experiences and skills, Support, and Personal characteristics.

\section{Motivation}

Several enabling factors listed by faculty were related to motivation. Some comments were directly about motivation, while others were closely related. The faculty's comments that were related to motivation revolve around three topics: students have an end-in-sight, student interest, and they realize they can do it. Paige, an astronomy professor, sees motivation as the most important factor.

I know that readiness is a factor, but my impression is anyone can overcome that if they feel motivated enough. I guess if they have motivation, that's probably the greatest factor. I know that it's easy to feel overwhelmed and maybe even to have that be a big enough 


\section{ENABLING AND THREATENING FACTORS AFFECTING PERSISTENCE}

barrier that you would quit, but if you do have the motivation, I think that can carry you through any barrier.

It is not just academic motivation that is needed, as Paige adds,

It's not easy to navigate that, so, you need a lot, just like persistence, motivation to persist through that difficulty. Like, going into the financial aid office and taking out loans and filling out all the paperwork, that's really difficult. But if you have the motivation to do it, you'll still just keep doing it. Keep calling the offices you need to call or whatever. Faculty believe that student's that have an end-in-sight or value their education is a form of motivation. Lydia summarizes this topic well.

The greatest challenge faced for persistence of rural first-generation STEM students is their perceived lack of value that an education has. What I mean by that is they're not sure how valuable their degree is actually going to be. So, if they see value, and that could be monetary, that could be emotional, that could be, you know, some other kind of value that's important to them, they want to be the first person in their family, if they see value in their degree, they will doggedly pursue it. If they lose sight of the value of a degree, they won't persist. They just won't. They weren't raised in a culture encouraging them to go to college.

Other faculty made similar comments that relate to Lydia's summary. Amy talked about the importance of having a career goal to get through a STEM major.

I see students who have gotten through and done well, and they're excited about their futures. They're going to grad school, some of them are going to med school. I had one student who wanted to be a science journalist, and she was getting a double major, and I mean some of the students have very focused ideas, and I think that helps a lot too. I 


\section{ENABLING AND THREATENING FACTORS AFFECTING PERSISTENCE}

think it helps a lot to have a focus. So, for example, I had a student who was doing really well and was going to go to med school, and he very specifically wanted to go into cardiology, for example. So, I think that helps a lot to really have that end point

Paige is not rural or first-generation and compared her experiences to what she sees with RFGC students.

They know why they're doing ... they have a reason. They know why they're going to college. I didn't have a real reason, like a real career I was chasing after. But I kind of do sense that the students that I've worked with, they have a vision for what they're trying to do.

Margo talks about students valuing or appreciating education.

I've also noticed that they tend to be more appreciative of their education and see the value in it. Because I know a lot of rural ones, they stop after that first year or two. The characteristics of the ones that still persist, [are] the ones who can see the benefit of their education. [This is] probably the greatest asset which causes them to persist within the STEM field.

The type of life and salary resulting from a specific career are typical factors that students consider when choosing a major. These factors turn into motivation while completing the coursework of a chosen major. Robert's response to what are enabling factors of RFGC students was associated with this type of motivation, "Probable future, higher income. I think most of them they see it as a way out from where they are. So, there's basically a little more of a hunger for them." Currently, STEM fields are in high demand, and a STEM major could see this as a relatively easy pathway to start a career. Paige considers this a motivational factor as she compares herself to RFGC students. 


\section{ENABLING AND THREATENING FACTORS AFFECTING PERSISTENCE}

I'm not rural or first-generation, but I do feel like my college experience is different than theirs. Like I said, it was just expected that I go to college. I had more freedom to just choose whatever I liked or just explore a little bit more. I didn't really have to think, could this be a job? [For me] it wasn't like a make or break [decision]. I feel like if I were growing up now, I would know that STEM would be a good [choice].

Having an interest in something is a form of motivation. Mike, an engineering professor, mentions how having curiosity, in general, is important for college success.

I feel that if you have any interest at all, you could... go to college and be successful. Some students just don't want to go to school, or they don't know what they want to do. They may think that they can't do it or that it is not their place, but they can do it. You can do it if you're interested. If you want to do it. Just because they're from the middle of nowhere [doesn't mean] they can't do it.

Margo feels that some students have a specific interest or passion for STEM.

I keep thinking of [my colleague] and his crayfish. If he lived in New York City, he might think that's only something that you order at a fancy restaurant. I think that their experiences, just in physical rural location, they have a greater desire for some specific STEM fields.

Students and faculty mentioned that their rural education was not up to par, and Deb, a math professor, cites this as a means of motivation.

It's a benefit to the student who comes in thinking, well, I might be starting lower, so I really have to work hard. I think that benefits; because we all know that no matter what background you have, if you don't put the work in, you're not going to pass the classes. 


\section{ENABLING AND THREATENING FACTORS AFFECTING PERSISTENCE}

Lydia feels that some students are motivated by their desire to prove themselves. "I feel like they're trying to maximize what they do. They're trying their utmost to impress because they feel like they have something to prove."

Some students may feel that they are not good at math or other STEM courses, or they may not have had a positive experience in high school. Once students find out that they can be successful in a STEM course, this becomes motivation to continue on into a STEM field. This can be especially true of those that are not sure of their major or career. Nik, a chemistry professor, pointed out that several of his general chemistry students have declared chemistry as their major after taking his course. He believes this is due to a positive experience in chemistry. [When] they actually follow those guidelines that I showed [them], they realize, "Hey, yeah, I can do this, and it's not that scary." And they decide, "You know, maybe this is something I want to do." I think a lot of people are put off by STEM fields because of the mathematics. And once they realize [that nobody else knows math that well], and they develop [those math] skills, they're like, "Yeah, I can do this. Why not?"

STEM faculty statements developed the enabling theme, motivation. The general codes were: motivation, end in sight, interest or something to prove, and realize they can do it. Eight of the ten faculty made a comment related to these codes that make up the theme of motivation.

Four of the ten faculty made direct statements of motivation being an enabling factor to RFGC STEM persistence. Without motivation, students will not take the initiative to reach out for help, make connections with faculty and peers, and/or do what it takes to persist in tough times.

Having an end in sight is a form of motivation because the student has a reason for attaining a degree. Five of the ten faculty made comments related to students having an end in 


\section{ENABLING AND THREATENING FACTORS AFFECTING PERSISTENCE}

sight. Without this motivation or end in sight, students will often lack a reason to stay in their STEM degree when they experience challenges. Having an interest or curiosity about a STEM field is a form of motivation. People that are interested in a topic will pay more attention to what is presented to them, and, if needed, they will find other resources to help them understand topics that they find confusing.

Faculty felt that rural students were viewed as having a desire to prove themselves because of their rural status or that their high school education was not up to par, and this is a form of motivation as well. They want to prove that they belong and can attain a degree and overcome the rural persona. Students also were viewed as having additional confidence and interest once the student experienced success in a higher education STEM course. This additional confidence and interest can help students overcome future challenges, which helps them to persist. The more positive experiences that students have, the more confidence and interest they may have. They may also develop much-needed skills from these positive experiences. Experiences and skills.

Faculty made several comments related to student's experiences and the related skills that they have developed as enabling factors for RFGC STEM students. The experiences that we go through can develop certain skills, either intentionally or unintentionally. The skills that faculty mentioned are typically inadvertently learned skills as they were developed as a result of everyday rural life. Will, an engineering faculty member, said that "They may have more experience with doing things with their hands, like maybe fixing stuff or taking things apart... a greater mechanical - more interaction with possibly real-life mechanical things and more electrical things." Lydia, a math instructor, made similar comments, saying that the skills are due 


\section{ENABLING AND THREATENING FACTORS AFFECTING PERSISTENCE}

to necessity, "I'll go back to skills. Many of them can take an engine apart and put it back together. They have to do that. A lot of times, they have to fix things."

The experiences and the skills that come with these experiences can also produce additional advantages. Lydia believes that "rural students are used to having to fix things and do things and use different tools to accomplish that. So, that brings a certain level of flexibility and creativity to the table." Lydia lists additional items that make being an RFGC student advantageous to the STEM field.

They're willing to work to problem solve in a way that non-rural students sometimes aren't...persistence and problem-solving are two things that I see from rural students. A lot of times... they'll keep pushing. And there's a stubbornness there, like I need to prove myself, and that stubbornness seems to translate nicely into persistence. You know, I'm here, I'm going to prove I can do this kind of thing.

Rural is often viewed synonymously with blue-collar, and faculty made comments related to RFGC student's working experience and the skills that come with working, especially time management. Robert, a chemistry professor, mentioned how RFGC students seem to have an:

Ability to plan. If they can make it through the first couple of weeks and figure out how to make things happen, they can basically plan their day. So that gives them an ability to overcome the normal issues that a lot of freshmen have. Which is no time management, anything in that line.

The physical environment that RFGC students grew up in was also mentioned as an advantage. Margo, a psychology professor, said,

I think that those in more rural environments, they have more experiences with like more natural environment due to where they live. They might be more likely to have played out 


\section{ENABLING AND THREATENING FACTORS AFFECTING PERSISTENCE}

in the woods, gone hiking, and have more of that natural scientific curiosity and experience. I think that their experiences, just in physical rural location, they have a greater desire for some other specific STEM fields. I think it may help them be able to put a definition to things that they have already experienced or applied. Like kind of backwards from what non-rural students may have had. They [non-rural students] may have had a lot of that textbook based; this is taxonomy, whereas a rural student might have actually applied and manipulated or used this material, those natural materials, and not just know what it's called.

Lydia adds to this idea, "A lot of times they've spent more time outside, a lot of times they spent more time putting together spare parts... and those kinds of things translate really well, especially in STEM fields."

STEM faculty statements were the basis of the enabling theme, experiences and skills. The codes related to this theme were skills and experiences. Seven of the ten faculty made a comment related to these codes.

Faculty mentioned that student experiences around "fixing things" and being around nature correlated to good STEM skills and basic content knowledge. The experiences that we have can lead to new skills, especially those experiences that are hands on, like fixing devices. This is advantageous to a RFGC STEM student because these experiences give them STEMrelated knowledge that other students may not have. These experiences are also helpful as realworld examples that can aid in their understanding and application of any new knowledge on which they are formally educated.

Faculty also felt that these experiences can enhance a student's creativity, flexibility, and problem-solving skills. These skills correlate well to many STEM fields, as students need to be 


\section{ENABLING AND THREATENING FACTORS AFFECTING PERSISTENCE}

creative, flexible and solve problems within their course work. The more STEM skills and knowledge that a student has going into a STEM program, the more likely they are to be successful. These experiences and related skills make for a good foundation for entrance into the STEM fields. These experiences may help to overcome what some students believed to be a lesser rural high school education.

\section{Support.}

Support comes in many different forms, including but not limited to financial, emotional, and academic. These types of support can come from family or from the institution. No matter the source or the type of support an RFGC student receives, it is viewed as an asset to persisting in their STEM career.

Being able to afford higher education is a barrier that needs to be overcome before any other obstacle in attaining a degree. Those students that have financial assistance do not need to worry about this hindrance and can focus on other items. Few faculty members recognize RFGC students as having adequate financial support. Those that do have financial aid need to keep it to stay in school. Deb discusses the importance of a specific WV scholarship.

"I mean that's the big thing in my opinion, is like if you get through high school, and you worked hard, and you make it to college with the PROMISE, then that can help you persist. This is a four-year scholarship, and, because they screwed up their first semester, that's really sad [they lose the scholarship due to low GPA].

Margo talks about emotional support and additional support that is not monetary, "Oh, I think both emotionally and, what's the word, just support like resources type of support." Faculty members discussed the importance of support from home and the institution. Lydia said, "Support, academic and emotional support. Academic support from within the institution and 


\section{ENABLING AND THREATENING FACTORS AFFECTING PERSISTENCE}

also emotional support from their family, their friends, their peers." Emotional support can come from your family and those from home as Deb states,

Some [students] have family members, maybe not their parents, but some may have other family members to encourage them. Some may have friends. It might be the fact that their family is really pulling for them to go because nobody else has gone or their parents haven’t gone, but they really want their kids to. And, so, they come with that, somebody at home is pulling for them to persist.

Paige gives a firsthand account of this support.

Family support seems like a really big deal. I have seen in West Virginia and rural Appalachia; you go to these towns and everybody knows everybody. Everyone's rooting for you. I feel like that would be a strength, if I was a college student here in West Virginia, to be able to go home to that and feel like everybody was like, "How's it going?'

Additional faculty comments discussed a wholistic view of support, such as Lydia's statements. Support, academic and emotional support. Academic support from within the institution and also emotional support from their family, their friends, their peers. I don't necessarily think it's just tutoring. I think there's a misconception that just throwing more tutoring assistance at a student is the answer. I think by academic support, I mean having people they can go to in order to get questions answered. Whatever questions they have. Occasionally, those will be academic. Occasionally, those will be, how do I find this on campus? And that needs to be accessible answers, and it needs to be transparent and very straightforward for them for them to know where to go for answers. 


\section{ENABLING AND THREATENING FACTORS AFFECTING PERSISTENCE}

Nik discussed the importance of the support that happens outside of the classroom, precisely that of peers.

A support network, that's \#1. If they have an outside of the classroom support network, whether that's on-line with students with their cell phones, with their internet access on their laptops. Something to keep them engaged outside of the classroom. Honestly, I started by trying to engage with myself, but I think it works best with peers. If you can do anything with, not even with upper level students, but students who are willing and have the ability to explain the material. They'd be in like a learning center, tutoring center or even on-line with just some questions and answers in a type of forum inside the learning management system or something like that... you've just got to kind of reinstitute or kind of teach them some study skills and stuff like that. This is where peer mentorship comes in, helping them with their study skills and study habits.

A few faculty members mentioned the importance of the institution's environment as an impactful attribute. Paige summarizes this by saying,

I think what college they go to; I think what resources are available once they get to college. They can be trying to go to as many help-centers as they want, but if there isn't really a help center, that's not their fault. But [that] depends on their environment, where they choose to go and what that place is offering, how welcoming and supportive it is.

Margo goes a step further by stating that students need a safe school environment, "Having a safe place to go that's on campus for students."

This section listed the most impactful statements made by STEM faculty that lead to the enabling theme of support. The number of faculty that made comments related to these codes 


\section{ENABLING AND THREATENING FACTORS AFFECTING PERSISTENCE}

were family and community support (4 out of 10 faculty) and institutional support (6 out of 10 faculty). This support involves financial, academic, and emotional support.

Securing appropriate finances is a necessity to enroll and continue through a college degree. Without this necessity, students will have to work to make up for missing funds and this will take away from their study time. If a student cannot obtain sufficient funds, they will not be able to continue in their pursuit of a degree. Those students that have secured funds are at an advantage to persisting compared to those without this support. This financial support comes from the institution, family members, community, and federal and state aid.

Academic support is important as RFGC STEM students need resources to answer questions concerning academic content and for college in general. FGC students do not have a parent or guardian that can typically answer these questions, but other family members or friends may. This is where some faculty felt that the institution and the student's peers can help fill this gap. While family might not be able to help with academic questions, faculty felt that rural students had a very supportive family and community.

Sometimes students need encouragement and a pick-me-up when they are going through tough times. This is advantageous to struggling students as this can increase their drive or motivation in attaining a degree. They do not want to let their family and community down by failing a course or dropping out of their STEM field.

All of these types of support help students to afford college, find answers, and fill emotional needs that help RFGC STEM students to persist through college challenges. 


\section{ENABLING AND THREATENING FACTORS AFFECTING PERSISTENCE}

\section{Personal characteristics.}

Several faculty members noted specific personal characteristics of RFGC students that are viewed as enabling factors affecting persistence. These characteristics were grouped into four common topics: responsibility and independence, acquiescence, resilience, and work ethic.

The first topic related to personal characteristics is that they demonstrate quality responsibility and independence. Students experience a significant amount of freedom compared to their days in high school. While this newly found freedom is great in some respects, it also means they are solely accountable for their academics. Students without responsibility and discipline may not be successful as a result of this new freedom. Amy discussed how RFGC students' work experience develops them into responsible students.

What I often see in these students is that many of them have to work. They have jobs while they're in school, and I believe that working those jobs teaches people that you have to show up at a certain time, you have to do a certain amount of work, and I think that's helpful as well.

When Robert was asked about RFGC enabling factors he cited that they are; "Self-efficient and take responsibility for their own actions a little bit more [than non-rural students]." This is a specific type of responsibility, intrinsic blame. Robert continued to discuss this idea, "Students around here, which I think is more rural, they tend to not have a complain environment. They typically will take responsibility for their own actions in terms of what they do wrong." Being an independent person is another form of responsibility. Amy has observed RFGC students demonstrating their independent nature firsthand.

That's the primary one that I've noticed. I mean, they show up and they do their work, and they are very willing to solve problems by themselves. I see kids who come in, 


\section{ENABLING AND THREATENING FACTORS AFFECTING PERSISTENCE}

they're independent, they want to learn how to do things, and then they want to solve problems by themselves, and that is something that I don't see in other kids.

Acquiescence is the second topic related to personal characteristics. Characteristics

related to acquiescence are accepting, obedient and compliant. Several faculty members felt that RFGC students take advantage of what others tell them. They listen to their instructors'

directions and tips for success. Lydia describes her feelings on this topic.

[RFGC students] don't have any preconceived notions about what college is supposed to be. A lot of times that can work in their favor because they will take what their professors say at face value. They'll believe their professor when the professor says they need to read, you need to work, and so a lot of times they'll put that work in without questioning because they have been told they need to do that.

Those students that listen to constructive criticism seem to excel more than those that do not. It is a characteristic of a studious student that teachers wish all their students had. Amy discusses such a situation.

[My] colleague has a [local student], and that kid is doing amazing work in the lab. He was actually working together with another student who had gone to a private liberal arts college, and the difference in the way they approached the problem was really amazing. The kid from the private liberal arts college didn't like criticism. He just felt that he came in with skills that were impeccable, and this other kid was willing to learn and to work and work and work until he got it.

Margo discusses how RFGC STEM students demonstrate an acquiescent attitude to adverse feedback, such as grades. 


\section{ENABLING AND THREATENING FACTORS AFFECTING PERSISTENCE}

So, they get a $\mathrm{C}$ on their biology test. It's not an "I'm stupid," it's an "Okay, this is information I need to know, so I can do better the next time.” They use feedback and criticism to better themselves. They see it as an opportunity, rather than as a "I can't do that.

Faculty believe RFGC STEM students are resilient given their experiences and background. Because these students have held jobs and have gone through challenging times, they seem to react better to college challenges. Instructors listed several characteristics related to students being resilient, as they used words such as: "adverse," "resourceful," and "tenacious." Margo mentions how RFGC students have resilience and grit that enable them to persist as a STEM major.

I find that rural students who continue on in STEM tend to [have] grit and resilience as well... and tenacity. I think they have a much higher tolerance level. I think they have a much higher breaking point, compared to students who don't have as high of a grit factor.

When people go through adverse situations it tends to change that person for the better and prepares them for future adverse conditions. Margo explained this in her interview, I think specifically coming from rural students, they are more likely than their urban counterparts to have had more adversity. They may be more persistent and be able to do more with less. The amount of anxiety and depression in students has significantly increased over the last four years, but those from rural environments, some have protections against that. I mean school is a different type of stressor, but they may have experienced adversity early on. They are more inoculated to it, so it's not that it doesn't affect them, but they may respond to it differently.

Amy also made similar comments concerning RFGC students. 


\section{ENABLING AND THREATENING FACTORS AFFECTING PERSISTENCE}

And just, you know, task completion and not getting frustrated when things don't work. You don't see them getting frustrated and kind of disappearing. They might need a little bit more assistance as far as getting up to speed with things, but they just have that persistence. Not be affected

Lydia envisions a specific instance that RFGC students go through that give them this "even keel" mentality. "If they have had to already overcome financial difficulties or other difficulties in life, then they seem to have a little bit more of a long-term look at the little small things that can happen in a classroom."

A few faculty members specifically stated that students are tenacious or stubborn. Lydia discusses how this is a good thing for a STEM major.

A lot of times, they're tenacious. They'll keep pushing. And there's a stubbornness there, like I need to prove myself and that stubbornness seems to translate nicely into persistence. You know, I'm here, I'm going to prove I can do this kind of thing. It's a little bit of a chip on the shoulder is how it can seem. But it's being proud and knowing that you've got something to prove.

Nik also views this as an advantage, as he discusses what it takes to be successful in a STEM field, "Just tenacity has to be involved, they have to take the initiative. Some of them do have that tenacity, that wanting this, especially our students that are rural."

Previously it was mentioned that RFGC students tend to do more with less or are more resourceful. This resourceful characteristic also involves students being flexible and creative. Margo made a statement that relates to this point, "I think specifically coming from rural students, they are more likely than their urban counterparts to have had more adversity, and so they may be more persistent and be able to do more with less." Lydia agrees with this RFGC 


\section{ENABLING AND THREATENING FACTORS AFFECTING PERSISTENCE}

advantage and gives specific details of the relationship between the student's rural life and their development of being resourceful.

Most of our rural families in West Virginia are lower-income families. So, from that comes the idea of how different classes deal with different things. They use tools in ways that somebody might not have thought to use a tool. If the tractor is broke down, you fix it, and maybe you fix it with other tools and other parts and other things that you have. So, substituting tools to get the job done and recognizing that "there's more than one way to skin a cat." That seems to be something that rural students embrace. I think that, that's lacking a lot of times in STEM fields; it's definitely in the math classes I teach. So, a willingness to just try something else is useful.

Work ethic is the fourth and last topic mentioned by STEM faculty that is related to personal characteristics. Will sees this as a benefit to RFGC STEM students, "Those students bring with them very strong work ethics, and a higher work ethic would be very positive. Work ethic is always a benefit, particularly in physics classes." Robert compares urban and rural student's work ethics, "Rural kids, especially around here, because they are farm kids, they have a tendency to be hardworking and just be able to put in effort, which a lot of times city kids don't have the ability to do." Deb believes that work ethic is what will help RFGC students to persist. "For West Virginia, I think that some of the strengths might be that they're hardworking. I think that that willingness to work hard is the main thing that will help them persist as a firstgeneration student." Nik describes how work ethic can overcome a student's lack of preparation. The big strength that I see, they have a pretty good work ethic. Maybe they're not the most prepared students on the face of the planet, but they have that decent work ethic that they want to do well. If you are doing the work, you're going to get the outcome of it. 


\section{ENABLING AND THREATENING FACTORS AFFECTING PERSISTENCE}

What I've seen in some of the students that come in from the rural areas, they struggle a little bit in Chem 1 and Chem 2, then they struggle a little bit in organic, but overall, they tend to do fairly. The people that tend to be from more urban areas, they tend to not have the same work ethic that I've seen in the rural areas.

Lydia gives a detailed rationale for why rural students have developed this highly valued skill, work ethic.

They're not afraid of hard work and often early morning hours are not a problem, especially if it's a rural student that has any kind of farm, or if they hunt, or if they do those kinds of things. It doesn't bother them to come to an 8 a.m. class, which is a real asset that I think they have over many of their peers. A lot of rural students are used to working a lot of hours and, so, they're not fearful of the workload that they have to put in. I think that's a big asset that they bring to the classroom. I think that the work ethic of first-generation rural students is rarely surpassed. They will put the amount of hours in that it takes. I don't feel like the work ethic is there from students who come from urban areas as much as it does from rural. I'm guessing it has something to do with just the amount of work it requires to keep a house going in a really rural area versus an urban. So, I'm thinking it's just a different experiential thing.

This section should how the theme personal characteristics was developed by the comments of the STEM faculty in this study. The number of faculty that made comments related to the codes were: responsibility and independence (2 of 10 faculty), acquiescence (6 of 10 faculty), resilience (6 of 10 faculty), and work ethic (6 out of 10 faculty). Every STEM faculty member made at least one comment that falls under the theme of personal characteristics. 


\section{ENABLING AND THREATENING FACTORS AFFECTING PERSISTENCE}

These statements are grouped together because they are not skills, but are independent characteristics of who a person is. These characteristics were viewed as favorable by the faculty and were a result of the student's status, especially that of being from a rural area.

Students in this study described that their high schools were not that challenging, and, therefore, they did not need to keep track of assignments and schoolwork. This was a challenge to overcome in college. The STEM faculty felt that RFGC students are more responsible and independent than most students, and this will help them adjust to the higher expectations in college. Responsibility and independence are qualities of a person, not a skill.

Acquiescence is another characteristic viewed by the faculty to favor RFGC STEM majors in persisting through college. This is an attitudinal characteristic that not all students have. Rural students that were given chores or held jobs are familiar with feedback given by others. Receiving feedback or criticism is natural to these students, and they are more open to instructor's comments. Students are more willing to complete tasks that faculty request, like reading a textbook or completing practice problems. Completing these recommendations are beneficial to finding success in STEM classes.

Resilience is another attitudinal characteristic described by faculty. Faculty commented that RFGC students were resourceful and even tenacious with their pursuit of a degree. These characteristics of RFGC students help them get through tough times. These students were viewed as having previous challenges in life that gave them their resilience to adverse situations. These experiences give students confidence and motivation to overcome any new challenges that they encounter. These students know that they just need to work on issues or problems that they encounter, and, if they do not give up, they will be successful. 


\section{ENABLING AND THREATENING FACTORS AFFECTING PERSISTENCE}

Work ethic was another characteristic described by faculty members as being advantageous to STEM students. Work ethic is not a skill. Work ethic is something that is developed and becomes a part of who they are. People who are willing to put in the work needed to complete assignments and to appropriately study should find success in attaining a STEM degree. This is especially true if you add in other characteristics like resilience and acquiescence. All of these characteristics can help students overcome their shortcomings or the challenges that they face in college.

The goal of this section was to determine, what do faculty view as the factors that enable RFGC STEM students to persist? The themes found in this section answer this question. The enabling faculty themes were: motivation, experiences and skills, support, and personal characteristics.

Note on faculty views.

Numerous STEM faculty made declarations about the limitations of their views. Some mentioned that they are not exactly sure which students are rural or first-generation. They discussed how their viewpoint is just based upon their observations, feelings and are only anecdotal. This aligns to the mission of this study, which is to gather the faculty's perceptions of the factors that enable and threaten the persistence of RFGC STEM students. The faculty also realized that some of their comments can relate to any student. This can be true if non-RFGC students' experiences or environments were similar to RFGC students, such as growing up in a "blue-collar" family. Will's comments demonstrate this awareness,

Certainly, any student at any level could develop those factors if they had the right home environment, so it's something where it may be more common in a rural student, but certainly you could be the kid whose dad owned the auto shop and have a lot of hands-on 
ENABLING AND THREATENING FACTORS AFFECTING PERSISTENCE

experience there. Or the kids who had to help out in their family business working, you know, 40 hours a week and going to high school. So, those experiences could be had by anybody. They may be, I guess, anecdotally, one might expect them to be more common in rural students.

\section{What factors threaten the persistence of RFGC students in STEM majors?}

The previous sections focused on assets and strengths that enabled RFGC STEM students to persist. The following sections discuss threats to, challenges for, and weaknesses of RFGC STEM students affecting their persistence. These elements are grouped together as factors threatening persistence.

\section{What do RFGC STEM majors perceive as the factors that threaten their persistence?}

RFGC STEM student interviews were analyzed to determine the factors threatening persistence and the common themes are: Drive, Experiences and skills, and Resources and support. These items were also found to be enabling factors. This correlation matches what was discussed in the literature review, where some factors can be either threatening or enabling.

\section{Drive.}

Several factors can be negative impacts to one's drive for attaining a college degree. A few of these are life events, negative school experiences, being homesick and a lack of interest. These threatening factors can impact a student's mental and emotional state to the point that students cannot take the stress anymore and leave school to reduce this pressure.

Life events can drain a person's desire to continue, as one interviewee, Chris, an exodus student, discusses how life events influenced his decision.

Probably just not being able to center on my own worries and stuff; there's a lot of things going on around me such as family things that get you down at certain points, and, at this 


\section{ENABLING AND THREATENING FACTORS AFFECTING PERSISTENCE}

stage in life, it's better to be independent than to still being living with your family. I've got two younger sisters, and there's a lot going on, in general, at any point in time in my family. So, it's a lot to deal with; family, college, trying to get a job, and all that stuff. So, honestly, the biggest weakness is probably trying to balance all of the areas of my life at the moment.

Courtney stated similar life events causing enough of an issue that she temporarily dropped out. Honestly, organic chemistry, this is my second time taking organic chemistry 1 . I took it in the fall of my sophomore year, and I got a D in it. There was... a week where I drove home, which is 3 hours away, for [a] memorial service, and then I drove back that night. Then I had a zoology lab practical the next morning, and I didn't even get to study for it, and I bombed it. That whole semester was a wreck with more of my personal life type stuff, but I considered changing my major because I didn't think I'd be able to get through the class, and then I took that spring semester off.

Abigail adds some additional life events that can be major obstacles.

Of course, [having a working car]. Any kind of family or crazy crisis or drama, [family member passing], anything like that can derail you easily. Of course, being a single parent is definitely a hindrance. Just the daily life stresses of things...I'm a homeowner. If anything, unforeseeable happens.

WV is experiencing a major drug issue, and Abigail discusses this as a threatening factor, "I hopped on the opiate epidemic when it first started in 2004-2005, but I've been in recovery since 2006... I think it is way worse now."

The accumulation of school and life puts a substantial emotional and psychological toll on a student and can affect their concentration and drive. Several student comments were 
ENABLING AND THREATENING FACTORS AFFECTING PERSISTENCE

focused around unexpected class-related items, especially how classes were harder than expected. Brenda discusses the rigor of STEM courses.

STEM classes are harder than any other class, so for any other class I feel like you don't really have to pay as much attention because you can always just figure it out on your own, and you essentially don't need as much time for other classes, unless you're like an art major... There was a large course load. We had to read chapters for each class that were kind of lengthy, but then there was on-line homework that came from the chapters, and it was just a big confusing mess.

Kerri also mentioned how hard the classes were and describes why this was unexpected.

I didn't expect it to be as difficult freshman year. I expected difficulty once I got junior, senior year, but I thought freshman year, I would go in and build upon stuff, and it would be easy to start out with and get harder. I didn't expect to just go in to like just full-on difficulty.

Brandy discusses how being in a STEM major and knowing students in other majors can cause doubt in being a STEM major.

I know from my point of view, it's hard when some of your friends get 4.0s, and you know that their major is not as exhausting as yours. They don't have to study all the time and their exams... they study for one day and pass it. You're taking harder classes and... can be disappointing to try so hard, and you still don't get that good GPA, don't get the grades you want. Because I know a lot of my friends [say], "I can’t believe you study all the time; you're doing this all the time, and I could never take that class." And I'm like, "Yep, I'm taking it, and I'm probably going to get a C in it. My GPA is going to drop even more. I can't wait." So, I think that's also like something that makes it hard to be a 


\section{ENABLING AND THREATENING FACTORS AFFECTING PERSISTENCE}

STEM major. It's just knowing that like you can try your hardest, and you're still going to have probably a worse GPA than like half your friends.

Chris, exodus student, discussed the unexpected time requirement of STEM courses, "I had mistaken how much time you had to put into the major to be successful at it, and I definitely was not enjoying biology and the STEM field enough to do that."

Certain subjects were found to be especially problematic, as Brandy states, "I think some challenges are just like the basic challenges for any STEM major, is like calc 2; it took me two times to pass it. And I think just passing those like math classes are a main issue." Courtney describes her struggles with chemistry.

I wouldn't have guessed that I would have struggled with it as much as I have.

Foundational biochemistry, which was fall semester freshman year, there was just material that I didn't understand, and I had to try really hard to try to comprehend it. I ended up not doing well on it, and it brought my grade down a lot. I guess I've always kind of been able to comprehend it eventually. But with chemistry, it never happened. And that happened in organic chemistry 1; I am retaking it the second time, there are concepts that I am finally like understanding to a good test level. Because all throughout high school, I had done good with classes. So, this was a first for me.

An additional threat to a student's drive was found with the interactions of students and faculty or the expectations of faculty and their teaching style. Some students made comments about not understanding their college professors, such as Abigail, "I had advanced machining calculations 1 and 2. The first semester, we had a teacher that all of us understood, I mean we all got it. The second semester...we had a new teacher. None of us understood it." Rural students are not accustomed to interacting with diverse individuals, and those instructors with accents 


\section{ENABLING AND THREATENING FACTORS AFFECTING PERSISTENCE}

were also found to be a challenge. As Devin states, "He's difficult because he's hard to understand, being Romanian. I have one professor... I don't know where he's from, but he has a strong accent, too. So, that will be difficult."

STEM courses are hard enough to pass without additional outside challenges. And when students are not able to take classes in the order they are meant, this creates even more of a challenge. Abigail discusses her issue as a non-traditional student and class order.

I was taking tech math 2 simultaneously with statics last semester. [Math] is a prerequisite, but you can take them as a corequisite. Probably would have been better to take the math first and statics after. Because by the end of the semester, in math I had learned things that would help me in the beginning of the semester in statics.

Devin also mentioned a scheduling issue.

It started with I couldn't fit my English in with the times allotted. And he said, "Well, take your chemistry, this would be a great time for your chemistry to get it over with." Well, there was no time for me to take my chemistry, either, but that on-line class was open.

In this situation, the chemistry course was not designed to be taken in the semester Devin's advisor suggested, and the course was online, which many inexperienced online students struggle with. This is especially the case if an RFGC STEM student is already experiencing other challenges or issues. Even if a student's advisor provides appropriate advice, meeting with them can be a challenge. Brandy mentioned that meeting with her advisor was difficult, "Your advisor, but they're not always able to help you because they have like tons of students."

Adjusting to the way college classes are taught was also a threatening factor. Courtney mentions the challenge of adapting to multiple teaching styles, 
ENABLING AND THREATENING FACTORS AFFECTING PERSISTENCE

I had to adjust to the teaching style of Dr. Cook taking botany; she uses PowerPoint slides, and I came from Huggins [she does not use PowerPoints]. So, I kind of did bad on the first exam, and then I had to adjust my study habits, and then I got A's on all the rest. Other students like Brandy discuss difficulties adjusting between high school teachers and college professors.

"I had this group project. And it was mentioned at the beginning of the semester, but they didn't tell us anything about it. We were halfway through the semester and like, all right, here's your group project. It's due the last week of classes, and I'm like what? And they were so blunt about it. It was like, this is what is due. And I was like, "Can we get more information?" I'm confused at what we're doing.

Don also discusses his transition to college instructors.

I think [my] expectation was that like your [professors] would care if you passed more... like a high school level, "Oh, you need to pass, do your homework." I didn't expect the freedom to fail. You could tell they wanted you to do well, but they're not pressuring you. They're not pushing you the same way like maybe a parent would at your home. I expected that. A hometown teacher may express disappointment when you fail or when you don't do homework or something. That affects you personally, you feel like you disappointed somebody. But in a college situation, like nobody cares. You just didn't turn it in, you move on.

Student frustrations arise when faculty lack compassion or understanding, such as the experience that Courtney had.

I drove home, which is 3 hours away, for my dad's memorial service, and then I drove back that night. Then I had a zoology lab practical the next morning, and I didn't even get 


\section{ENABLING AND THREATENING FACTORS AFFECTING PERSISTENCE}

to study for it, and I bombed it. But the fact that it was the lab practical, there was really no way I could even make it up because she has to set up like hundreds of things, and so making it up wasn't an option.

When asked if she contacted the teacher and let her know what was going on, Courtney said, "Yeah. I let her know that, and she said that you can't really make up a lab practical. That was something specifically that I knew I was going to do horrible on."

The rigor of STEM courses was found to be a barrier for students, but the courses themselves are not the only source of stress. Courtney stated the impact that non-class related stress had on her studying. "I had a whole bunch of extra stress throughout my semesters because of my family, so essentially someone who didn't have that extra stress, they would be able to focus on homework more than I was." Don also discusses the stress due to course workload, which impacts his ability to keep a balanced life.

The biggest is a lack of socializing. I stay so busy. I always have my face in books. You don't have very much time... to go hang out with friends, and that's like the biggest thing is that [being a STEM major can stifle you]. [It] can suffocate you, especially if you're having trouble juggling the workload as well as trying to keep yourself sane and not overstress.

Misty describes the challenges of living at home and lack of technology.

I did not think it was going to be as hard as it is sometimes, not having all the technology, like the smartphone and tablet and unlimited internet. That is a big one, actually, we have very limited internet here, and sometimes I have to spend the whole day down at the school to download [an] update. 


\section{ENABLING AND THREATENING FACTORS AFFECTING PERSISTENCE}

Chris, an exodus student, describes how being first-generation and being unfamiliar with college was a big challenge,

I didn't really know the environment of the school at all. If I knew how to better navigate, you know, the multitude of offices and different places I had to go to get things done and different processes I had to go through, there are certain things that would have been a lot easier. Just being new is basically the whole reason that I ended up switching [major].

Brandy experienced similar issues as Chris, but she stated explicitly that understanding the financial aid process was a challenge, “.... and a lot of my friends that had gone to college didn’t have financial aid or anything. So, I just did not know what to expect with that and then just like college itself, I didn't know what to expect."

Experiencing a new school environment or atmosphere was found to be an issue as Chris, exodus student, talks about the issue rural students have with college housing, "The living condition is probably one that gets a lot of students. I know there are a lot of students from my area that had problems living on campus." He goes on to discuss how students have to find ways to afford living off of campus, "So they have to go off and have extra work and keep themselves up to live." Sometimes the living arrangements are so different from their typical rural spaces; they have to escape the foreign environment. Devin describes his coping mechanism when this issue arises, "I find myself a lot, if I'm stressing out bad, that I've just got to go somewhere. I'll go to Walmart and just walk around. I've just got to get out of my little dorm." The absence of a rural environment was also a challenge for Chris. "Coming from my area, outdoorsmanship is basically more important than the Word of God in a sense, and being close to nature is, in my opinion, the best medicine for anything you've got. It really helps the soul." When asked how much time he spent with outdoor activities he said, "As much as possible. During hunting 


\section{ENABLING AND THREATENING FACTORS AFFECTING PERSISTENCE}

season, I rarely studied. I definitely passed, but rarely studied and rarely did anything else but hunt. Any chance I got; I was in the woods." Devin also misses the rural atmosphere, "I have family that live [close to my college], and they have a lot of acreage and stuff, so I go there sometimes." When asked if this is how he relieves stress, he said, "Big time for me." He also has altered his class schedule so that he could be home for long weekends.

Monday, my first class is at 6 p.m., and I'm done for the week at 3:00 on Thursday. And I go home all the time, because I'm always homesick. So, I go home Thursday night. I don't have to come back now till Monday afternoon.

Homesickness and how far RFGC students are from home were also discussed as negative factors. Brenda explains her lack of support due to being away from home, "Oftentimes, in rural areas, there's not a huge university around or anything, so a lot of times [students] have to move really far away from their family, and they need support from their family." Devin also mentions the impact of being from a rural area.

I feel like a lot of people that are rural and their parents didn't go to college, they don't get out a lot. So, then when you move out, I think homesick would be one of the biggest issues. Not used to staying away from home too often.

Aside from the physical environment of the school, student interactions and social life can negatively impact RFGC STEM students. Chris, exodus student, describes the competitive nature of college classes, "The students were really competitive, really self-centered, there were a few good ones. It's just very competitive and [being in a STEM major is] a completely different environment from what I'm in now [music major], and it's the same university."

Ariel discusses how meeting new friends was a challenge at first, "I started off expecting to easily make new friends, and I don't know, just do what you do in college, and I didn't really. 


\section{ENABLING AND THREATENING FACTORS AFFECTING PERSISTENCE}

I had trouble making friends at first." Michael also has similar fears with making friends and describes why this is stressful for rural students, "I was worried about the social aspect. Just a new area and like people I've never met before. Being rural, you have like a close group of friends, and it's always been that way, so it's weird getting out there."

Chris describes how rural freshmen students will experience a more diverse population, as compared to the area they grew up in.

Definitely, I mean our [high] school, it wasn’t very diverse. [My college] is definitely more diverse. Where I come from, race wasn't seen. Concord is close in certain areas but it's not an as homey environment. It definitely taught me how to be generous and kind to others, especially others who are very different from me. It prepared me to deal with other people. I know some people who come from schools who only had one culture and they have a hard time adjusting to college. They're not used to the diverse cultures.

More populated areas tend to have more crime, and this can be a shock to some RFGC students like Devin, "When I came down here and I got an email in the first week saying there was a rape, and I was like, "Oh, my God! We never had that back home.” He goes on to describe how this impacts his willingness to socialize, 'I'm even scared to go out to those parties and stuff, I won't go to them just because you don't know what's going to happen, it's just a different atmosphere."

Another factor that impacts students' drive is their interest. Brenda discusses how STEM classes were not what she expected and severely impacted her interest in the field. "I feel the material is harder because it can be really bland and you're absorbing just a bunch of numbers." When asked why she left biology for sociology she said, "Yeah, lack of interest definitely. I was expecting it to be more interesting than what it was when I got there. It was mainly just numbers and equations that I didn't really want to do." Courtney stated, "Chemistry was something that I 


\section{ENABLING AND THREATENING FACTORS AFFECTING PERSISTENCE}

struggled with just because I didn't find it that interesting." Brandy discusses switching her major because she did not know what her original major entailed, "It ended up being more like hardware and I didn't really want to do hardware. Then I took the CS class, and I was like this is a lot better. I liked programming more, so I switched to CS.”

Having other options aside from college can persuade a student to leave a rigorous STEM

field. Don discusses how he can see the temptation especially being from a rural area,

You may be pushed towards maybe a more manual job...in a rural town because of the environment of the town, especially if you live in like a super country area. Maybe people there work at a certain pipeline or at a certain plant or something, and that is the work in that town. It's hard to separate yourself from what may be your hometown's wishes for you, you know, what they or your family wishes for you, or what you're expected to do. It's hard to break away from that.

Drive was found to be a threatening theme derived from RFGC STEM students' comments. The number of students that made comments relevant to the codes are as follows: drive and life events (6 out of 11 students), negative school experiences (11 out of 11 students), distance and homesick ( 3 out of 11 students), and lack of interest (9 out of 11 students). All eleven of the students made at least one comment related to drive.

Life events were discussed as negative factors to a student's drive for continuing in their degree. Life events, such as family sickness or death, having to work, being a parent, and dealing with drug or mental issues can cause difficulty in finishing a STEM degree. These life events either take up a student's time or put an emotional toll on them to the extent that they have difficulty focusing on schoolwork, and some even dropout of school. 


\section{ENABLING AND THREATENING FACTORS AFFECTING PERSISTENCE}

Students discussed numerous school experiences that negatively impacted their desire to continue in their STEM major. College classes were found to be much harder than students expected. This caused students to doubt their abilities (they do not belong in college, not smart enough) or doubted their desire to attain a STEM degree. Additional issues concerning classes dealt with the interaction with the teacher's teaching style or accent. These concerns can cause students to lose interest in a class especially when the content is hard enough on its own. If a student has a hard time following what the teacher is doing or expecting out of them, then the course may be viewed as impossible to pass, and the student may give up.

Non-academic issues were also found to be negative impacts to a student's drive. Some of these include, but are not limited to, lack of technology, balancing work and life, and navigating the college processes. These challenges on their own may not cause students to leave, but when a student is experiencing multiple challenges, it is the accumulation of issues that may cause the student to leave.

If a student does not adjust to their new college environment, this factor alone may cause a student to leave without experiencing any other issues. Being homesick, or being far away from family or a rural environment, may cause students high anxiety. These students may feel as if they do not fit in, or they may believe that they cannot live in their new environment. These students naturally seek out the place that they feel more comfortable, home.

Drive and interest are similar, and a number of students stated lack of interest as a threatening factor. Students either realized that they did not like the content matter of their courses or that their major was not what they thought it would be. If the students have other options aside from college and going through a STEM degree, they may decide to take the other 


\section{ENABLING AND THREATENING FACTORS AFFECTING PERSISTENCE}

career path. The factors listed above can negatively impact a student's drive, or desire, or interest in continuing in their STEM degree.

\section{Experiences and skills.}

The second threatening theme is a lack of skills or experiences from the RFGC student's perspective. This section includes comments concerning academic preparation, high schools that were not challenging and students not having academic skills.

Most of the RFGC students interviewed made comments related to their academic preparation or the lack of preparation. Specifically, STEM subjects were discussed as either lacking in quality or not taken in high school. Kerri said, "I think schools in rural areas, the science and math really aren't great. So, I think that when they go into STEM fields that they probably struggle a little bit to begin with. They are at a disadvantage." Ariel's comments emphasize the low math quality and the drastic impact it had on persistence.

My math education was behind that of other students, and that could be from the rural area that I grew up in. But I've noticed that, with some other kids, they came from a rural high school. They weren't as good at the math and stuff as they needed to be to just go right into their major. Not having the same level of math education from high school that other students did, I struggled with that a lot. I do still struggle with it. I feel like I'm very behind. It's also like very discouraging. Sometimes, you just don't want to ... you think, Oh, is this really the major for me because I'm really struggling with math because I didn't have an as advantageous background as some of these other kids.

Chris discussed the impact poor high school preparation created for him.

It [high school] was pretty low end, we didn't have any good teachers especially in the math. I was in [college] chemistry 103 right off the bat because of my SAT scores, 


\section{ENABLING AND THREATENING FACTORS AFFECTING PERSISTENCE}

however, I definitely was not prepared for that level of class already. I had chemistry the year before in high school, but the most we got done was balancing simple chemical equations and memorizing the periodic table, and the first day I was told memorizing the periodic table was useless because [there will] be one in every lab and classroom I would ever be in. So, it set me off to a bad start and that was pretty much the whole reason, just not a good enough education for the required courses I had to take.

Chris and others mentioned that some of their teachers were not certified.

"We didn't have very good math teachers... we honestly didn't even have a math teacher for two years at my high school. There were certified ones in the school, just not teaching at my grade level. They just put someone in there who was not certified in math to basically watch the class.

Like Chris, Courtney also mentions the issue of lower quality teachers in high school.

I took biology in high school, just the basic first one and the teacher was absolutely horrible, and it's actually funny because I hated biology in high school. But I knew that it was something I was still interested in, but literally his teaching style, it just like completely put me off, and I could have taken bio 2, but I learned that he would be teaching bio 2 as well, so I didn't take bio 2, and I actually took chemistry instead.

Kerri went to a larger rural high school, and, when she was asked about how her classes prepared her for college she said, "I did well in math in high school, it just was not to where it should have been for my college classes." Don compares the schools he went to and he views rural schools as less preparing schools, “Learning that you get from a rural town isn't as good as a higherfunded...school, you know? I've been in a lot of school systems. I've been in over 12 school 


\section{ENABLING AND THREATENING FACTORS AFFECTING PERSISTENCE}

systems." Even very successful high school students feel that they were not prepared for college. Brandy said,

I think my high school didn't really prepare me for college classes at all. My sister graduated third in our class, and I graduated fourth, and I still didn't expect ... I still struggled. It didn't matter that I had above a 4.0 GPA in high school because in college it was like I was getting Cs.

The availability of high school courses was a popular comment, and Abigail discusses how this limited her financially and even prevented her from attending college until later in her life.

We did arena scheduling, where they let us all in the library to make our schedules, and by the time I got there, my honors classes were full. So, that eliminated me from the running for the PROMISE scholarship. My senior year, they said, well, too many people qualify, so we're going to change it. You've got to have AP classes, and so I was bitter. I couldn't really afford it out of pocket, so I ended up taking a semester off, that turned into 10 years.

Brandy also discussed the lack of academic options as threats along with the lack of rigorous high school classes.

I know some people that went to college, they took computer science classes in high school, and we didn't. We took a computer science class that was like Microsoft Word for college. We didn't have technical classes and stuff like that. And so, I feel, some kids that come into college, they might be better prepared because their school offered [more diverse and harder classes], but ours didn't. 


\section{ENABLING AND THREATENING FACTORS AFFECTING PERSISTENCE}

Even when quality STEM courses are available, the fact that they are not required causes a persistence issue. Kerri describes her experience with this situation, "I dropped [chemistry] the first semester because I was doing poorly. I would have been better off if I had been required to take chemistry in high school because that wasn't a requirement to graduate."

Several student comments were made related to a lack of high school rigor or that their school was not challenging enough to prepare them for college. Most of the students interviewed commented that they rarely had to study. Not having to study for high school classes created a void in study skills, which were a necessity for their STEM courses. Kerri stated that, "I did not study very much. I did my homework but ... I understood it well in class, so I didn't feel the need to study, and I did well on tests." Michael discussed the complication he experienced in college,

In high school, I did not study at all really. I'm sure that's a common story, but it really is an adjustment to get used to, like putting in the time for homework and studying and balancing five classes at once. You go from high school, where everything just seems so simple, you can just absorb it, like it's no issue. But [in college], it takes practice and application to truly understand what you're doing, so that's the main adjustment.

Content knowledge was not the only way that students felt unprepared. Devin discussed the ways that he had to adjust to the college rigor.

In high school, I never had to study. I didn't even take a backpack to school my senior year. And now it's not easy anymore. I have to study, I have to do my homework, I have to keep myself on schedule. That's been one of the hardest things.... Because I've never done it. 


\section{ENABLING AND THREATENING FACTORS AFFECTING PERSISTENCE}

Brandy discusses the challenges she faces in college and how she felt unprepared, even though she took AP courses.

I think my high school didn't really prepare me for college classes at all... I was not expecting the course load to be hard, like that hard. Even taking the AP classes, you might have to study the night before. But it wasn't like college, where you have to study a long time in advance and make sure you are going to study sessions. [In high school] you took the exam, and you got an A. I don't know if it was just because I went to a smaller school, so the education wasn't as advanced as like some other schools. I just feel like if I would have had to study more in high school, I would have had like better study habits and better time management. My study habits, I'm still struggling to study the best way possible.

Don confirms Brandy's points and emphasizes how this is the greatest challenge and weakness of being an RFGC student.

I wasn't as prepared as I thought I was. I think I had chem 115, bio 115, and some engineering classes, and I think there was a history class in there, too, but it was more than I had been asked of before from any kind of educational system. It was the biggest challenge I had ever faced, that first semester, the size of the challenge of college. I didn't know what I was doing and didn't know how to look at the material and learn it, because in high school, I just watched the teacher in class, and I knew what to do. And the material wasn’t challenging enough for me to develop good habits. So, that was probably the biggest challenge or weakness.

Previously, students gave numerous reasons that they felt unprepared for college. Some of these comments included a deficiency in skills related to academics, such as study skills and 


\section{ENABLING AND THREATENING FACTORS AFFECTING PERSISTENCE}

time management. Brandy explains how a lack of studying abilities was a significant issue for her.

I think study skills is like the biggest weakness because if you don't know how to study, that really gets you behind on the exams. My test scores weren't really that great because I just didn't know how to study. My first semester... I studied but no information stayed in my head for the exam. I feel like if you knew how to study going into college and knew what you needed to do to retain the information...it helps you pass your classes and get good grades.

Several students mentioned that they did not have to keep track of assignments and test dates in high school. Devin described how this impacted his ability to manage college requirements. The biggest issue would probably be time management, just trying to catch up on homework and do things like that. In high school, I never had to study. I have to teach myself how to do it. The studying I knew I would have a problem with because I've never done it. But the time management, I thought I'd be able to pick up a lot easier than I did.

Don related how a fellow rural student did not adjust to these new challenges and eventually dropped out of school.

I think his mom went to college, but they're still very rural. He was in engineering with me, and he became complacent. He felt like he was doing well, but he didn't really put in that extra effort that I've seen from some of my other friends that really try hard, and he lost the opportunity. He actually dropped out this past semester All eleven of the RFGC STEM students made at least one comment related to the theme experiences and skills. The number of students that made comments relevant to the codes are as 


\section{ENABLING AND THREATENING FACTORS AFFECTING PERSISTENCE}

follows: skills and knowledge (10 out of 11 students), preparation (10 out of 11 students), and high school not challenging (9 out of 11 students).

Several students made comments about the lack of quality STEM classes, or the availability of college-prep STEM courses, while they were in high school. This lack of academic preparation made the students fall behind compared to other students, which they then needed to spend extra time on catching up. This situation made students feel as if they did not belong in college, which could impact their desire to stay in a STEM degree. Because the students would spend additional time catching up on content, this left less time for learning the college level material. This time crunch put these students at high risk to fail the course or not attain high grades, which could impact their career aspirations. For an aspiring doctor, low college grades could cause them to pursue other careers, even those outside of STEM fields. Because RFGC STEM students' high schools were not very challenging, the students stated that they lacked academic skills. These skills include, but are not limited to, note taking, time management, keeping track of assignments, and preparing for college level tests. Students that lack these skills have a hard time adapting to the challenges that they face. This challenge can be so great that students may decide to quit their STEM degree or college all together because they struggle to adapt.

A few students mentioned that they are not very social or are more of an introvert. Devin said, "I don't talk to a lot of people. I just kind of keep to myself, doing my own thing." Misty describes this of other students and the negative impact it can have with not reaching out for assistance, "I know a lot of them can be more shy than other people. They won't ask for help as easily. I mean, just because they're afraid to or something." The lack of social skills as a product 


\section{ENABLING AND THREATENING FACTORS AFFECTING PERSISTENCE}

of being a RFGC student may impact a student's ability to get help when they are experiencing difficult times.

\section{Resources and support.}

The last threatening theme that was found among the RFGC student comments was the lack of resources or support. Students discussed a number of items, such as; not having resources, threats related to the money-work-time cycle, lack of family or emotional support, and issues associated with being first-generation.

Students use technology in several ways to assist in their schooling. Misty discussed the disadvantage she experienced by not having technology.

I don't have a tablet or a phone or anything to make my life a bit easier...it makes it more convenient to have that stuff. [Other students] take pictures and they keep their notes on their tablets and take pictures of the board, and they can always stay up on the latest announcements or whatever, and I have to wait until I get home or something and check my email. Unlimited internet. That is a big one, actually, we have very limited internet here.

Abigail does have high-speed internet and states this a necessity for her but a disadvantage to others, “[If] I didn't have the high-speed internet, it would make this way harder. That would be a big difficulty around here, access to broadband. I forget that most people don't have it, so that's a big one." Misty goes on to describe how her major requires her to have a high-tech laptop and the financial impact this has.

Every semester I have these things we need to get, like [fixing] a car. We're hoping to with my summer internship to get a new car, well, another used car. But we had to adjust our budget and what we could do and what we couldn't do when I found out I had to get 
ENABLING AND THREATENING FACTORS AFFECTING PERSISTENCE

the laptop. It had to have certain capabilities. It had to do complex computations with python. I couldn't just get a cheap laptop. [Also], having to download new software for every class.

Considering students must commute from their rural homes, reliable transportation is a major requirement. Abigail describes her transportation struggles.

Getting here on time, transportation, making it to class and stuff. Struggling to get to tutoring and things because I do have a daughter and other responsibilities. Difficulty with transportation. I know if my car breaks down, I am SOL. I miss Asheville for [public transportation].

Most of the resources described above can be resolved if students had additional financial support, but extra funds are not readily available for most RFGC students. Several students, like Brandy, work to help pay for costs. She describes how attaining a vehicle opens up more opportunities for employment, "I worked like closer to campus my freshman year because I was living in the dorms, but I got a car finally, so I work off-campus." Owning a vehicle can be costly in and of itself, and Brenda describes how this is a bit of a vicious cycle between the need for money, working, and the costs associated with transportation to get to work.

People with cars and stuff, they're going to have to have money to pay their car bills, their car insurance, gas. They have to buy their own food; they have to pay for stuff. And not everyone who is a full-time student can also be a full-time employee. So, money would be really tight, and it could hinder your education by not being able to afford the materials or not being able to afford your books, and how you live.

Numerous comments were made like Brenda's that talk about the connection between moneywork-time cycle. Later in Brenda's interview, she continued to discuss this relationship. 
ENABLING AND THREATENING FACTORS AFFECTING PERSISTENCE

If I'm in class all the time, I don't have time to work full-time, so I work part-time, but sometimes if your parents can't help you pay your bills, then you have to pay them yourself, and then you have to pick up extra hours, and it can sometimes get in the way of your school.

Brandy also mentioned this work and time relationship, but her time concern is not about how much time she has, but when she has time to study. She struggled with the late-night studying period.

I'll go to work some days until like 10 p.m. and then it's like it takes everything in me to go to the library after that until like midnight... it's harder to get yourself in that study mode. Sometimes I'll be at the library until 1 a.m., trying to do homework before [the next day when it is due].

Misty describes that her greatest challenge is money and that she spends a significant amount of time trying to find the cheapest books she can, but this takes up precious time.

I spend a lot of time trying to find the books that I need [as cheap as possible] from wherever. I might not have a book for a couple weeks, when everybody else just buys it as soon as they know what book it is at the bookstore at school. I will spend days trying to find the cheapest deal and making sure that it's the right book and everything. In addition to the stress of battling the money-work-time dynamic, several students were concerned about keeping their financial assistance, which enables them to stay in school. Ariel feels that this is especially true for RFGC students, "Financial, that's a big one for rural first-gen students. I know kids who are worrying about how they're going to pay for college. If they don't pass classes, they lose scholarships, and then they can't afford to be here." 


\section{ENABLING AND THREATENING FACTORS AFFECTING PERSISTENCE}

Brandy receives money from the government, given her situation, and, without this support, finishing her major would not be possible. "The only thing that would keep me from persisting is...if I didn't have any money... I get help from the government. I worry that I have a good enough GPA to [keep] my scholarships.”

A few students, like Courtney, mentioned a particular WV scholarship program as a reason for persisting. "I have a full ride, but people from rural areas typically don't have money, but I was grateful enough to get [the PROMISE scholarship].” If RFGC students do not attain scholarships or grants to pay for college, students struggle with the idea of going into debt and the value of their education. Abigail discussed this in her interview.

It will make you kind of question things. Should I be doing this, am I wasting my time and money to go into debt, for nothing? I heard on NPR yesterday, West Virginia has the highest student loan default rate in the country.

Most of the resources and support mentioned so far have been financially based. Don discussed the dynamic of financial need and a lack of support from his family.

My family isn't able to support me the same way [as] someone from the city would be able to, depending on the situation, obviously. I come from a pretty poor town, and it's pretty hard to ask my family members to help me financially in any way. That's probably the biggest weakness as a rural STEM student.

While there were several students that discussed a lack of monetary support from their family, others discussed other ways that their family were not supportive. These items are especially true of first-generation students. Brenda mentioned that some families are not supportive of their children's pursuit of a degree. 


\section{ENABLING AND THREATENING FACTORS AFFECTING PERSISTENCE}

They might not get support from their parents. I know that a lot of people who were in the blue-collar workforce might encourage their children to do so as well. They might just want them to work in the family mill. Or logging companies, which is something that's really popular here where I'm at.

Other students, like Don, made similar comments to Brenda's. Don mentioned the mental struggle that students experience when they go against other's wishes.

You know, you may be pushed towards maybe a more manual job or a physical job in a rural town because of the environment of the town, especially if you live in a super country area. Maybe people there work at a certain pipeline or at a certain plant or something, and that is the work in that town. It's hard to separate yourself from what maybe your hometown's wishes for you... what they or your family wishes for you, or what you're expected to do. It's hard to break away from that.

Chris mentioned similar feelings but also adds the extreme mental impact this can have.

Some families try to keep their family in the area. I've [heard] families tell their children they're worthless, and they're not going to be able to do what they want to do, and they shouldn't even go to college because it's useless, and they'll kill their spirit just to keep them [home and at the same status].

Devin discussed a similar situation with friends as he struggled with his career choice and seeing his friends enjoying life.

A lot of my friends that didn't go to college have jobs, and they're making good money with oil fields, and we have the river right there. They're working on barges, that type of thing. So, it's hard seeing them making so much money, and I'm down here going into debt. I come back here, and I get on social media, and they're all out doing fun stuff, and 
ENABLING AND THREATENING FACTORS AFFECTING PERSISTENCE

I'm sitting in my little closet of a dorm doing homework. So, it's just one of those things that I'm tempted to pack up and go home and go get a job with them.

Family and the local community were found to discourage students with their college aspirations, they also did not provide emotional support in other ways. Don discussed how the absence of family contact created loneliness, which impacted his willingness to be away from home.

A lot of my family really doesn't contact me very much. My mom does probably the most. Sometimes I feel kind of alone. It's easy to forget about your kid at college and forget that they need a little bit of encouragement, especially if they're going through a hard major like a STEM. If you can't understand what someone is going through, how are you able to sympathize and support them? It's definitely hard for people to grasp the kind of challenging situations that I'm going through, even though it's not necessarily their responsibility.

Don's statement also emphasizes the real impact of being first-generation in that those that have not experienced college really cannot offer any significant support. Chris explained how he was searching for some guidance with his career choice, but mentoring options were limited for RFGC students.

[My uncle] he was a chemistry major and works for the City of San Francisco; he would have helped a lot. However, he is very far away, and we don't have much contact with him. I don't really have a lot of help. Not many people from this type of place have a lot of help in that respect.

Brandy described why guidance is important for a STEM major. 


\section{ENABLING AND THREATENING FACTORS AFFECTING PERSISTENCE}

It's going to be one of the harder routes to take, unless you know somebody that went to college for engineering or something like that. If you don't [have someone], it's just going to be more difficult to adapt and know what to expect because you don't have anybody there to tell you like this is what happened when I went to college.

In addition to academic advice, RFGC students desired additional guidance, as Abigail explains, "I get very frustrated with it sometimes. You know, going through the whole financial aid process and the paperwork and all that to get in is a nightmare." Chris knows firsthand the importance of having an experienced mentor to get through the first year of a STEM major. "To be honest, first-generation, you need someone who knows the college environment and [your] field to help you get [through], especially the first year in that kind of field. If you don't have that, then good luck!"

Courtney described how family situations and dynamics can create distractions for students. "I had a whole bunch of extra stress throughout my semesters because of my family, so essentially someone who didn't have that extra stress, they would be able to focus on homework more than I was." Sometimes family expects their children to complete chores and favors. If parents understood the demands of college, they probably would think twice about asking for such favors. Michael believes that his parents would expect him to complete tasks if he lived at home, which would be a significant distraction.

I would worry that [staying at home] would affect my education, like maybe my parents would expect me to be doing something. My parents never went to college, so they don't really understand the gravity of missing classes. So, they might be like, oh, you can just skip today. I need you to do something for me. You can't go today or something like that. I could see how that could happen. They went to the beach for a week, and my Mom tried 
ENABLING AND THREATENING FACTORS AFFECTING PERSISTENCE

to talk me into living at home for the week and driving over an hour each way just to like take care of the animals and stuff. She was like, "well, you could just not go to class on this day."

Chris, the only exodus student, described his overall view of being an RFGC student. The STEM field benefits people from a higher income, more educated, more urban environment. It's not intentional. It definitely benefits them, and that's just the way the system is. Honestly, being rural first-generation is the worst combination for any STEM field, in my opinion. You've probably had different experiences, but where I'm from, not many can make it. There are a few that do.

RFGC STEM students' comments developed the threatening theme, resources and support. All eleven students made at least one statement that relates to this theme. The number of students that made comments relevant to the codes are as follows: general resources ( 3 out of 11 students), finances (10 out of 11 students), and family and social support (10 out of 11 students). Six of the eleven students made statements that surround issues with being first-generation college student. These students are included under the code family and social because being FGC is directly related to a lack of family support with college related issues.

One of the codes only had a few student references, but is still worth mentioning as they can severely impact a student's persistence if they are lacking. The few comments centered around general resources such as technological devices, internet access, and transportation. A reason for the lower number of student quotes related to "other resources" is that there is a very close relationship between these other resources and money. If a student has more money, they can afford certain technologies and transportation. Also, students that have more financial resources do not need to work as much, and, therefore, they have more time. Four out of eleven 


\section{ENABLING AND THREATENING FACTORS AFFECTING PERSISTENCE}

students discussed this money-work-time cycle. This cycle is included under the finances code. Because of the cost associated with college expenses, daily life expenses, and any technology and transportation needs that a student may have, some students will need to find resources to pay for these items. Those students that do not have sufficient financial resources will need to work to attain more money, which will take away from their study time. Also, add in the fact that it costs money to work if transportation and other resources are needed.

Family and non-institutional sources were not available to some students to pay for school. These resources also lacked in the areas of moral and emotional support. Some families and communities do not support a person going to college, and this can be an emotional turmoil for a student already in a rigorous STEM degree. Even if a RFGC STEM major's family and community are supportive of their college aspirations, they still may not be able to support the student by guiding them through their college issues, as they have no college experiences. Any time resources or support is lacking for a student, this puts them at a higher risk of not persisting in their STEM degree.

This section was focused on answering the question, what do RFGC STEM majors perceive as the factors that threaten their persistence? The themes found in this section answer this question: drive, experiences and skills, and resources and support.

\section{How do RFGC STEM majors handle or deal with the challenges they face?}

Understanding the challenges that an RFGC STEM student experiences along with how they overcome these challenges are critical components of this study. The goal of this study is to increase the success of under-represented groups like RFGC students. Determining how participants have successfully overcome these challenges, along with understanding how the 


\section{ENABLING AND THREATENING FACTORS AFFECTING PERSISTENCE}

challenges changed over time, will inform practitioners of possible means of increasing student success.

\section{What are their successful means to adapting to these challenges?}

RFGC students were asked how they overcame challenges. Numerous comments were made surrounding students acquiring assistance, particularly online learning resources. The first place that students looked for course help was with those individuals involved with the class. Brandy stated,

I know that everybody always tells you to talk to your professor if anything happens. As soon as I start noticing that I am struggling, I went to talk to the professor. Or talk to the TA that was in the class or just somebody else to see what I was doing wrong, what I needed to fix. What's causing me to do this bad on certain homework or programs or exams.

Additional school personnel were also utilized by RFGC students and assisting with their issues. Brenda listed her sources of help, "I go to my Mom a lot...professors...my friends. I ask them for advice. I asked people at Student Support Services about any challenges I have, and they can usually help me out." If a student did not have a support system, they were found to develop one by reaching out to others. Even Chris, the one exodus student interviewed, realized this importance.

Just making a network of people to communicate with, figure out what's going on and how to solve things is another issue I've been able to overcome. Mainly college personnel pretty much, because they're the ones you're talking to when you're doing business stuff. Everyone helps out. [My school] is a very friendly place in my experience, and the faculty is really helpful. [The Director] in the Academic Success Center, she 


\section{ENABLING AND THREATENING FACTORS AFFECTING PERSISTENCE}

helps a lot. She is able to help me contact people that I wouldn't necessarily be able to contact and get things done a little faster than I would be able to do on my own.

Several students discussed how they use online resources to comprehend course material.

Abigail explained how she complements lecture with online resources, "I spend a lot of time on YouTube looking up videos to help supplement lessons from classes. You know, 50 minutes [of lecture] isn't enough to learn electronic circuitry." She later discussed how she overcomes homework challenges by using an online resource. She uses this resource to understand how to complete statics problems, not just to find answers.

I ended up paying for a subscription to the CHEG. Our homework is not really graded, we just get points for doing it. So, it doesn't really do any good for cheating, but it would break down all the problems for me that I didn't have looking in the back of the book to the answer to see if I was right or not. I couldn't figure out where I was going wrong, so I got that subscription service and that helped out a lot. This semester, I've gotten a perfect score on every quiz up to the mid-term, so it's working, and I'm happy for that.

Additional sources of help that Abigail and other students utilized where tutors and major specific peer mentors. 'I've pursued other tutoring services and things like that, and I've accessed the [engineering peer mentor] last semester and this semester a little bit. I've had to ask for help a lot more, but it's worked."

Several students, like Abigail and Brandy, mentioned their struggles with math-based courses and the resources they found helpful. Brandy stated,

If I don't talk to the professors, I go online. [I] go to YouTube... Khan Academy. There's a lot of places, especially online that are free for you to get help. Even [for] math classes, 


\section{ENABLING AND THREATENING FACTORS AFFECTING PERSISTENCE}

there were math machines online. If you don't know how to do a problem, you can type it in. Click step-by-step and it can help you, show you step-by-step what to do.

As was discussed earlier, students declared that they lacked study skills and time management. In high school, they did not need these skills to pass their courses. Michael's statement summarizes this point, "You go from high school where everything just seems so simple. You just absorb it. It's no issue. But [college], it takes practice and application to truly understand what you're doing, so that's the main adjustment I've made." Given their past academic experiences, it was no surprise to hear that many of the students needed to improve upon these academic skills or just start utilizing them. When Devin was asked what he did to adjust or change concerning his studying, he said, "I just had to pick up a technique." Other students need to enhance their skills, such as Courtney.

I will admit that coming into college, my study habits weren't the best, but just through the semesters and kind of learning how the instructor teaches and how to take notes [in] lectures. That's definitely helped develop my study habits into what they should be concerning the material and the course load of the classes.

Students made some changes by limiting their activities, so that they could focus more on academics. Michael discusses his adaption by concentrating more on his academics, I had a lot going on with football... I didn't take it as seriously as I should have. There was no reason to struggle with the classes that I was in. This semester, I focus fully on my school and stuff like that, and it pays off, and it helps. It's just a lot of management and putting your dedication in the right places.

Students also made comments about working harder, like Abigail, "I had to force myself to do more practice problems, even if I feel I got it. [I] re-read stuff more than once. I've just had 


\section{ENABLING AND THREATENING FACTORS AFFECTING PERSISTENCE}

to force myself to buckle down." Students like Abigail and Michael stated specific ways that they improved upon their skills. Michael said, "I'll go through the textbook. I'll do an example. Then I'll change everything about it, change the numbers and see if it makes sense afterwards. That's pretty much how you know if you can do it or not." Abigail also talked about her improvements with time management.

I've gotten better organized and set my time aside for studying every day. I've been better at time management this semester with getting things done. That's a first. I keep my planner [updated]. I've got my whiteboard, and I've got several little document hanger things on my wall.

The students were asked to state what their greatest asset or strength is. Courtney responded, "Probably being adaptable to the workload and having to change my study habits." Adaptability was found to be significant characteristic of the RFGC students. Courtney continued her discussion and described the importance of being able to adapt. "Just because you're going to [have] different professors... different types of classes, where you have to adapt because everyone teaches differently and it's different material in each of the classes." No matter what areas students needed to adjust, they felt that adapting or being open-minded was a key component to their success. When asked what advice they have for future STEM majors, Brenda commented, "I would just encourage them to have an open mind. Not only academically, but as a person. Don't expect everything to go exactly how you planned it. I just feel like it's important to be able to adjust." Brandy gave a good example of how those that do not adjust or adapt are not successful.

I know some [students] that have taken calc like three or four times, and I feel like they're not putting in more effort. They're just putting in the same effort, and then they're 


\section{ENABLING AND THREATENING FACTORS AFFECTING PERSISTENCE}

getting the same outcome. They go into each semester saying, "I'm going to pass it," and then they do the same thing of just like not giving it their all. They'll have an exam, and they won't study any different. They'll just study a few days before and not pass the exam again. I feel like those are the people that don't succeed as much because they don't change ... they don't adapt.

\section{How do these challenges change over time as a STEM major?}

Educational practitioners strive to increase student success. Understanding how student challenges change over time will help in preparing appropriate assistance for students. The RFGC students stated that their most challenging problems occurred during the first semester, but they were able to adjust to this demand. Once they overcame this test, they felt confident to take on any challenge that may come their way. Even though Chris has decided to leave the STEM field, he believes that he is prepared for any future trials, "Everything is going well. There are a few problems, there's always something. Compared to August of last year, it's been way better. I have had no problems really that I can't handle or can't find a way to handle."

Several students discussed their experience of how the rigor of college fluctuated. Brandy discussed the changes in rigor that she experienced and her expectations of future classes. "I know there's going to be more tough classes to come, but I don't feel like that would make me change my major or like drop out of college. Even if I have to stay an extra semester." Don discussed his transition from his freshmen semester. "I wasn't prepared for the academic requirements... the requirements to really think. My first semester here was probably my worst. I definitely feel that I have good study habits now. I definitely have more discipline than my first semester." Though Don has adjusted well, he still believes that there will be additional challenges, especially with the content of higher-level courses, "I mean, the content is definitely 
ENABLING AND THREATENING FACTORS AFFECTING PERSISTENCE

challenging, especially when you get to the upper level, like I'm starting to get into now. It's starting to get a little bit harder than maybe some of the intro classes were." Many freshmen courses start with content that was covered in high school and then they advance into more complex or unfamiliar content. Devin discussed how a student can have a false sense of confidence within a freshmen class.

Technical math started out easier than what I expected. Turned out to be my worst grade because it started out easy, and I think I blew if off, thinking I already knew that stuff, I don't need to study, and it ended up hurting me in the end.

College classes can be unpredictable with the amount of rigor, and students need to be able to adjust as soon as possible. Brandy discussed her experience adjusting to college.

It took me at least like the first year to get any study habits. I was just kind of trying to learn everything the night before the exam and it was not working. It took a lot to figure out how to take notes and pay attention in class while doing it, not just like slopping everything down and then trying to figure out what they were talking about.

Not only did students advance their study skills, but as Courtney discussed, their study groups also evolved.

In the first chemistry class, we would just text each other when we were struggling with stuff, and then we would maybe meet. We never really had a set study time after each class or anything like that. Currently, in organic chemistry 1, we have specific meet up times to help study.

Courtney went on and discussed that, once her studying habits were improved, her willingness to ask questions in class also enhanced. 
ENABLING AND THREATENING FACTORS AFFECTING PERSISTENCE

If I did not understand the topic, I would feel like not bothering to ask for them to reword it... I hadn't done everything on my end to understand it myself. I didn't read the chapter before class, so then I wouldn't ask. The way I changed was I did come prepared to class more and then I [felt that it was] more reasonable to ask a question.

Students promptly getting help was a critical aspect to success in a course. If they get too far behind, it may be too late to recover. Brandy discussed how this almost happened to her and how she no longer hesitates to ask for help. "In one class, I didn’t get help for a while. I was like, I can do it myself. Then the slope was getting steeper and I was falling even faster. Now I make sure that I ask for help." Brandy went on to discuss how she was timid to talk to professors early on.

Freshman year, I always felt intimidated by professors, and I didn't want to ask questions. I didn't want to feel dumb or for them to think that I wouldn't be able to understand the course. I feel like just talking to your professors, kind of helps you open up and ask them any kind of question. Even if you feel like it's stupid, at least they know that you're just trying to understand.

The last "change over time" mentioned by the students was students' feelings toward their majors. Brandy discussed how she changed her major early on, and she was fortunate, as it is harder to switch the longer you wait to make this change.

I went into [college], I was like, “Oh, I'll just do [computer engineer] because it has computers in it, but it ended up being more like hardware, and I didn't really want to do hardware. Then I took the CS class and I was like, "This is a lot better." So, I switched to CS. After a certain point, CS majors are kind of like stuck. If you want to switch, all of your classes are CS, so if you switch, you'd have to start pretty much over. 


\section{ENABLING AND THREATENING FACTORS AFFECTING PERSISTENCE}

Students also discussed how their career aspirations also changed as they went through their schooling. Ariel said, "When I first came here, my goal was to work for NASA, but after talking to some people and realizing how strict their standards are, I've kind of accepted that that may not be what [I want]." Brandy also aspired to work for NASA, "I wanted to be a robotics engineer for NASA. Or some big space company. But now the more I go through my schooling and the more I think about careers, I'm like, that's just a lot of work." With some majors, students can attain multiple degrees and students like Devin may change their minds with finishing their four-year degree.

I can pay 50 bucks and get my associates degree which, I'm going to do. But I plan on going on and get [my bachelors] degree. I know it's going to be hard for me to continue because I'm going to think, "Right now, I can go make money."

\section{What do faculty view as the factors that threaten RFGC STEM students' persistence?}

Faculty interview statements related to threatening factors were analyzed, and four major themes were derived. These themes are: Institutional environment and faculty, Lack of preparation, Lack of support, and More challenges than others.

Institutional environment and faculty.

Faculty members believe that the institution and even their colleagues can be threatening factors for RFGC students. These threatening factors range from the physical environment to their peers to the classes they take. Mike discussed how students can get homesick and the emotional toll this can take.

I would have lived [close to the university] growing up and then went to that [university] and I was living [on campus], you know, I'm not that far from home so from an 


\section{ENABLING AND THREATENING FACTORS AFFECTING PERSISTENCE}

emotional standpoint if I got homesick, a student could easily go home, versus further away... I think there's a little bit of an emotional thing there.

Lydia also shared her feelings on homesickness along with the change in atmosphere and the challenge this presents.

I mean, homesickness, is another big factor for these students for lack of persistence. They are comfortable in a rural area, and a lot of times they haven't ... a lot of times their knowledge of just really basic things, like traffic lights and bus schedules and how you get around, I mean, those kinds of things, especially if they're going to a really big school, those can be barriers. They are homesick. It's very different. There aren't necessarily a lot of other people having the same experience around them unless an institution has really invested in helping them through that.

Nik specifically discussed how the culture shock can impact RFGC students.

It can be a little bit of a culture shock to them. ... when they were in [high school], they were in smaller classes... their graduating classes were smaller, maybe they had a more close-knit group of friends ... that they were interacting with all the time, and whenever you get to the college level of class size, it's bigger, diversity gets more, and sometimes they ... sometimes they can have trouble adjusting to the more diverse nature of a college, especially if they go to a really large institution, that can be kind of challenging. Sometimes it can just be a cultural challenge for them. They grew up in an area where maybe most of the people had similar ideologies that they had, and they get to a college or a big institution and they umm ... they ... they find other people with differing opinions and things like that. Sometimes, it can be a little challenging for those students to accept the different opinions. 


\section{ENABLING AND THREATENING FACTORS AFFECTING PERSISTENCE}

Will described some outcomes of RFGC students interacting in a new environment.

For rural students, the big thing is when they're standing on the corner of [the main street of the university], is it overwhelming? Do they know how to resist certain temptations that are here? Then, having to all of a sudden function in a town of 30,000 residents plus 30,000 more students might be a challenge, and it's just a very claustrophobic town, so maybe it just feels like something that's not your place, so you don't continue.

Lydia also described a similar viewpoint to Nik's,

There's a lack of a culture ... there is a lack of a college-going culture for these students. They just don't know very many people who went to college, or the people that they know that went to college seem very different from them, and they don't understand why they seem different, and that's a challenge. They often come from communities that... are the same - there's not a lot of diversity where they come from, and that's part of what I mean when I say that "lack of exposure." Students that come to us from cities have spent a lot of time around a lot of different kinds of people. Students that come from rural areas often haven't. They haven't met somebody from Asia. They haven't met somebody from Africa. They haven't ever met a Jewish person, for example. Those are the kinds of... when I say, "lack of exposure," that's kind of what I mean. They haven't necessarily interacted with as large of a cross-section of people as students that are not rural firstgeneration students.

Additional faculty comments were more specific with the cultural differences as they discussed

RFGC students fitting in to their new environment. Will talked about his concern with students at a larger university. 


\section{ENABLING AND THREATENING FACTORS AFFECTING PERSISTENCE}

It may be that since we are in a city that, even though it's only 30,000 , is very large for a city in West Virginia, and rural students may feel that they don't fit in. And I do actually see that in my students sometimes, not them feeling they are not fitting in, but them actually not fitting in. Their speech pattern or something like that. Any education, you're joining a community of others, so if you feel like an outsider in that community, you'll be less enthusiastic about continuing, maybe put in less effort, be less successful and it becomes a downward spiral. I do worry about the fitting in issue, but I don't know how to address that. It would take a lot of resources to address it.

Deb added that she is concerned about RFGC students finding others to relate to. "They may have never been away from home very much. They may ... how do I put it? You know, they may not have anybody to identify with." Lydia also has a similar viewpoint. "It makes them feel like a fish out of water right away, and so they need to feel homey. It needs to feel homey for them, they need to feel accepted quickly for them to persist."

College classes being harder than high school courses was a frequent topic that faculty mentioned. This topic was the most common threatening factor related to institutional environment. Will discussed why college courses seem harder for students.

Content, and then it's also rigor. You know, how rigorous was your high school preparation? Was your high school calculus class a real cal-1 class, or was it something pretending to be cal-1? And then, at college you also get into the issue of what level of academic competition are you used to. So, if you went to a high school where many students don't go to college, and you were the best student, that may mean something different than if you were taking all the AP classes at [city high school] and everybody's going to college. So, it really is when you sit down in a university STEM class, you're 


\section{ENABLING AND THREATENING FACTORS AFFECTING PERSISTENCE}

competing with every student in the room, and they're all good. So, if you're good but not used to putting forward the effort, then you have problems.

Mike also discussed why college classes are harder than high school classes.

You take a college class, this is kind of what's expected and ... you need the book, you need to come to class, you need to do the homework, and all these things. It's not necessarily like high school. I mean, I don't know, I don't know what's done in high school now. I don't know how much homework these students have and how much effort they actually have to put in but, you know, some students I think go through high school, and they do good with very little effort. It's not going to be like high school. You're going to have homework, you're going to have projects that you have to do. It doesn't become something optional.... it's going to be a lot of work, and it's going to be a struggle.

Additional faculty comments related to the hardness of college courses contained specific points of emphasis. Deb stated, "I think that maybe the high schools do more hand holding than the college faculty will do." Amy thinks that the "sciences probably run into it especially." Paige specifically describes why RFGC students may struggle, "Rural first-generation students... don't have as much experience, sort of like the fast-paced learning environment or even just exposure... in some rural areas, you can't even take an AP class if you wanted to." Part of the college environment is the interactions with college personnel. The interaction of students and faculty was discussed. Will talked about his view of students not adjusting to the "college culture".

So, if you are behaving in a way that I find somewhat off-putting, then I am less likely to provide you with opportunities. It's just the reality. If you come in as somebody who's 


\section{ENABLING AND THREATENING FACTORS AFFECTING PERSISTENCE}

not polished, you have to have some professors look past your lack of polish and give you opportunities where it may be because if you're not fitting in well with me, you're probably not fitting in well with my graduate students and things like that. So, there are negatives to not being part of the culture you're trying to enter.

Lydia, a RFGC STEM faculty, stated her experience as a student and believes that similar situations exist today.

I was once told by a professor that if I was ever going to be successful, I needed to lose the accent... it hurt, and it really stuck with me... an accent shouldn't have anything to do with it. Higher ed needs to be slightly less elitist... These students aren't even sure if they want to be in this club.

Margo discussed the importance of faculty and college staff understanding RFGC issues. If the faculty don't have an awareness of the potential different needs of first-generation college students, especially in that freshman year, and how those minor stressors can add up, that may not even be directly tied to their class - things that I think faculty don't think about; like I knew one person who missed the first two weeks of class because they thought it only met on Tuesday. They didn't know what the R stood for. So, I think just lack of awareness in faculty and administrators can threaten them persisting in STEMthe attitude that some may have of, you know, I've got a 50\% fail rate for faculty, I think, can be very off-putting to rural students, who are just looking to do the best that they can, and then have them do that rather than a cut type system as opposed to a more supportive system.

STEM faculty statements derived the threatening theme of institutional environment and faculty. The number of faculty that made comments related to these two codes were homesick 


\section{ENABLING AND THREATENING FACTORS AFFECTING PERSISTENCE}

and new environment ( 5 of 10 faculty) and faculty influences ( 5 of 10 faculty). At least one comment related to this theme was made by eight of the ten faculty members.

Students that are experiencing homesickness, or those that have bad interactions with a new environment, can feel like they do not belong or feel uncomfortable. These types of feelings can drastically impact a student's desire to stay in this new environment. The institutional environment is comprised of peers, faculty, staff, and the physical elements of a campus. Depending upon the types of interactions a student has with these elements, it can determine their desire to stay in school. This threatening environment could just be isolated to the environment surrounding their STEM major.

Faculty are a major component of a school's environment as they have more influence on a student than any other aspect. Faculty influence the curriculum, class environment, and interactions outside of the classroom. How a faculty member runs their course and corresponding learning environment often determines how the student feels about the class. The types of interactions that faculty have with students outside of class will govern how the student feels toward their major's faculty, advisors, and even the STEM field itself.

All of these factors that deal with student interactions will impact how the student feels about school. If their interactions lead to feeling welcomed, belonging, and comfortable, students are more likely to stay when other challenges arise because they have made a connection to the campus or major. Without that connection, it may not take much for a student to leave that school or major. In fact, an interaction may be so devastating, that a student may leave school based on this single event.

\section{Lack of preparation.}


ENABLING AND THREATENING FACTORS AFFECTING PERSISTENCE

Of all the faculty themes related to what threatens the persistence of RFGC students, the most-discussed item was related to the student's preparation. Mostly discussed was content preparation, but faculty also mentioned a lack of student knowledge about their major and lack of study skills.

Will's concern with RFGC students is that they "went to less rigorous high schools" and "if you get outside of the very small handful of larger cities, the resources of the educational systems are very poor." He also talked about rural schools' advanced classes, "There's a lot of pressure from admin to put in these Advanced Placement or honors classes, but that doesn't mean they're actually Advanced Placement or honors classes."

Josh's comments summarized the issue with the lack of preparation,

The fact that most of our students come from small schools means that... [they haven't had] all of the same opportunities ... [that] the kids in bigger schools. And I think that's a real problem, and that it happens with regard to the availability of AP classes, the availability of a qualified teacher in every classroom in all the grades. And it happens in STEM. I think the challenge or issue would be that people will come in unprepared, and they're more likely to fail their early classes. And people who fail their early classes are not likely to persist... And the reason they have the ground to make up isn't because of their lack of innate ability, I mean if they finished first in their high school, they're probably quite able. There's no reason to expect that they weren't. It's just that they didn't have the challenges through all 12 years of school that other kids had and kids from other families had.

Deb added a few additional points that relate to what Josh stated. 


\section{ENABLING AND THREATENING FACTORS AFFECTING PERSISTENCE}

Well, we know that when they get to college, they're going to be expected to have a certain level of understanding of high school topics. And if they haven't had rigorous high school classes and try to remediate, you know, but sometimes those concepts that they're lacking really cause them to fail at the beginning, and then they want to drop out... many students have had the content but not at the depth that they need it to be successful and sometimes that's even worse. Like, for example, calculus. Most high schools are offering calculus now, and I wish they wouldn't because they're not getting at this precalculus treatment because they're hurrying, and then they think they know calculus, but they really haven't had the depth that we would like it to have in calculus, so I think, you know, that's been a big challenge, especially when kids say, "Well, I've had this before." But it's not at the right level.

Amy added that some rural schools not only can't provide college prep courses, they also struggle offering senior-level science courses.

I had a student tell me that there were only 11 students in her graduating class, and they had to vote for whether they wanted chemistry or biology. And chemistry won. She never even had a biology course in high school.

Amy also described another student's situation where basic content was not covered. "I had another student [tell] me that they did not cover evolution because parents had complained about it, and the teacher offered, if students were interested, she would provide them with materials on their own time." Amy does not have much hope for a change in high school preparation, "K-12 education and I don't see that improving any time soon."

Some of the STEM fields are heavily reliant upon mathematics and Nik, a chemistry professor, sees this as a major threat for his students. 
ENABLING AND THREATENING FACTORS AFFECTING PERSISTENCE

Well, the \#1 asset that I think you can have in STEM fields is mathematics skills. Anyone that comes in with good mathematic skills is going to succeed in the STEM field, in my personal opinion, because they'll have logical and critical thinking skills and application skills and that sort of stuff. That being said, I see that very rarely from all of my students, not just the rural students but, in general, I see a lack of the mathematic background. The other students who are first-generation but aren't from rural areas, I'll be honest with you, it seems as though they come from better high schools, so their mathematic skills are a little bit better than those students that come from rural areas. It seems as though the rural areas is where the mathematic and technology skills are just really, really lacking.

One of the known struggles of rural schools is attaining certified teachers, and this is even more of an issue in the STEM fields. STEM faculty that were interviewed consider this to be another reason that students are underprepared and, therefore, a factor that threatens student persistence. Deb stated,

I think that coming from [a] rural high school is sometimes a weakness, but not always. Sometimes, they're not as prepared because a lot of high schools in West Virginia don't have certified math teachers, for example. So, I'm sure they're lacking certified physics and biology teachers as well, and that is probably a weakness, you know, not coming from a school where they have certified teachers, or they don't have the equipment that other schools would have.

Josh echoed similar response to Deb's.

For rural schools, my experience is that not all of our students have had qualified teachers in all of their classes and, in particular, they might not have always had qualified math and science teachers in all of their classes. And that puts students very far behind. 
ENABLING AND THREATENING FACTORS AFFECTING PERSISTENCE

An interesting aspect that emphasizes the faculty's view that schools are not providing much of a challenge is that faculty see all types of students struggle. Robert discussed how students come in overconfident because of their high school success.

A lot of them may come in with the misconception of their own self. Not a lot, but some of them will come in and have an over estimation of what they are capable of. So, they will think they are a straight A student, but when they then show up, they're not necessarily a straight A student at that point in time. They would then see that as a complete failure. And that I think that somehow prevents...them...from continuing on; they just give up.

Deb gave another example similar to Robert's.

A lot of times they are overconfident. I've had some kids in my office who say, "Hey, but I've had this before," and they are overconfident - they don't think they have to work a lot of times, and they think they know, but they don't really know.

Faculty members discussed how even valedictorians have a tough time their first couple of semesters. Amy stated, We did have one student; he had graduated valedictorian of his class and a small class in an area that's quite impoverished... he just couldn't do it. He was a smart kid, but he was required basically to learn things that other kids had learned in high school, and it was a tremendous effort for him.

Amy discussed another student's struggles and the impact it had on them.

She had done well in high school, but she was really struggling... She had done really poorly, and I asked her, "So what is your goal after you get out?" And she started crying and said, "I don't know now." ...I think it can be a tremendous disappointment to them. I 
ENABLING AND THREATENING FACTORS AFFECTING PERSISTENCE

think it really, again, their world view is kind of shattered. The idea that they've done so well before, and they'll just work hard, and they'll succeed.

No matter the student's high school academic record, if they are underprepared, then they will have to catch up. They will need to catch up on what they were expected to learn in high school, along with the college-level material. Paige summarized the overall issue of enrolling in college as an underprepared student.

I think it's just going to take them more time to catch up on all that stuff, and time is a valuable commodity in college...it might take them an extra year and then that's like an extra huge chunk of change. Yeah and then the semester is over, and they got a D or something or they failed ... and then their GPA is too low and, yeah, it's a compounding effect. So, then they're going to graduate with a lower GPA.

Paige believed that other factors were more important, but as the interview went on, she grasped the severity of being underprepared.

Well, now you've got me thinking, catching up in the semester, that seems like the greatest weakness because there's only so much time. And it's in that first year that you have to do everything. You have to get oriented to what college is, how it's a whole new social life, a whole new personal life. You know, maybe a whole new work situation in addition to school. It's just a lot to manage.

Deb discusses how underprepared students may require additional time to attain their degree, which would increase the financial impact.

If they come in lacking preparation for their courses, then they get stuck back, it could be six years instead of four years. And then, once they see how long it's going to be, or if they're not doing well in these classes, then they just... that weakness takes over. 


\section{ENABLING AND THREATENING FACTORS AFFECTING PERSISTENCE}

Faculty discussed threatening factors surrounding student career aspirations. Some students may have unrealistic career aspirations and cannot attain the required grades for graduate school. Several faculty members mentioned the need for higher grades than what the students were acquiring. This is especially the case if they desire to go to medical or graduate school. Will said,

It's really hard to deal with an inadequate high school experience, so there are strategies on campus, but you're playing catch-up, you know? If you went to a poor school system for six years, you can catch up some, but it's hard to catch up all the way. The firstgeneration part, you know, a student could make good use of advising, so that they have somebody who can give them authentic advice, or they could reach within their home community and find a mentor who could tell them that a $\mathrm{C}$ isn't doing very good in college, and they should withdraw instead of fail.

Amy specifically discussed a struggling student that had average grades, but desired to be a doctor.

I had a student working in my lab some years ago and he ... his dream, he wanted to be a doctor and go back to the rural area that he had grown up in because he said the closest doctor is an hour away or so. But he had As, Bs, and Cs. And I saw that kid in class struggle and work and he just couldn't. Again, he was too far behind.

Josh discussed how some students may have unrealistic career goals.

And people coming in without realistic expectations because they're first-generation college students, you know? ...I was the smartest kid in my high school. I guess I could be a doctor. You know, that's probably not true. Not if you got an 18 on your math ACT. 


\section{ENABLING AND THREATENING FACTORS AFFECTING PERSISTENCE}

Certainly, you've got a lot of work until you're ready to start preparing for your undergraduate career.

Aside from academics, students can be underprepared for college in other ways. Students may be unsure of their major, or they did not have a clear understanding of their career path. Deb said,

I think the biggest one is that they'll come and not know what they're getting into, and they'll be overwhelmed the first semester, and they'll want to go home... They may think they want to be a doctor, and they come to school. They really don't know what it entails, the classes that they're going to have to take. A lot of times, kids are caught off guard because the classes are harder than they thought they would be, or they have to take a lot more math than they thought they would have to take. Or they might start out lower than they thought they would have to start out, and it will take them longer. So, the misconceptions that they come with that might cause them not to persist. And then a second one would be misconceptions about what is involved in the study towards a certain major. I know math kids that come in wanting to study math, they're often clueless of where they might be able to use math and what kind of jobs they might have in the future.

Some students just go to college or major in a certain field because someone told them to. Amy discussed the danger of students following the career advice of their ill-informed parents.

I see this in a lot of these kids; they come in with not a very good background, they struggle, but they're determined to be doctors because their parents told them, "You like biology, and you're smart; you're going to be a doctor." And so, they end up being very 


\section{ENABLING AND THREATENING FACTORS AFFECTING PERSISTENCE}

narrowly focused when they're just not necessarily able to meet that bar because you can't ... you can't get Bs and Cs and get into med school, it just doesn't work.

Josh described the importance of students knowing what they want to be and how they need to be focused on this goal from day one of college.

Students come to college and, if you want to be a biology major at my college, there's 120 hours you need to have, and you might have six or nine elective hours available to you over those four years; in other words, if you want to graduate in four years, you need to know walking in the door as a first semester freshman that you're going to be a biology major, and you need to be prepared to pass every single one of those classes in the right sequence. I mean, that's daunting, and for most of our students from small high schools, whose parents maybe didn't go to college themselves, it's pretty close to impossible. And it's like, so, well, what's the big deal? It's another year. Well, another year is another $\$ 10,000, \$ 15,000$, for kids who can't afford it. Well, most kids can't afford it.

Other times students have been misled or misinformed about the major they are pursuing. Deb mentioned this during her interview.

People see things like forensics on TV and think that looks like a cool career, or they've heard of other STEM careers, and they don't really know what goes into that, and so that's why they would pick a major, maybe because it looks interesting. Other kids pick for different reasons, but I think that they're all looking for something that they find interesting. But when they get into it, they don't really realize its lot of hard work.

Sometimes students pick a major for the wrong reasons. Nik noted this during his interview. 


\section{ENABLING AND THREATENING FACTORS AFFECTING PERSISTENCE}

I have to question as to whether or not they really wanted to be in STEM, or if someone said, "Hey, you can make a lot of money if you get a degree in science and technology," and they say, "Okay, I want to do that," without ever really understanding what they were getting into.

While RFGC students' experiences and skills were found to be an enabling factor, some faculty felt that some of these students lacked skills that are important for academic success.

Robert mentioned the importance of critical thinking to be successful in STEM courses.

Content is strangely enough is less of an issue...for me it is a lack of critical thinking. Critical thinking skills are almost null and void. It comes out clearly when you think about just the issues that students have with mathematics. It is not that they do not have the ability to do mathematics, they just do not have the background, actually let me rephrase that. They have the knowledge available or the book knowledge... If you give them the formula they can, you know, recognize the formula. They just can't use it and apply it. Which to me, even if they do have the book knowledge, the critical thinking skills needed to be able to solve problems, does not exist.

Lydia noted a lack in "time management (is a big one)," and Nik believes that the lack of a challenging high school education led to many students not developing study skills.

They perform very, very well in high school, all As and Bs. And many times, whenever that happens, students maybe didn't necessarily develop study skills necessary to highly achieve in classes where, let's say, they have to put forth a little more effort that they did in high school. So, what can happen there is you've just got to kind of reinstitute or kind of teach them some study skills and stuff like that.

Nik also mentioned that technological skills related to academics or scientific uses are lacking. 


\section{ENABLING AND THREATENING FACTORS AFFECTING PERSISTENCE}

You know, almost all the students coming in know how to use their cell phones to text and all that kind of stuff, but to use the technology for actual scientific purposes, that can be a challenge for them. Many of them will come without things like laptop computers and stuff like that that most of us take for granted these days. They won't have that sort of stuff. The other students who are first-generation but aren't from rural areas, I'll be honest with you, it seems as though they come from better high schools, so their mathematic skills are a little bit better than those students that don't come from rural areas. It seems as though the rural areas is where the mathematic and technology skills are just really, really lacking.

Every STEM faculty member made at least one comment related to the threatening theme lack of preparation. The number of faculty that made comments related to these codes were academic content (10 of 10 faculty), knowledge of major and career ( 6 of 10 faculty), and academic skills (3 out of 10 faculty).

These codes were all grouped together because they are related to the college preparation of the student. Academic content is based upon the type of education that the student received, the types of classes, the quality of classes, grades earned, etc. These items can impact how much the student has to learn while in college classes. The less knowledge they attained in high school, the more they will need to learn while in college. The more knowledge that a student needs to learn, the less likely the student will pass the course. This is especially the case if foundational knowledge is absent from the student's high school preparation.

A student's knowledge about their major and career is also derived from their college preparation. This preparation can involve their high school teachers and staff, family, and themselves. The exposure the student had with their desired career can determine the level of 


\section{ENABLING AND THREATENING FACTORS AFFECTING PERSISTENCE}

surprise the student experiences when the student learns about that career while in college. Some students realize that a career path is not what they expected, and they decide to leave that field.

Academic skills are developed when need arises. Students in this study stated that they did not need these academic skills in high school. The faculty viewed students as lacking these academic skills coming into their college level classes. This is a lack of K-12 preparation from the perspective of the faculty. If students do not adapt to this challenge by developing appropriate academic skills, they may not be successful in passing their STEM courses.

\section{Lack of support.}

Previously, support was discussed as an enabling factor but what about those students that do not have support? Or the support is not aligned with the student's goal of attaining a STEM degree. The items discussed by faculty related to threatening factors of support include both emotional and financial. These comments were mostly focused on family and community members and the lack of support given by this group. A family's negative beliefs and attitudes can be averse to any student, but especially to those that need encouragement during challenging times. Amy described such a situation,

A student who was doing poorly last semester with her parents saying we're just not going to pay to help you anymore. And, you know, maybe they just don't have the resources or, again, they feel like, you know, it's your own problem. You have to deal with it. So, I think the parents are very supportive, but to an extent. They still fall back into that, well, you just need to work harder and then you'll succeed. [The students] might get some hassles from people from home who think, "Now you think you're smarter than everybody else" or what not. 


\section{ENABLING AND THREATENING FACTORS AFFECTING PERSISTENCE}

Lydia discussed how family and community can negatively impact students because of their beliefs and their misinformed viewpoints of college.

Lack of support, particularly lack of support from their family. I think probably the biggest obstacle, particularly in West Virginia, is a culture and a community that does not necessarily understand or always support or even believe in higher education and the value of a higher education degree...it's not that their family outright is saying that they don't support them. It's just that, if they haven't gone to college, they don't know how to support this endeavor for their student. So, even if they really, really want their student to get a degree, sometimes that is even pressure... family has preconceived notions, too, and their family's stereotypes and misconceptions can sometimes give kind of a general lack of support. Like, if it's good enough for grandpa to just go to work in the coal mines, why isn't that good enough for you, kind of thing. I think males especially still feel a lot of pressure to be working, possibly even full-time, while they're in college, and that puts a lot of pressure on them, that they have to be earning a paycheck right now while they're in college. And, if they're working and commuting potentially and/or have family obligations and their family doesn't understand college, you just kind of have this buildup of what feels like a lack of a support network. - there's a lack of a culture ... there is a lack of a college going culture for these students.

Students may struggle with balancing family obligations and college requirements. These additional family duties are not meant to add to the student's stress as the request is part of their daily life. As was stated before, family members may not realize the time commitment required to be successful in college. Mike discussed this situation. 


\section{ENABLING AND THREATENING FACTORS AFFECTING PERSISTENCE}

I know in a rural area you've got a lot of families that have farms and things, and you've got a parent or whatever that has a farm and, you know, you grew up there and helped them with that. There may be a need for you to still help on that farm or whatever...for some students that's maybe worse, more so that they need to be home to help on the farm and they're busy with that and that's consuming time, along with driving hours to school and getting their schoolwork done.

Lydia gave an example of threatening family duties.

I think that you're often looking at more responsibilities in terms of family, you know, taking care of family business. I had a student this past semester whose family had to leave, and he had to go back to take care of the farm. I mean, so, that can instill the work ethic in those students, but it's also - the reality is they have guilt on them, whether it's intentional or not, that they're away from their family... the reasons those first-generation students don't come to class or drop out or don't persist is almost entirely non-academic. I mean, it's a lot of outside factors. It's family responsibilities; it's work; they need flexibility in scheduling.

Margo mentioned that her institution collected data on why students leave school and found that, "most of the time it is due to a medical or family issue." Robert believes that family obligations is more prevalent with RFGC than other students, "I have seen it more in rural than anywhere else."

As support includes emotional, financial and other resources, a student's rural or firstgeneration status directly impact these forms of support. Will discussed how being a firstgeneration student means that there is a lack of understanding higher education in general. 


\section{ENABLING AND THREATENING FACTORS AFFECTING PERSISTENCE}

...first-generation students, whether big city or small town. They don't have the same wealth of experience of going through a college...so for first-gen students, not having the same kind of expectations about what you need to do in high school and not having a store of knowledge about what college is like and what you have to do succeed in college does not help with their success.

Mike made similar statements to Will's,

So, you're getting into, you know, it attaches well to the first generation where you have parents that didn't go to college, so they really don't understand what college is about and how, well, you don't necessarily have to be a genius, you know, to go. I just feel like, if you're looking at first generation, they don't have a parent that is going to push them to do that and be able to help them through that process.

Lydia described how initially the challenges are greater for RFGC students compared to other students, but eventually they catch up.

They have a steeper learning curve in the beginning. They have to figure out more stuff to begin with than what a student whose family has gone to college would have. After the first year, I don't think first-generation students look a whole heck of a lot different than other students. I think it's that steep learning curve at the beginning and that's the time period when we have to get them for persistence, because, if they're successful in that first year, they'll come back, even if they have to step away for a year.

All ten of the faculty members made at least one comment related to the threatening theme lack of support. This theme was derived from similar comments related to emotional and financial support. Their responses were mostly related to the lack of family support and being a first-generation college student, 9 of 10 faculty. 


\section{ENABLING AND THREATENING FACTORS AFFECTING PERSISTENCE}

Support is an outside resource that helps a student in some capacity. Support can be classified as emotional, academic and financial. The comments surrounding the lack of support mostly came from the fact that students are FGC. Students and their family members and friends do not know about college resources and other intricate details about college. Not only were family and friends not able to provide help concerning college in general, but also with financial needs. Family and community financial resources are limited for many of these students. Emotional support was another common comment by faculty. The lack of emotional support can be detrimental to a student's motivation to continue school, especially when the student is experiencing tough times. Family may not understand the pressure and time dedication that comes with college courses. Family members and friends may not be sympathetic to this challenge. This lack of sympathy can impact the student's emotional state in a negative way. Family and friends can create additional emotional anxiety on a student by the events that impact family and friends. These events can be medical or drug issues or can be expectations of the student and can be significant distractions.

\section{More challenges than others.}

As the faculty mentioned in their interviews, these threatening factors impact all students, not just RFGC students. But given the combination of being rural and first-generation, RFGC students have more challenges than most students. Margo stated, "They have more threatening factors compared to non-rural students as well as non-first-generation. I don't think they are necessarily all, specific ones that are different, but I just think they have more." When asked if there are differences in threatening factors between those that are RFGC and those that are not, Lydia said, 


\section{ENABLING AND THREATENING FACTORS AFFECTING PERSISTENCE}

A lot of them are the same. You have a student who's shy, introverted, or isn't sure, lacks confidence, that kind of crosses boundaries. But I do think that not finding your way around a new place, like if they've come from a really rural area and they haven't ever seen, I do think some of them can be very different. I think some of their experiences are different just because of what their environment has been prior to coming to college.

Amy discussed how the biggest difference for RFGC students is the combination of threatening factors.

I kind of see it all as coming together. So, the lack of preparation going into school, the idea that you just need to work harder, the inability to really devote extra resources if necessary, to succeed, the resistance to asking for help, and the lack of knowledge of what the diversity of jobs are out there. I see it all as just kind of coming together as a lot of hurdles that these students have to overcome that other students just don't have to deal with at all.

Many of the challenges or threats have been discussed in the previous sections, institutional environment and faculty, lack of preparation, and lack of support. Additional threats, barriers, or challenges were also mentioned by the STEM faculty that add to the belief that RFGC students experience more challenges than other students. Two common areas of additional challenges were personal items and resources. Margo discussed one such personal item, "Rural students are more likely to... deal with mental illnesses or substance abuse issues." RFGC students having to deal with drug issues is not just about the student using drugs but others in the community, including family and friends. Robert said, "I know one of the issues in the US right now is just plain drug use. Especially in rural communities... there seems to be an increase in the amount of drugs available and being used." Lydia specifically talked about WV 


\section{ENABLING AND THREATENING FACTORS AFFECTING PERSISTENCE}

being impacted by drug issues, "Especially right now with the opioid crisis in West Virginia... they have firsthand knowledge of a family member struggling with addiction." Amy discussed a specific situation and the impact on a student, "I had a woman working in my lab a few years ago, and her sister was struggling with opiate addiction, and she would just have to leave and go deal with her sister's problems."

In the enabling factors section, faculty discussed the advantages of being an independent and hardworking RFGC student. Though this can be an advantage, if a student goes to the extreme point that they are not getting help when needed, then this characteristic is now a threatening factor. Amy stated such a case.

Well, the independence is a double-edged sword... I had a student last semester who was very uncomfortable about asking for help. They don't want to come in, they don't want to ask for special favors. They see that as being a negative if they need help. So, I had a graduate student a while ago who had to leave the lab eventually because we had just reached this impasse where he was so independent, and he wanted to solve problems by himself, that he just did not want any faculty input. I have a student I actually asked her if she was a first-generation student because she had approached me after class and said, "I feel ... I know ... I don’t want to bother you, I don't want to come in and talk to you," and that's something I hear from first-generation students... they don't want to bother me... I can always talk after class, but they're just so much more resistant to it.

Lydia described some reasoning for this unwillingness for asking for help, "Especially rural firstgeneration students... they don't want to be made to feel dumb, and they don't want to feel embarrassed... They will feel like perhaps they're asking a question that everybody else knows the answer to.” This reluctancy not only happens with professors as Margo states additional 


\section{ENABLING AND THREATENING FACTORS AFFECTING PERSISTENCE}

situations, "[rural students] are very hesitant to access student services because they feel they need to prove themselves."

Resources were found to be threatening factors affecting persistence specifically money and time. Additional challenges were related to the money-work-time cycle. These three topics are grouped together intentionally, as they are caused and impacted by each other. For instance, if a student does not have enough funds for their expenses, they will seek employment, but working will take time away from studying. Amy discussed the time-work relationship, "so this student was working at a theater, so she was often there late at night and, you know, she's going to be tired. She has to do work afterwards for classes, so their time is much more limited." Students working while in school has become more of the norm. Margo estimated the number of her students that work, "A lot of our rural students here, they have to work. I would say probably $70 \%$ of my students have at least a part-time job and [40-50\%] have a full-time job at some point while they're in college." Amy talked about how limited funds and time are disadvantageous for RFGC students.

Students from a wealthier family, their parents have money to help them maybe get a tutor, a private tutor for them, whereas the other students [do not]. The workload as well... they're not able to get the help that they need and they're not able...to spend the time that they need if they need extra time to complete assignments because they're working ... I mean, they just don't have enough time.

Lately, it seems that summer schooling is even more important, especially for non-traditional students or students that need to work. Robert discussed this situation.

Availability is also a big thing for them because they can't just, at least here, for them to just show up in the summer isn't always that easy because a lot of them actually have to 


\section{ENABLING AND THREATENING FACTORS AFFECTING PERSISTENCE}

work in the whole of the summer to make up any kind a of money that they need for the next year. So, I do have a lot of kids doing that. They are farming kids. Summer is busy farming season. So, for them to be able to take a course when they need, it is very important.

Resources and finances are viewed as major barriers for RFGC persistence as Amy said, "Poverty is a big issue because then they're going to have fewer resources from their parents and they'll be saddled with student loans... likely to be working, taking up a lot of their time." Many students commute to school and there are additional barriers with commuter students. Lydia discussed the lack of home resources, "A lot of our students here still don't have internet at their houses...A lack of technology when they go home, and most rural students go home frequently." Some students have long commutes. Robert described such a situation, "[a few students] drive an hour to an hour and a half just to get to campus every day. I mean, if you are a student, that is a lot of time and that is a lot of money." Robert goes on to discuss the sad reality of RFGC students having to stop pursuing their degree due to finances,

So, for them the big thing is money. We have a lot of kids or I have seen a lot of kids that have potential and would like to learn more but they just they have to quit because they have to go home to take care of the family or they just run out of money.

Eight of ten STEM faculty made at least one comment related to the threatening theme of more challenges than others. Personal items and access to resources were two codes found under this theme. The number of faculty that made comments related to these codes were personal items (6 of 10 faculty) and access to resources ( 8 out of 10 faculty).

This theme started as its own code when a few faculty members discussed how RFGC STEM majors experience more challenges than those that are not RFGC STEM majors, four of 


\section{ENABLING AND THREATENING FACTORS AFFECTING PERSISTENCE}

the ten faculty. A number of additional threats were mentioned by faculty that did not fit other threatening codes. Out of those comments two codes developed, personal items and access to resources. Though these items were personal items, they are items that multiple RFGC students can experience. The accumulation of the different personal items from this study reinforced the idea that RFGC students deal with more challenges than others. These challenges were in addition to those already discussed in this study.

Faculty also mentioned a lack of resources that did not fall into other categories. A lack of resources is typically tied to a lack of funds. Though these items are related to finances, (support theme) and could be lumped into that section, they are placed under the theme of more challenges than others. People need to understand how some of these items (lack of resources) are specific to RFGC STEM students. For instance, not having high-speed internet can be due to a lack of finances but it can also be due to the absence of an internet carrier in their rural region. Another example is that a computer science major does not have access to an expensive software that is required by their major. Even if the school has the software installed on campus computers, rural students may have limited access due to the distance they live from school and other challenges like a job and kids.

This section's goal was to answer the question, what do faculty view as the factors that threaten RFGC STEM students' persistence? The themes developed in this section answer this question: institutional environment and faculty, lack of preparation, lack of support, and more challenges than others. 
ENABLING AND THREATENING FACTORS AFFECTING PERSISTENCE

\section{Chapter 5: Discussion}

Quantitative and qualitative data were collected and analyzed to answer the research questions of this study. Both faculty and student responses will be used to answer the two primary research questions. The first primary question (RQ1) is: What factors enable the persistence of RFGC students in STEM majors? The second primary question (RQ2): is What factors threaten the persistence of RFGC students in STEM majors? The survey data only relates to the question on threatening factors, as the survey items were difficulties of finishing a STEM degree. Both forms of data will be used in corroboration to answer RQ2. Opatz's Persistence Pyramid, see figures $1 \& 2$, will also be used to compare the findings of this study.

RFGC STEM student responses will be used to answer the sub-questions of research question RQ2, as only RFGC students were asked questions related to these research questions. In addition to determining factors affecting persistence, this study also aimed to determine how students handled the challenges or issues they faced as a STEM major. The first sub-question that will be answered in this section is: what are the students' successful means to adapting to these challenges? The other sub-question is: how do these challenges change over time as a RFGC STEM major?

The summary of the literature review revealed that several factors affecting persistence were found to be both enabling and threatening to students. The same relation was found in this study. Whether a factor is enabling or threatening to an RFGC STEM student's persistence, is dependent on the individual student and his or her experiences.

\section{What Factors Enable the Persistence of RFGC Students in STEM Majors?}

Student and faculty interview responses were analyzed using content and thematic analysis to determine the enabling factors of RFGC STEM students. The strengths of RFGC 


\section{ENABLING AND THREATENING FACTORS AFFECTING PERSISTENCE}

STEM students are also included in this analysis. Student and faculty interview responses generated three similar themes, with one additional theme coming from the faculty interviews. The common themes were Drive or Motivation, Experiences and skills, and Resources and support. The additional faculty theme was Personal characteristics.

\section{Student enabling themes.}

Eleven RFGC STEM students were interviewed and three themes were generated: Drive, Experiences and skills, and Resources and support. Not only did students specifically say the word "drive" in their interviews, they made comments relative to drive. The student's comments that were related to drive centered around confidence in their chosen major and in themselves, determination to attain a degree, having a special interest in their field of study, or believing that attaining a STEM degree will lead to a better life. All of these drive factors enable students to push through the tough times that they may face. The more drive students have, the greater the challenge they can overcome. Previous research by Geier (2016) and Hunley (2015) also listed similar enabling factors, but their study only focused on first-generation (FG) students that were either female STEM majors or from an Appalachian region.

RFGC STEM students described how their previous experiences and skills have been beneficial to their academic progress. In relation to experiences, RFGC STEM students made comments about work they completed or activities they participated in. These experiences gave them fundamental knowledge about their STEM major or skills that are beneficial to them as students. Geier (2016) also found that female FG students have drawn from their previous experiences to become successful STEM majors. These activities include, but are not limited to, fixing items, extracurricular activities, hobbies or recreational activities. Students credited their high school education for preparing them for the rigors of college, including the level of content 


\section{ENABLING AND THREATENING FACTORS AFFECTING PERSISTENCE}

knowledge and appropriate study skills. The students' experiences were also credited with developing a strong work ethic, discipline, and time management. The more experiences and skills that students have, the more likely they are to be successful in college.

RFGC STEM students discussed multiple forms of support that have enabled them to persist. Two categories were found within the theme of support: institutional support, and family and community support. Social capital was a common topic with both of these categories as faculty, staff members, peers, family and friends were utilized as sources of help and emotional support. School personnel and peers were credited with creating a positive environment for their success and enhanced their desire to stay in their major. Phillips (2015) also stated that the positive environment of the campus, along with available resources and opportunities, can assist rural FG students in persisting regardless of their major. Student groups, tutoring, peer mentoring, and other school support programs or offices were also mentioned as factors that helped RFGC STEM students to succeed. Other authors found that successful participants were active with campus activities (Geier, 2016; Hunley, 2015; Phillips, 2015; Tinto, 1975). Their participants were all FG students and either a STEM major or from a rural area or lived in Appalachia. Beasley (2011) and Geier (2016) state that in addition to positive psychological effects, these types of relationships can lead to numerous beneficial opportunities (career, school involvement, academic success).

Financial support was another common topic shared between institutions and the student's family and community. This support was needed to help pay for the costs of college or living expenses. Financial assistance is necessary to enroll in classes, and it also relieves the stress of finding these funds and lessens the time required for a student to work. Additional support mechanisms were related to course design and access to educational resources. The 


\section{ENABLING AND THREATENING FACTORS AFFECTING PERSISTENCE}

course design helped students adjust to college-level courses by spreading the content over a more extended period, and some instructors helped students adjust by providing class notes. Students were enabled to complete course work with access to rather expensive class resources, like computer software. Access to these resources was provided at periods that benefited students, especially later in the evening.

\section{Faculty enabling themes.}

Based on the ten faculty interviews, four main themes developed as to what enables RFGC STEM students to persist: Motivation, Experiences and skills, Support, and Personal characteristics.

Similar to the RFGC STEM students, STEM faculty made comments involving Motivation as an enabling factor. This is very similar to the student's theme of Drive and these words are often used synonymously. Some faculty comments were not specific as to why students were motivated, but the faculty emphasized how motivation was a key to continuing in their major. Motivation was viewed as a necessity to get through rigorous courses and to navigate nonacademic challenges, such as the financial aid process. Faculty discussed how students with an end-in-sight was a positive influence on their persistence. This end-in-sight factor revolves around students believing that a degree would be a means to a lucrative career or that they had a keen interest in their field or profession, such as being a doctor and giving back to their rural community. Geier (2016) and Hunley (2015) also found that some FG and STEM or Appalachian students are driven to be successful in college because they view their potential degree as a means to a better life.

Faculty also felt that RFGC STEM students were driven or motivated because they had something to prove or that the students were underprepared. Uche (2015), found that FG STEM 


\section{ENABLING AND THREATENING FACTORS AFFECTING PERSISTENCE}

students worked harder because they did not want to disappoint those that contributed to their financial assistance. Beasley (2011) and Phillips (2015) found similar statements from FG rural students as they were inspired to prove subjective people wrong because they have been stereotyped due to their background. RFGC STEM students knew they were underprepared, and therefore they needed to work harder. Their lack of preparation was an enabling factor because they studied more than they would have if they were not trying to prove others wrong. Students that lacked confidence or interest in STEM and later found success in a college STEM course developed a belief that they could major in a STEM field. This new belief in themselves created motivation or desire to be a STEM major.

Faculty and student interviews both produced the enabling theme of Experiences or skills. These experiences revolved around students working with mechanical or electrical apparatus and their interaction with nature. Faculty explained how these types of explorations could develop knowledge and skills related to STEM fields. These experiences give students an advantage in developing a deeper understanding of relevant material. Student experiences were also thought to be a catalyst with problem-solving, creativity, and time management. Students that demonstrate these items will have a better chance of being successful in a STEM major.

The last similar enabling theme between faculty and students was the faculty theme of Support and the student theme of Resources and support. The faculty believed that the source of support comes from either family or the institution. The types of support can be emotional, financial, or academic. Emotional support can benefit students' psychological health and give them the encouragement they need to push through challenging times. Multiple authors reported that students who have existing support networks consisting of family, peers, school personnel, or the community, were found to be successful (Beasley, 2011; Geier, 2016; Hand \& Miller- 


\section{ENABLING AND THREATENING FACTORS AFFECTING PERSISTENCE}

Payne, 2008; Phillips, 2015). Their findings came from participants that were FG and either a STEM major or from a rural area or Appalachia.

Not only is financial aid needed to enroll in higher education, but it must persist so that students can finish their degrees (Beasley, 2011; Geier, 2016; Phillips, 2015; Uche, 2015). Securing financial support can also relieve stress and the need to work. If a student does not need to work while going to school, they will have more time to focus on their academics. Academic support can come from institutional personnel or programs, or peers. The more avenues of academic support available, the more likely the students will use them to get through their rigorous coursework.

In the previous section, common themes between students and faculty were discussed. This section will discuss one additional enabling theme that was developed from the faculty interviews. This additional theme was found to be Personal characteristics of RFGC STEM students. Two similar personal characteristics discussed by faculty were responsibility and independence. While most students did not need to utilize these traits a great deal in high school, faculty see these characteristics as advantageous to those college students that have developed them before college. Given that college students are typically away from their family, all responsibilities reside with the student. If students do not adjust to this new freedom, they may not be successful in their college classes because they lack discipline.

Acquiescence was another topic that faculty viewed as enabling. Faculty view an acquiescent student as favorable because they are more open to criticism and feedback.

The faculty also mentioned resiliency as another advantageous characteristic of RFGC STEM students. Faculty believed this to be the case because of their background and experience. The faculty have observed how RFGC STEM students respond appropriately to adverse 


\section{ENABLING AND THREATENING FACTORS AFFECTING PERSISTENCE}

situations. Their previous experiences have developed a higher tolerance to difficulties, which allows them to focus and complete the task at hand. These earlier trials give RFGC STEM students additional confidence in their ability to overcome challenges. Schutz (2003) and Phillips (2015) reported similar findings with FG and rural students which corresponded to Geier's results with FG and STEM participants. They found that their students had experience dealing with complex tasks and successfully overcome challenges.

Hand and Miller-Payne (2008) described similar traits to those in the previous paragraphs with FG and Appalachian students. They referred to these admirable and desirable characteristics as having an "internal locus of control." This is where students have a sense of responsibility for their success: focus, determination, motivation, set goals, strategies to attain goals, monitor progress. These types of students do not blame their shortcomings on others or external factors, such as luck, teachers, or lack of resources. Students need more than just an "internal locus of control" to get through tough times; they must also put in an appropriate amount of work.

The STEM faculty's most popular comment was that RFGC STEM students have a great work ethic or are hard working. Faculty believe this to be advantageous as RFGC STEM students are accustomed to working in adverse conditions and have labored through long days. STEM faculty feel that these students are not afraid to put in the work to be successful in STEM courses. Faculty viewed RFGC STEM students as being stubborn as they do not give up easily when course activities become strenuous, especially with solving problems. Additional faculty comments, related to work ethic, were grit and tenacity, which enable students to conquer challenging times. These personal qualities were viewed as very desirable and make for a successful STEM major. Phillips (2015) found that a student's rural status created specific strengths that enabled them to be successful FG students. Phillips labeled his theme, statuses 


\section{ENABLING AND THREATENING FACTORS AFFECTING PERSISTENCE}

serving as impetuses for success, which included work ethic, self-sufficiency, internal motivation or drive, not feeling entitled, being frugal, and having money management skills.

An interesting aspect of this study is that the STEM faculty discussed personal characteristics as an enabling or positive factor and the students only sparsely mentioned any characteristics. This is especially true of the items relevant to growing up in a rural environment, especially those environments where students are actively working and interacting with STEMrelated phenomena. Faculty saw this as an advantage to a STEM major where the students did not realize this benefit. I am a RFGC student, and I did not recognize all of the beneficial factors that I had going through a STEM major until I completed this study. I was fortunate to watch plants and animals grow and reproduce. I was exposed to electrical and mechanical devices and tools. These experiences helped to form my science knowledge by connecting my rural memories with the science content taught in school.

This disparity between faculty and student views concerning personal characteristics and the advantage of living in a rural area, may be due to their different viewpoints. The faculty had the advantage of comparing numerous students over multiple years, and they recognized several differences between those that are RFGC and those that are not. Gandhi-Lee, Skaza, Marti, Schrader, and Orgill (2015) findings agree with this study as they investigated STEM faculty views on the barriers of STEM students. The authors found that the faculty believed that students have specific characteristics that are key to student success: curiosity, excellent problem-solving capabilities, ability to synthesize information, and good communication skills. They also discovered that the faculty viewed these students as having a good work ethic and positive attitudes.

\section{What Factors Threaten the Persistence of RFGC Students in STEM Majors?}


ENABLING AND THREATENING FACTORS AFFECTING PERSISTENCE

The following section discusses threats, challenges, and weaknesses of RFGC STEM students as viewed by RFGC STEM students and STEM faculty. These elements are grouped as factors threatening persistence. This section is an accumulation of the findings from the student and faculty surveys and interviews.

\section{Survey result discussion.}

The participants ranked each Likert-type survey question (difficulty) according to the following response options: $1=$ Untrue, $2=$ Somewhat untrue, $3=$ Somewhat true, and $4=$ True. RFGC STEM students were not too concerned about the items listed in the survey. Of the eighteen factors listed in the survey, only six factors had a mean score above 2. See Table 16 for a summary of the students' top six concerns. The students' most concerning survey item, Q5.1_7 Professors in my STEM classes tend to lecture a lot, had an average rank of 2.91. This item was the students' most concerning difficulty, and the mean score is closest to the ranking of "Somewhat true," which leads one to believe that this is a moderate concern to the students. Table 16

Most Concerning Student Survey Items

RFGC STEM Student Survey Item

n Mean

Q5.1_11 Because I have a job, I do not have as much time as I need for studying.

Q5.1_9 I do not have friendships with people in my STEM classes.

$117 \quad 2.07$

Q5.1_12 I might not be able to afford finishing my degree.

$119 \quad 2.09$

Q5.1_2 I am having a hard time developing study skills that enable me to pass my STEM classes.

Q5.1_1 It is difficult to adjust to the academic demands of my STEM classes. 


\section{ENABLING AND THREATENING FACTORS AFFECTING PERSISTENCE}

Students felt that being able to keep up with the academic demands of their STEM courses was their second most notable concern with an average ranking of 2.56. Considering a score of 2.5 is in the middle of this 1-4 scale, this survey item is also a moderate concern to the students. The students third-highest ranked item was being able to develop study skills at a 2.29. These last two concerns are related to each other as the students are worried about adapting to their college classes. Several students stated that college classes were more challenging than their high school courses. Rounding out the RFGC STEM students' top six concerns is: (4) their ability to afford the rest of their degree, (5) having friends in their STEM classes, and (6) having time for studying because they have a job. The fourth and sixth highest concern of the students were related to finances. Students realize that a college education is a significant cost and that they must be aware of throughout their college career. Paying for all of their education would be especially concerning for those students who are already working a job to pay for current costs. Having a support network is an essential component of being successful in college. The students felt that having friends in their field of study was a slight concern as they ranked this as 2.01 , where a "2" meant "somewhat true."

The faculty members ranked all but one survey item higher than the students. Table 17 lists all the faculty survey items that were scored above two. The one item that the faculty scored lower than the students was related to disliking lectures. The students scored this item as a 2.91, whereas the faculty score was 2.18 . The students felt that this factor would be more of a negative influence on their persistence than the faculty did. The faculty felt that 14 other items that were more of a risk to student persistence. The faculty feel that their lectures' level of engagement will not impact student success, but students feel that their STEM lectures will have the greatest 
ENABLING AND THREATENING FACTORS AFFECTING PERSISTENCE

Table 17

Most Concerning Faculty Survey Items

\begin{tabular}{llc}
\hline \multicolumn{1}{c}{ STEM Faculty Survey Item } & $\mathrm{n}$ & Mean \\
\hline Q3_7 Disliking lectures & 60 & 2.18 \\
Q3_8 Finding STEM classes to be more boring than expected. & 61 & 2.23 \\
Q3_16 Feeling that they do not belong in college. & 62 & 2.35 \\
Q3_6 Finding that STEM classes have too many students in them, limiting & 64 & 2.44 \\
individual support from professors. & & \\
Q3_9 Lack of connection to other STEM students outside of classes. & 60 & 2.63 \\
Q3_14 Feeling lonely or homesick. & 57 & 2.95 \\
Q3_4 Feeling intimidated by professors. & 68 & 3.15 \\
Q3_3 Difficulty understanding what professors expect academically & 69 & 3.23 \\
Q3_10 Interference of social life with studying. & 63 & 3.25 \\
Q3_5 Finding the math they have to do in in their STEM classes too hard. & 67 & 3.27 \\
Q3_13 Not having as much time as needed for studying because they need to & 62 & 3.27 \\
help their family. & & 64 \\
Q3_12 Being unable to afford finishing their degree. & 3.30 \\
Q3_1 Difficulty adjusting to the academic demands of STEM classes & 69 & 3.43 \\
Q3_2 Difficulty developing study skills. & 63 \\
Q3_11 Not having as much time as needed for studying because they have & 64 \\
jobs. & 64.43
\end{tabular}

impact of all the factors listed. The lack of student engagement in a class may cause a student to become disinterested in the topic and ultimately can lead to poor performance.

The faculty ranked all but one survey item as a 2, "Somewhat untrue," or higher. The students did not rank any of the survey items above a three, but the faculty ranked nine of the sixteen items above a 3, "Somewhat true." Although the mean scores of the survey items seem 


\section{ENABLING AND THREATENING FACTORS AFFECTING PERSISTENCE}

drastically different between the students and faculty, this difference is not a focus of this study. This disparity could be worth investigating.

Some commonality was found between what items were ranked highest. Faculty and students ranked four survey items relatively high in their list of most concerning difficulties. The four common difficulties were: Question 11, not having enough time to study due to having a job; Question 2, having difficulty developing study skills; Question 1, having difficulty adjusting to academic demands of STEM courses; and Question 12, being able to afford finishing their degree. Not having enough time to study due to having a job and being able to afford to finish their degree, were relatively severe concerns for both students and faculty. Both of these factors revolve around finances and time. When a student needs to work, this can be an academic distraction or limit the time available to study. As will be discussed in later sections, this is related to the money-work-time dynamic of many RFGFC students. Faculty and students were also concerned with adjusting to the academic demands of STEM courses and developing study skills to combat this challenge. Students and faculty recognize the struggle with adjusting to college and the need for appropriate study skills to adapt to the challenge. This topic will be discussed in more detail in the following sections and will relate the student's experiences and how they have adjusted. These survey findings will be addressed in corroboration with the interview results later on in chapter five.

\section{Interview results discussion.}

In comparing the threatening themes found in the RFGC student and STEM faculty interviews, three comparable themes emerged. The faculty theme of Institutional environment and faculty corresponds to the student theme of Drive. Faculty mentioned that the Lack of preparation as a threatening factor. This faculty theme relates to the student comments 


\section{ENABLING AND THREATENING FACTORS AFFECTING PERSISTENCE}

concerning a lack of Experiences or skills. STEM faculty members and students both mentioned items related to Resources and Support that were threatening factors. The last threatening theme, More challenges than others (non-RFGC students), was only found within the faculty comments.

\section{Student threatening themes.}

RFGC STEM student interviews were analyzed to determine the factors threatening persistence. The themes were the absence or the lack of Drive, Experiences and skills, and Resources and support. The theme Drive developed from student comments that revolved around life events, negative school experiences, homesickness, and just a lack of interest in school or subject matter. These sub-themes negatively impacted students' motivation or desire, and, if this impact is severe enough, students may leave their major or even college altogether. Even if students do stay in school and their STEM major, these factors can affect their desire to study, which could lead to low course performance, and they may be forced out of a program or college.

The topics that formed the theme, Experiences and skills, were academic preparation, high schools that were not challenging, and students not having academic skills. RFGC STEM students stated that their high school experiences did not prepare them for college. Some students discussed the fact that their high school academic choices were limited with few honors and AP courses, or even regular STEM classes. Students felt that additional options would have prepared them more for college courses. Both the academic content and the rigor of high school courses were mentioned as lacking. RFGC STEM students stated that they did not put much effort into school and easily attained good grades. Several of these students indicated that they did not need to study, and therefore, did not develop quality study skills. Participants also described how some of their teachers were not certified and that they rarely had a consistent math teacher. 


\section{ENABLING AND THREATENING FACTORS AFFECTING PERSISTENCE}

Beasley's FG rural participants made statements that mirror the RFGC STEM comments with a lack of both quality high school courses and consistently qualified teachers (2011).

Another effect of a less challenging high school experience is that RFGC STEM students did not develop time management, responsibility, or self-discipline traits. Students discussed the struggles they experienced while in their first couple of semesters of college because they lacked these skills or attributes. If students do not adapt to the more demanding college courses by developing appropriate skills and traits, they are less likely to continue in their program.

RFGC STEM students discussed several items related to Resources and support, such as not having resources, the money-work-time cycle, lack of family or emotional support, and topics associated with being first-generation. Resources that the students found to be lacking were internet access, technological devices, and transportation. Students mentioned how they had issues navigating non-academic items like the financial aid process. Schutz (2004) and Beasley (2011) stated some items that rural FG students are incognizant of: higher education costs, benefits of relationship building, the rigor of college courses, course structure, and professor expectations. RFGC STEM students were also negatively impacted by the money-work-time dynamic, which is directly tied to resources and financial support. The money-work-time dynamic will be further discussed later in this chapter.

The support component of this theme involves both emotional and financial matters. RFGC STEM students discussed how funds were limited, including their family's monetary sources, and how financial assistance was vital to their college quest. This economic struggle is especially true in the Appalachian region (Hand \& Miller-Payne, 2008). Funds were also limited to pay for unexpected college costs such as books, special fees, or organization fees. Schutz's 2004 study on FG rural students agrees with the surprise costs and Phillips' (2015) FG rural participants also 


\section{ENABLING AND THREATENING FACTORS AFFECTING PERSISTENCE}

stated that there are additional costs to participate in certain activities. These college fees are in addition to their regular living expenditures with which they may already be struggling.

Emotional support can help a student get through hard times and encourage students to continue with their degree aspirations. Without support from family, friends, and school personnel, students are more likely to give up. Beasley (2011) found that significant others (boyfriends, girlfriends, spouses) can persuade FG rural students to quit school or not even enroll. Phillips (2015) found family and community to be enabling factors, but they sometimes discouraged FG rural students from attending college.

\section{Faculty threatening themes.}

STEM faculty interview statements related to threatening factors were analyzed and four major themes emerged. These themes were: Institutional environment and faculty, Lack of preparation, Lack of support, and More challenges than others.

STEM faculty discussed how Institutional environment and faculty could harm RFGC STEM students' desire to continue in their degree. This is related to the student theme of Drive. Negative student interactions with the school environment, personnel, or peers can impact students' desire to stay at that school or create a negative opinion of classes or of their major. RFGC STEM Students may also become homesick and desire to go home frequently or permanently. Beasley (2011) found that FG rural students were hesitant to leave their hometown and that they had a special attachment to their family and home.

A few RFGC STEM students mentioned that they miss the rural environment as they enjoy being around nature or are active outdoorsmen. These students did not state that this threatened their persistence, but it was a distraction. This could be a potential reason that 


\section{ENABLING AND THREATENING FACTORS AFFECTING PERSISTENCE}

students eventually leave, as Schutz (2004) found a lack of a rural setting adversely impacted the FG rural student's view of college and their continuance in their career path.

STEM faculty mentioned that the Lack of preparation, typically academic preparation, was a threatening factor to RFGC STEM student persistence. Previous studies focused on rural or FG or STEM students, but not all three combined labels, also stated similar findings. These participants experienced lower quality mathematics and science classes or had no advanced STEM course options (Beasley, 2011; Uche, 2015; Versypt \& Ford-Versypt, 2013). This correlates to the RFGC STEM student theme of lacking Experiences or skills, needed to navigate college and be a successful STEM major.

Both RFGC STEM students and STEM faculty discussed how the lack of Support or resources could be an adverse condition for completing a STEM degree. Support can come in the form of emotional support and financial support. A lack of emotional support can be especially troublesome for students when they are lacking confidence or are in the midst of a challenging time. Without emotional support at the right time, a student may decide to give up due to frustration or loss of motivation. Financial support was found as a challenge in several other reports; Beasley (2011) and Phillips (2015) focused on FG and rural students, Geier (2016) and Uche (2015): FG STEM students, Hunley (2015): FG Appalachian undergraduates, and Versypt \& Ford-Versypt (2013): rural STEM majors.

Financial support can come from the institution in the form of financial aid, or from family or community resources. Financial assistance enables students to enroll and continue through to graduation. Attaining financial support can have a positive effect on persistence factors, such as reducing the need to work, which increases the time available for school and campus activities (Hand \& Miller-Payne, 2008). This situation is what I refer to as the money- 
ENABLING AND THREATENING FACTORS AFFECTING PERSISTENCE

work-time cycle. Several other studies found similar results, but their participants were not rural, FG, and STEM majors. Most of their participants needed to work, and many struggled to find a balance between home life, work, and school (Geier, 2016; Phillips, 2015; Wilson, Lyons, \& Quinn, 2013). This money-work-time dynamic is especially threatening if there are other weaknesses, challenges, or threatening factors that the student must face.

Another theme that was only found in the faculty interviews was that RFGC STEM students Experience more challenges than others, those that are not RFGC STEM. The threatening factors that have been mentioned in this study can impact all types of students, not just RFGC STEM students. The faculty are aware that all students have challenges that they must overcome, but they discussed how RFGC STEM students have more than the typical student. Many of these threatening factors were discussed previously. Two additional issues that were not previously discussed are that students have to deal with mental illnesses and drugs (family and themselves), and due to their independence, they may not seek out help when needed.

Phillips (2015) recommended several ways that the institution can support FG rural students. Colleges can increase communication efforts and information sharing, especially about how college works. Institutions need to make sure that students are aware of the available institutional resources and offer students information sessions on academic success tips, budgeting skills, and career advice. Phillips also states that the institutions can create a more empathetic environment by increasing faculty and campus personnel's awareness of rural firstgeneration issues.

\section{Survey and interview corroboration.}

There are commonalities between the survey results and interview themes. Faculty and students ranked four survey items (difficulties) as significantly concerning. The four common 


\section{ENABLING AND THREATENING FACTORS AFFECTING PERSISTENCE}

factors were: not having enough time to study due to having a job, having trouble developing study skills, having difficulty adjusting to academic demands of STEM courses, and being able to afford finishing their degree. These four survey items correlate to the themes found in the interviews.

The survey items, "not having enough time to study due to having a job" and "being able to afford finishing their degree" relates to the interview theme of Resources and support, specifically the money-work-time dynamic. The survey statements "having difficulty developing study skills" and "having difficulty adjusting to academic demands of STEM courses" correspond to multiple interview themes. The faculty theme of Institutional environment and faculty parallels these two survey items, as the students are experiencing difficulties due to the college courses' setup or environment. The college classes are harder than what students were accustomed to, and they need to adjust to these higher demands. These two survey responses also relate to the faculty theme of Lack of preparation and the corresponding student theme of lacking Experiences or skills. Because of students' previous high school experiences or the lack of challenging high school courses, they have limited capabilities and therefore struggle with the more rigorous college classes.

\section{Comparison to Opatz's Persistence Pyramid.}

Leslie Opatz's qualitative study was focused on successful low-income students at a large urban doctoral-granting institution with high research activity. A significant outcome of his dissertation study was his Persistence Pyramid. Opatz developed the pyramid by finding common topics among previous persistence research. He did not separate these items into enabling or threatening factors for the construction of the pyramid. The pyramid was then used to determine which of the pyramid factors impacted his low-income students the most. 


\section{ENABLING AND THREATENING FACTORS AFFECTING PERSISTENCE}

The pyramid is composed of student and campus factors affecting persistence. The student factors are Academic, Economic, Psychological, and Social. All of Opatz's student factors were found in this study's themes. The Academic factor relates to the enabling theme of Experiences and skills and the threatening themes of Lack of preparation and Experiences and skills.

Opatz's Economic student factor was found to be a major theme in this study as both an enabling and threatening factor, Resources and support. Both faculty and RFGC student's themes match with Opatz's factor.

This study's theme, Resources and support also match Opatz's Psychological and Social portion of the pyramid. Students and faculty mentioned the need for emotional support to be successful as a STEM major. The student enabling and threatening theme, Drive, and the faculty's enabling theme of Motivation also relates to Opatz's Psychological component of the pyramid. Drive or motivation is a psychological element that impacts a student's desire to stay in school. The faculty's threatening theme of Institutional environment and faculty also relates to Opatz's Psychological and Social aspects of the pyramid as specific institutional environments and faculty were viewed as having a negative psychological effect on RFGC students, which in turn can cause social issues.

The Campus factors of the pyramid are Caring Culture, Educational and Curricular Support, Involvement Opportunities, and Support for Diversity \& Community. Opatz’s Caring Culture, Educational and Curricular Support, and Support for Diversity \& Community relate to RFGC student's themes of Drive and Support. A caring culture and support services can positively impact a student's drive, enabling them to continue through their major. A Caring Culture, Educational and Curricular Support, and Support for Diversity \& Community also relate 


\section{ENABLING AND THREATENING FACTORS AFFECTING PERSISTENCE}

to the combined faculty and student theme of Resources and support. A campus's student support efforts can be beneficial to student success and create a welcoming and supportive learning environment. Institutional support services can help students to improve any deficient elements that they may have, such as study skills and academic preparation, which relate to the themes of Experiences and skills, and Lack of preparation. This support can also address the faculty's threatening theme of More challenges than others. Opatz's Involvement Opportunities, an institutional factor, has a slight relation to this study's themes. Involvement Opportunities can create a sense of connection between the student and the college. If students make a connection to the campus, such as liking their course work or befriending school personnel or peers, then students will have a stronger urge (Drive or Motivation) to stay because of these positive and beneficial connections. If a campus does not produce a favorable environment for RFGC students, this becomes a threatening factor, which the faculty mentioned as Institutional environment and faculty. Support for Diversity \& Community are also related to the Institutional environment and faculty as an institution can be proactive in making a more welcoming environment for those that are from diverse backgrounds, like RFGC students. If faculty, staff, and peers are more welcoming of RFGC students, this may help them form support networks which can enable them to persist through challenging times.

\section{How do RFGC STEM Majors Handle or Deal with the Challenges they Face?}

Students that struggle in college can learn from more successful students. Students can mock successful student habits and practices to improve upon their deficiencies and overcome the challenges they encounter. RFGC STEM students' responses were analyzed to determine how they successfully conquered college issues and to determine if these challenges changed over time. 
ENABLING AND THREATENING FACTORS AFFECTING PERSISTENCE

\section{What are their successful means to adapting to these challenges?}

Student interview responses identified ways that RFGC STEM students adjusted to college. Students described how they acquired assistance from institutional personnel and online resources. Institutional personnel included professors, tutors or peer mentors, classmates, and other school support services.

Several students utilized technology such as YouTube, Khan Academy, and CHEG to help with content attainment. Asking for help or knowing what to ask can be a significant hurdle for students. One student specifically mentioned that, due to her increased class preparation, she was more confident and willing to ask for help, especially during lecture.

Adaptions to students' study efforts and habits were also discussed. Students found that their high school study skills were not adequate for college-level courses. Students adapted to this challenge by developing or enhancing their notetaking and study habits. Students increased their studying efforts by setting aside more time for reading and even re-reading. They also realized that studying the night before a test was not sufficient, as they started studying for tests multiple days in advance. They were also found to repeat homework problems and even make their own problems to prepare for tests.

The previous statements are specific ways that students adjusted to the demands of college. Recognizing the need to adjust and then being willing and able to adapt was found to be important for continued success. Courtney's statement summarizes this importance, "probably being adaptable to the workload and having to change my study habits... because you're going to [have] different professors... different types of classes, where you have to adapt because everyone teaches differently and it's different material in each [class]." And if a student does not 


\section{ENABLING AND THREATENING FACTORS AFFECTING PERSISTENCE}

adapt to their challenges, they may not continue in their major. Brandy gave a good example of how those that do not adjust or adapt are not successful.

I know some [students] that have taken calc like three or four times, and I feel like they're not putting in more effort. They're just putting in the same effort and then they're getting the same outcome. They go into each semester saying, "I'm going to pass it," and then they do the same thing of just like not giving it their all. They'll have an exam and they won't study any different. They'll just study a few days before and not pass the exam again. I feel like those are the people that don't succeed as much because they don't change ... they don't adapt.

\section{How do these challenges change over time as a STEM major?}

Quantitative and qualitative data were collected to answer the question of how challenges

change over time for a STEM major. The quantitative data provided specific examples that were statistically different among freshmen, sophomores and upperclassmen. Four survey items were found to be different between at least two groups. The question, "My STEM classes have too many students in them, so I do not get individual support from my professors," was different between the Upperclassmen and Sophomores. The Upperclassman group ranked this higher than the Sophomore group, as they feel that the statement is truer of their views. Typically, freshmen level courses have higher student-to-teacher ratios, therefore, students would desire more oneon-one interaction with their instructor. This study's findings counter this conventional belief. This may be due to the difficulty of the material in upper-level courses. The Upperclassmen desired more one-on-one time with the instructor to understand the material.

The Upperclassmen also ranked the question, "Professors in my STEM classes tend to lecture a lot," higher than the Sophomore group, meaning that they feel that this statement more 


\section{ENABLING AND THREATENING FACTORS AFFECTING PERSISTENCE}

accurately represents their feelings. This could mean that the upper-level instructors spend more time lecturing and that the content itself may warrant more of a lecturing method. This could also mean that the instructors of upperclassmen are not interested or knowledgeable in other methods of instruction.

The Freshmen group felt that the question, "I do not feel safe on campus," reflects their views more accurately than the Sophomore group. This can be expected with a group of freshmen that are rural and first-generation. Many of their college experiences are new and unexpected. Crimes can be rather disturbing to a RFGC student. Devin, a freshman, mentioned such an event in his interview, "I got an email in the first week [of classes] saying there was a rape, and I was like, "Oh, my God! We never had that back home." He went on to say that this impacted his view on socializing, "I'm even scared to go out to those parties and stuff, I won't go to them just because you don't know what's going to happen, it's just a different atmosphere." This is another college item that RFGC students need to adapt to, and, if they cannot acclimate, they may leave college.

The Freshmen also ranked the question, "I do not feel that I belong in college" higher than the Sophomore group. This means that the freshmen had more doubts about their place in college than the Sophomore group. Considering several of these RFGC students felt underprepared and had to alter their study habits and increase their efforts, this is an expected outcome. Even valedictorians were found to struggle in the few semesters of college. If very successful high school students are unexpectedly struggling in their first few semesters, this will cause them to doubt their abilities and feel as if they do not belong. When students start to encounter harder classes and are not attaining the grades they did in high school, doubt may arise, and they question their abilities and their decision to go to college. 


\section{ENABLING AND THREATENING FACTORS AFFECTING PERSISTENCE}

The interview data and survey data do not overlap with common themes that change over time. One theme from the student interviews was that the first semester was the hardest or was the one point in college which required the most adjustment. Students explained that the challenge of this period was adjusting to the rigor and expectations of college courses. Students have to be careful and not become overconfident in introductory courses, as they may start off easy as the content is familiar, but this can quickly change. If students do not make adequate adjustments, their grades can suffer, and even worse, they may find themselves behind the rest of the class and cannot catch up.

Students also voiced confidence in themselves and their ability to overcome future hurdles once they adapted to their initial challenge(s). Students described how they adjusted their study habits and dedication to studying. Several students discussed that they expect future challenges with their course work but were not frightened about these upcoming challenges, as they were confident in their abilities to adjust.

The last topic mentioned as changing over time was that students' career aspirations changed over time, but this was not found to impact their persistence or desire to finish a STEM degree. For example, some students discussed a desire to work with the FBI, after a few semesters they changed their minds. They either changed their mind once they knew more about their career options or felt that this goal was unrealistic.

\section{Conclusion}

It is essential to understand the factors affecting the persistence of RFGC students so college personnel can make policies and procedures to assist these students. The education field needs to understand that both rural and first-generation students need to be recognized as an underrepresented group (Versypt \& Ford-Versypt, 2013). This is true for any major but given the 


\section{ENABLING AND THREATENING FACTORS AFFECTING PERSISTENCE}

need for additional STEM workers, it is even more critical to increase the number of successful students that desire to attain their STEM degree

Almost all of the students made a comment concerning adjusting or adapting to challenges or issues that they faced while pursuing a STEM degree. They emphasized the importance of adapting and how it enabled them to persist. The themes found in this study impact a student's ability to adapt, which increases a student's chances of attaining their STEM degree. The overall themes were found to be Drive or motivation, Experiences and skills, and Resources and support. Faculty also believed RFGFC STEM students have Personal characteristics that enable their persistence. If students have these traits or resources, they are more likely to be able to adapt to the challenges that they are faced with as they pursue a STEM degree. If they do not make the appropriate adaptions, they are more likely to drop out of their STEM program or even worse quit school altogether. Enabling factors can be thought of as a student's toolbox to use to get through tough times. The tough times are the threatening factors to which a RFGC STEM students must adapt. If there are too many threats or if students do not have the appropriate tools, then they may not finish their STEM degree because they cannot adapt to the challenge.

The themes found in this study support previous research with just minor distinguishing components. The threatening themes were found to be Drive, Experiences and skills, Support and Resources, Institutional environment and faculty, Lack of preparation, and More challenges than others. The theme More challenges than others adds a little more detail to what was found in the literature as Status Impact. Previous studies found that being rural or first-generation both impacted persistence. Being rural was found to be both enabling and threatening whereas firstgeneration was only viewed as a threat. The research used in this study only included at max, 


\section{ENABLING AND THREATENING FACTORS AFFECTING PERSISTENCE}

two of the three criteria of being a student participant in this study: rural, first-generation, and in a STEM field. None of the literature was found to have all three criteria of this study's participants. It is interesting that the faculty theme More challenges than others was produced. When the faculty were asked about the challenges that RFGC STEM students face they came to the realization that the more underrepresented backgrounds the more challenges they will face. Then add in the fact that a student may be in one of the more challenging fields, STEM, this just increases the number of threatening factors that these students may face. This is not to say that other combinations of backgrounds and majors will experience less challenges than RFGC STEM majors. This study's findings do suggest that the more background combinations, the more challenges that person may face. For example, an urban, low-income, first-generation, black male is more likely to experience more challenges than those that do not have his background.

Limited research mentioned favorable factors of a RFGC STEM student. The faculty supported these findings with the enabling theme of Personal characteristics - responsibility and independence, acquiescence, resilience, and work ethic. This reinforces the findings of Geir (2016): work ethic, discipline, goal setting, ability to deal with adversity, and determination to not fold under challenging times. Phillips' (2015) work also mirrors these reports: statuses serving as impetuses for success, includes work ethic, self-sufficiency, internal motivation or drive, not feeling entitled, being frugal, and having money management skills. These favorable attributes of RFGC students need to be recognized and utilized to fill the states need for additional degrees. 
ENABLING AND THREATENING FACTORS AFFECTING PERSISTENCE

\section{Limitations}

A few limitations to this study relate to self-reported data from the survey instruments. To determine a student's FGC status, this study relied upon a student's response to the question: Have either of your parents or guardians graduated from an institution of higher education? The accuracy of this data relies upon each student's knowledge of their parents' or guardians' higher education. Even though some students were labeled as first-generation according to the study's definition, a few students had family members with degrees or college experience.

Students were labeled as rural or non-rural dependent upon their high school's zip code and name. The issue with determining rurality is that students may not remember the correct school zip code or exact name, or the school name and address may have changed. Some participants were removed from the study because their school could not be found in the database or they were homeschooled. Another limitation occurs with the situation where a participant lived in a more urban area, but they were labeled rural because most of the students in their school are from a rural area.

Even though this study included a wide range of students and faculty that correspond to a WV college, this was still a relatively small sample of the broader population, and caution should be used in generalizing the findings from this study.

Some decisions had to be made with a few of the institutions' majors, as they were not common majors. These newer STEM majors did not align exactly to the NSF approved STEM majors list.

A participant was removed from the study if they were a person familiar to the researcher, if their pertinent information was void, or if their school rurality could not be determined. 


\section{ENABLING AND THREATENING FACTORS AFFECTING PERSISTENCE}

The survey instrument that was utilized had some limitations, especially with the

wording. The words used as responses to each survey item: Untrue, Somewhat untrue, Somewhat true, and True may be confusing to participants, as this goes against the traditional Likert-type words of "agree" and "disagree". This wording may also create confusion when students are trying to determine what response to give. The combination of the survey statement and the response create a double-negative of sorts and can confuse the participant. They may give the wrong response they intended. For example, with the statement "I do not feel safe on campus," if a student is trying to match their response of somewhat untrue of me, the combination statement and answer create a double negative. This may cause a participant to choose the opposite response that they desired.

There was another limitation with the survey instrument and methodology. One of the research questions was, how do challenges changes over time? This answer would be best derived by repeat survey participants. The survey instrument also limited the corroboration of data between the interview data and survey data because the survey instrument did not include enabling factors affecting persistence.

The number of exodus (leaving the STEM major or college) students were limited, as only one student responded for an interview, luckily, he was interviewed. It is difficult to include exodus students in a study like this, especially if they have already left the college. Email was utilized to send out study invites, and this is another limitation. Those students that are not checking email are not seeing the study invite and are not a participant. These may be the exact students we want to talk to, as they may not know how to access their email; or just do not check their email. These types of students may be those students that really struggle with their new atmosphere and college demands. 


\section{ENABLING AND THREATENING FACTORS AFFECTING PERSISTENCE}

\section{Implications}

Retention of RFGC STEM students can be improved upon if faculty and staff understand the factors that enable and threaten persistence. Institutional personnel that understand these factors could demonstrate more empathy for RFGC STEM struggles and can choose appropriate resources and support for these students.

Faculty that understand that students typically do not have academic skills coming into college can adapt their course structure to help students acclimate to the rigors of college. Faculty need to understand that numerous students did not need to keep track of due dates and assignment details while in high school. Faculty may want to facilitate note taking skills especially in a student's first semester. Providing students with an outline of lecture content or partial presentation slides may be a good start in assisting students with note taking. This note taking assistance can be scaled back once students develop efficient note taking skills. This weaning process can be applied to other skills that are found to be inadequate. If students are taught academic skills early on, the students will need less of this help as they move through their college career. Programs may want to review their curriculum and make necessary adjustments if passing rates are low $(<60 \%)$ in freshman and sophomore classes. Low pass rates may indicate that the rigor, expectations (keeping track of assignments, developed study skills, etc.), and content are too steep for incoming students. Programs may consider scaffolding techniques with their curriculum. Freshmen courses can be designed to have less rigor and higher-level courses have more. I am not suggesting that programs decrease what is expected of graduates, just scale the program from where the students are to where you want them to be. This way program objectives are still met. Higher pass rates would benefit students' psychological state. This would minimize the stigma that some classes are given, such as weed-out courses. 


\section{ENABLING AND THREATENING FACTORS AFFECTING PERSISTENCE}

Students would start these courses with more optimism and drive which could lead to higher pass rates. Increasing pass rates would decrease the need for students to repeat courses, possibly reducing their financial costs for their degree.

Institutions may utilize these findings to adjust or add to their current resources and student success efforts. For instance, understanding how challenges change over time for RFGC STEM students, staff can more efficiently coordinate when support and resources are communicated and offered. Timeliness of help is crucial as students may not be responsive to academic support unless they realize that they need it. Students may only realize that they need help when they experience a significant challenge that they are not sure how to overcome.

Institutions should consider year-round orientation and student success workshops because students experience challenges at different times of the year. Orientations that occur before students start school should only be focused on developing social and support networks and helping students to familiarize themselves with the campus. Workshops focused on developing academic skills should be reserved for after the semester has started, and students have experienced some struggles. Institutions need to understand that students typically did really well in high school and found it relatively easy. Students come into college not knowing how different college may be from high school and this may be a major psychological disappointment.

Peer mentor programs may be a practical student success tactic that address RFGC STEM issues (academics, social capital, and other college challenges) in a holistic manner. Peer mentors may be available at the "right" time when students need someone to discuss challenges they face. Faculty and staff are not always around but peers are more likely to be available. Mentors can ease student concerns with their struggles. Peer mentors that have also struggled can 


\section{ENABLING AND THREATENING FACTORS AFFECTING PERSISTENCE}

empathize with the student and help them understand that challenges are normal and can be overcome. Appropriately trained mentors can then support students to overcome these challenges or refer the student to other institutional resources.

This study and others like it found that RFGC students have favorable characteristics of a STEM major. These are important enabling factors that faculty and higher education administrators need to realize. RFGC students are not as appreciated for their academic worth as other students from more prestigious backgrounds. These findings demonstrate that RFGC students have favorable personal characteristics that may benefit them as STEM majors. Given the shortage of majors in the state of West Virginia and other rural states, higher education personnel should take advantage of their rich resource of RFGC students to fill these needs.

RFGC STEM students can benefit from the findings of this study as they can be comforted to know of how others have struggled and that they are not alone. They will know that obtaining help is not only normal it may be a necessity to get through a STEM major. Students need to understand that if they have the desire to attain a degree and they are willing to change (adapt), then any STEM degree is possible. Students need to understand that academic success in their first semester is vital to finishing their career aspirations. They need to seek out help as soon as any complications arise.

Numerous students mentioned that high school was easy and that they did not need significant academic skills. Personnel in K-12 schools need to realize that there is a significant difference between high school academics and college freshmen level courses. If K-12 personnel can help bridge this gap by any means, their efforts can help freshmen become more successful. AP, Honors, and dual enrollment courses may be significant means to reduce the difficulties 


\section{ENABLING AND THREATENING FACTORS AFFECTING PERSISTENCE}

experienced by college freshmen. These types of courses can involve higher expectations of enrolled students that includes higher content and rigor than general studies courses.

Parents can benefit from understanding the struggles that their RFGC STEM student may be experiencing and can provide appropriate support and empathy. Parents can benefit from understanding that struggle is normal, and that high school and college are distinctly different. Parent expectations need to be realistic to the experiences that their son or daughter is experiencing. For example, achieving high grades in college is going to take a lot more time and effort than it did in high school.

Students, parents, K-12 and higher education personnel need to recognize that programs like the Health Science and Technology Academy (HSTA) have shown that diverse individuals can be successful in STEM fields given their participation in enriching STEM experiences (Benson-McKendall, Kasten, Hanks, \& Chester, 2014). "HSTA graduates have been successful in pursuing post-secondary education..., stay in college to graduate, and major in science, technology, engineering, and math (STEM) subjects at higher rates than both the general West Virginia and the national population" (p. 41). The participants are WV residents and a large portion come from diverse backgrounds, 32\% African American, 73\% first-generation college, and $63 \%$ financially disadvantaged. These participants start the program while they are in the ninth grade and complete two summer camps held on a WV college campus and includes lecture and hands-on activities designed to help transition these students from high school to college.

\section{Recommendations for Future Research}

An emphasis of this study was to determine how student challenges change over time.

Completing a chronological study would be an improvement to the method used in this study. The study should have the same students studied throughout the period and complete interviews 


\section{ENABLING AND THREATENING FACTORS AFFECTING PERSISTENCE}

in the earlier part of a student's education. A case study or phenomenological approach may be beneficial to help determine how a student's experiences change over time and to determine what exactly these struggles are.

Additional studies should be conducted to include other institutions, especially community and technical colleges, as this study was limited to four-year institutions. Those students that go to a community and technical college may have different persistence factors compared to this study's participants. Consideration should be made to include undeclared students in future STEM studies, as this would allow undeclared students to have a voice in the study if they are thinking about majoring in a STEM field.

Future studies should invite participants in the earlier part of a semester to capture those students that may drop out early in the semester. This study only interviewed one Exodus student, and this did not provide an appropriate sample of this group and their experiences. These students are those that we especially want to hear from as they have decided to quit their pursuit of a STEM degree. The early part of a student's first semester is when a high number of students drop-out and it is almost impossible to communicate with these individuals once they do dropout. Having contact with them prior to their dropout should increase the participation of Exodus students in a study. A quick and enjoyable interview at the beginning of the semester may help create a friendly relationship between the researcher and an Exodus student. If such a relationship is developed and personal contact information is collected, not an institutional email, an Exodus student may be more inclined to participate after they have dropout. Institutional email accounts are typically closed once a student is no longer enrolled. Even if the account is still active, students are very unlikely to check their institutional email after they have left school. 


\section{ENABLING AND THREATENING FACTORS AFFECTING PERSISTENCE}

It may be beneficial for a study to utilize additional contact methods in conjunction with emails. Social media or face-to-face invites may collect participants that are not email savvy. These student's communication preferences may be factor to student success. At the very least a researcher may find that this group enriches the sampling of other studies that relied upon emails as a source of study advertisement.

Studies that want to utilize a survey instrument may want to add enabling factors to the instrument as this study's instrument only included threatening factors. Survey studies may also want to incorporate a more traditional Likert-scale. For the survey scale, future researchers may consider using a five-point scale instead of a four-point. Some researchers like a four-point scale to force participants to respond one way or the other instead of providing a neutral response.

I believe the best scale would utilize a range of agreement or disagreement for responses. For example, each item can be rated as to how much a participant agrees with a statement. A scale of zero to four can be utilized, zero means that they do not agree at all, and four means that they fully agree with the statement.

Within the survey analysis it was found that faculty and students significantly ranked the survey items differently. The faculty thought that the factors listed in the survey instrument would have a greater impact on student persistence than the students felt. Considering the survey ranking was a four-point scale, the faculty ratings were approximately one ranking higher than the students. A studying utilizing such survey items followed by interviews focused on the participants ranking rationale may help understand why this discrepancy exists.

For this study, the students' faculty came from different types of higher education institutions defined by the Carnegie Classification system, future research may want to create sub-groups based upon the different types of institutions. This type of study could investigate if 
ENABLING AND THREATENING FACTORS AFFECTING PERSISTENCE

there are any differences in the way the students and faculty view factors that affect persistence based upon the type of institution. 
ENABLING AND THREATENING FACTORS AFFECTING PERSISTENCE

\section{References}

Baum, S., Ma, J., \& Payea, K. (2013). Education Pays 2013. Retrieved November 26, 2017, from Trends in Higher Education:

https://trends.collegeboard.org/sites/default/files/education-pays-2013-full-report.pdf

Beasley, S. E. (2011). Country roads take me...?: An ethnographic case study of college pathways among rural, first-generation students. Boston College, Lynch School of Education. Ann Arbor: ProQuest LLC.

Benson-McKendall, S., Kasten, K., Hanks, S., \& Chester, A. (2014, January). The Health Sciences and Technology Academy: An Educational Pipeline to Address Health Care Disparities in West Virginia. Academic Medicine, 37-42. Retrieved from https://www.ncbi.nlm.nih.gov/pmc/articles/PMC3939059/\#idm140194500148848aff-info

Big Ten Academic Alliance. (2014, March 7). NSF Approved STEM Fields. Retrieved March 28, 2017, from btaa.org: https://www.btaa.org/docs/default-source/diversity/nsf-approvedfields-of-study.pdf

Chen, X., \& Soldner, M. (2013). STEM attrition: College students' paths into and out of STEM fields . U.S. Department of Education. Washington: National Center for Education Statistics.

Childs, P. Y. (2015). Factors affecting the academic achievement and persistence of quota students in STEM: A case study of a public university in Brazil. University of Maryland. Ann Arbor: ProQuet.

Choy, S. (2001). Students whose parents did not go to college: Postsecondary access, persistence, and attainment . National Center for Education Statistics. Jessup: U.S. Department of Education. 


\section{ENABLING AND THREATENING FACTORS AFFECTING PERSISTENCE}

Commission, W. V. (2015, December 16). Following record degree production, West Virginia higher education leaders collaborate to 'Double the Degrees' by 2025. Retrieved April 27, 2017, from West Virginia Higher Education Policy Commission:

http://www.wvhepc.edu/following-record-degree-production-west-virginia-highereducation-leaders-collaborate-to-double-the-degrees-by-2025/

Corbin, J., \& Strauss, A. (2008). Basics of Qualitative Research: Techniques and Procedures for Developing Grounded Theory (3rd Edition ed.). Thousand Oaks: Sage Publications Inc.

Creswell, J. W. (2007). Qualitative Inquiry \& Research Design Chosing Among Five Approaches (2nd ed.). Thousand Oaks, CA: Sage Publications Inc. .

Dika, S. L., \& D'Amico, M. M. (2016). Early experiences and intergration in the persistence of first-generation college students in STEM and Non-STEM majors. Journal of Research in Science Teaching, 53(3), 368-383.

Gandhi-Lee, E., Skaza, H., Marti, E., Schrader, P., \& Orgill, M. (2015). Faculty perceptions of the factors influencing success in STEM fields. Journal of Research in STEM Education, $1(1), 30-44$

Geier, S. (2016). The educational journeys of first-generation college women in STEM: A grounded theory study. Purdue University. West Lafayette: ProQuest.

Hagedorn, L. S. (2006). How to define retention: A new look at an old problem. University of Southern California. N/A.

Hand, C., \& Miller-Payne, E. (2008, Fall). First-generation college students: A study of Appalachian student success. Journal of Developmental Education, 32(1), 4-15. 


\section{ENABLING AND THREATENING FACTORS AFFECTING PERSISTENCE}

Hicks, T. (2012). College experiences and self-efficacy of first-generation students versus other students enrolled in a STEM discipline at a historically black college and university. North Carolina State University. Ann Arbor: ProQuest.

Higher Education Research Institute. (2016). 2016 Your First College Year Survey. Survey. Los Angeles, CA, USA: Regents of the University of Minnesota.

Hunley, R. D. (2015). Understanding factors contributing to the persistence of first-generation college students from Appalachian distressed counties: A Phenomenogical study . Liberty University. ProQuest LLC.

Hutchins, B. C., Meece, J. L., Byun, S.-y., \& Farmer, T. W. (2012, Winter). Planning for the future: An Investigation of Work-bound rural youth. Rural Educator, 33(2), 7-19.

Medrano, E. (2015). Predictors of success for first-time community college students pursuing STEM degrees: A Quantitative study. California State University, Educational Leadership. Ann Arbor: ProQuest LLC.

National Center for Education Statistics. (n.d.). Common Core of Data. Retrieved May 10, 2017, from National Center for Education Statistics : https://nces.ed.gov/ccd/rural_locales.asp

Opatz, L. J. (2013). The Persistence Pyramid: Factors Related to Persistence for Low-Income Students in Baccalaureate Programs. University of Minnesota. ProQuest LLC.

Patton, M. Q. (2002). Qualitative Research \& Evaluation Methods. Thousand Oaks, CA, USA: Sage Publications.

Phillips, A. (2015, May). I had to learn that on my own: Successful first-generation, low-income college students from rural areas at an urban institution. University of Luisville, College of Education and Human Development. ThinkIR. 


\section{ENABLING AND THREATENING FACTORS AFFECTING PERSISTENCE}

Phinney, J. S. (1992). The Multigroup Ethnic Identity Measure: A new scale for use with diverse groups. Journal of Adolescent Research, 7(2), 156-176.

President's Council of Advisors on Science and Technology. (2012, February ). Energy.gov Files. Retrieved May 13, 2017, from ENERGY.GOV: https://energy.gov/sites/prod/files/Engage\%20to\%20Excel\%20Producing\%20One\%20Mi llion\%20Additional\%20College\%20Graduates\%20With\%20Degrees\%20in\%20STEM\% 20Feburary\%202012.pdf

Ratcliffe, M., Burd, C., Holder, K., \& Fields, A. (2016, December). Defining rural at the U.S. Census Bureau. Washington, D.C., US.

Schutz, P. F. (2003). Upon entering college: First semester experiences of first-generation, rural students from agricultural families. Colorado State University, School of Education. Ann Arbor: ProQuest Information and Learning Company.

Schutz, P. F. (2004). Upon entering college: First semester experiences of first-generation, rural students from agricultural families. The Rural Educator, 2(1), 48-51.

The Carnegie Classification of Institutions of Higher Education. (n.d.). Retrieved April 3, 2020, from About Carnegie Classification: http://carnegieclassifications.iu.edu/

Tinto, V. (1975). Dropout from higher education: A theoretical synthesis of recent research. Review of Educational Research, 45(1), 89-125.

Tinto, V. (2006-2007). Research and practice of student retention: What next? . Journal of College Student Retention: Research, Theory \& Practice, 8(1), 1-19.

Trachtenberg, S. J. (2014, April 1). 3 Cheers for Associate Degrees. Retrieved October 24, 2017 , from Inside Higher Ed: https://www.insidehighered.com/views/2014/04/01/essay-callscolleges-award-associate-degrees-those-who-finish-two-not-four-years 


\section{ENABLING AND THREATENING FACTORS AFFECTING PERSISTENCE}

U.S. Department of Education. (2017, April). Undergraduate Retention and Graduation Rates . Retrieved November 18, 2017, from Institute of Education Sciences, National Center for Education Statistics: https://nces.ed.gov/programs/coe/indicator_ctr.asp

Uche, A. R. (2015). The retention of first-generation college students in STEM: An extension of Tinto's longitudinal model. University of North Carolina. Charlotte: ProQuest.

Versypt, J. J., \& Ford-Versypt, A. N. (2013). Mapping rural students' STEM involvement: Case studies of chemical engineering undergraduate enrollment in the states of Illinois and Kansas. 120th ASEE Annual Conference \& Exposition (pp. 1-26). Atlanta: American Society for Engineering Education.

Ward, C., Jones, K. W., Madsen, R., Coles, R., Rich, L., \& Knapp, S. (2014). Mentored research in a tribal college setting: The Northern Cheyenne case. Journal of Research in Rural Education, 29(3), 1-17.

West Virginia Council on STEM. (2014, September). Retrieved from http://www.governor.wv.gov/Documents/STEM\%20report-FINAL\%20for\%20web.pdf

Wilson, R. E., \& Kittleson, J. (2013). Science as a classed and gendered endeavor: Persistence of two white female first-generation college students within an undergraduate science context. Journal of Research in Science Teaching, 50(7), 802-825.

Wilson, S., Lyons, T., \& Quinn, F. (2013). Should I stay or should I go'?: Rural and remote students in first year university STEM courses. Australian \& International Journal of Rural Education, 23(2), 77-88. 


\section{Appendix A}

Projected Job Openings in STEM Occupations, 2008-2018

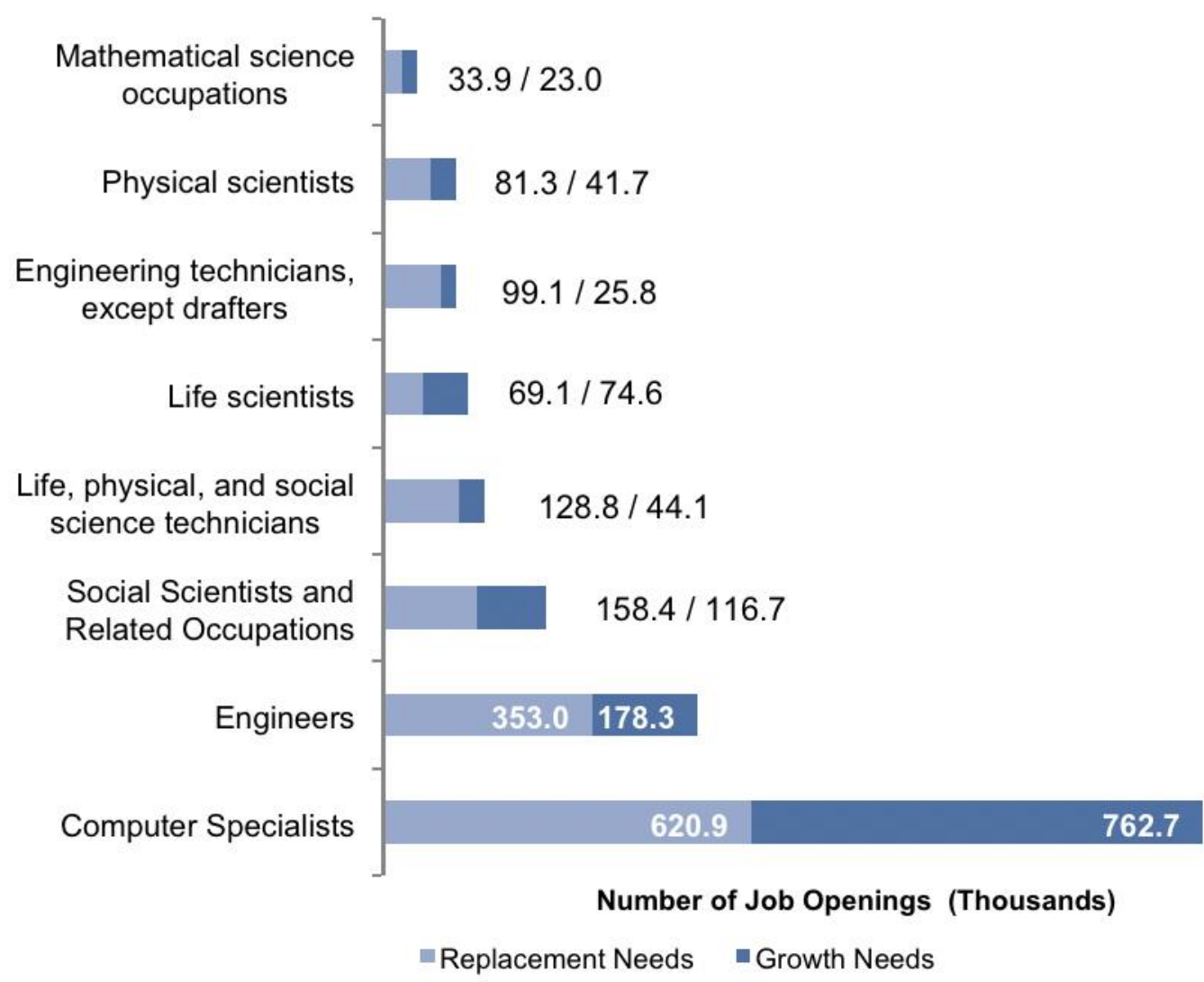

Derived from: Bureau of Labor Statistics. As reported in President's Council of Advisors on Science and Technology, 2012 
ENABLING AND THREATENING FACTORS AFFECTING PERSISTENCE

\section{Appendix B}

\section{NSF Approved STEM Fields}

\section{CHEMISTRY}

Chemical Catalysis

Chemical Measurement and Imaging

Chemical Structure, Dynamics, and Mechanism

Chemical Synthesis

Chemical Theory, Models and Computational Methods

Chemistry of Life Processes

Environmental Chemical Systems

Macromolecular, Supramolecular, and Nanochemistry

Sustainable Chemistry

Chemistry, other (specify)

COMPUTER AND INFORMATION SCIENCE AND ENGINEERING (CISE)

Algorithms and Theoretical Foundations

Communication and Information Theory

Computational Science and Engineering

Computer and Information Security

Computer Architecture

Computer Systems, Networking, and Embedded Systems

Databases

Data Mining and Information Retrieval

Graphics and Visualization

Human Computer Interaction

Informatics

Machine Learning

Natural Language Processing

Robotics and Computer Vision

Software Systems and Software Engineering

CISE, other (specify)

\section{ENGINEERING}

Aeronautical and Aerospace

Bioengineering

Biomedical

Chemical Engineering

Civil Engineering

Computer Engineering

Electrical and Electronic

Energy

Environmental

Industrial Engineering \& Operations Research

Materials 
NSF Approved STEM Fields (continued)

ENGINEERING (continued)

Mechanical

Nuclear

Ocean

Optical Engineering

Polymer

Systems Engineering

Engineering, other (specify)

\section{GEOSCIENCES}

Atmospheric Chemistry

Aeronomy

Biogeochemistry

Biological Oceanography

Chemical Oceanography

Climate and Large-Scale Atmospheric Dynamics

Geobiology

Geochemistry

Geodynamics

Geophysics

Glaciology

Hydrology

Magnetospheric Physics

Marine Biology

Marine Geology and Geophysics

Paleoclimate

Paleontology and Paleobiology

Petrology

Physical and Dynamic Meteorology

Physical Oceanography

Sedimentary Geology

Solar Physics

Tectonics

Geosciences, other (specify)

\section{LIFE SCIENCES}

Biochemistry

Biophysics

Cell Biology

Developmental Biology

Ecology

Environmental Science

Evolutionary Biology 
ENABLING AND THREATENING FACTORS AFFECTING PERSISTENCE

Genetics

NSF Approved STEM Fields (continued)

LIFE SCIENCES (continued)

Genomics

Microbiology

Molecular Biology

Neurosciences

Organismal Biology

Physiology

Proteomics

Structural Biology

Systematic Biology

Life Sciences, other (specify)

MATERIALS RESEARCH

Biomaterials

Ceramics

Chemistry of materials

Electronic materials

Materials theory

Metallic materials

Photonic materials

Physics of materials

Polymers

Materials Research, other (specify)

MATHEMATICAL SCIENCES

Algebra, Number Theory, and Combinatorics

Analysis

Applied Mathematics

Biostatistics

Computational and Data-enabled Science

Computational Mathematics

Computational Statistics

Geometric Analysis

Logic or Foundations of Mathematics

Mathematical Biology

Probability

Statistics

Topology

Mathematics, other (specify)

PHYSICS AND ASTRONOMY

Astronomy and Astrophysics 
Atomic, Molecular and Optical Physics

Condensed Matter Physics

NSF Approved STEM Fields (continued)

PHYSICS AND ASTRONOMY (continued)

Nuclear

Particle Physics

Physics of Living Systems

Plasma

Solid State

Theoretical Physics

Physics, other (specify)

\section{PSYCHOLOGY}

Cognitive

Cognitive Neuroscience

Computational Psychology

Developmental

Experimental or Comparative

Industrial/Organizational

Neuropsychology

Perception and Psychophysics

Personality and Individual Differences

Physiological

Psycholinguistics

Quantitative

Social

Psychology, other (specify)

\section{SOCIAL SCIENCES}

Archaeology

Biological Anthropology

Cultural Anthropology

Anthropology, other

Communications

Decision Making and Risk analysis

Economics (except Business Administration)

Geography

History and Philosophy of Science

International Relations

Law and Social Science

Linguistics

Linguistic Anthropology

Medical Anthropology

Political Science 
ENABLING AND THREATENING FACTORS AFFECTING PERSISTENCE

Public Policy

Science Policy

Sociology (except Social Work)

NSF Approved STEM Fields (continued)

SOCIAL SCIENCES (continued)

Urban and Regional Planning

Social Sciences, other (specify)

STEM EDUCATION AND LEARNING RESEARCH

Engineering Education

Mathematics Education

Science Education

Technology Education

STEM Education and Learning Research, other (specify) 


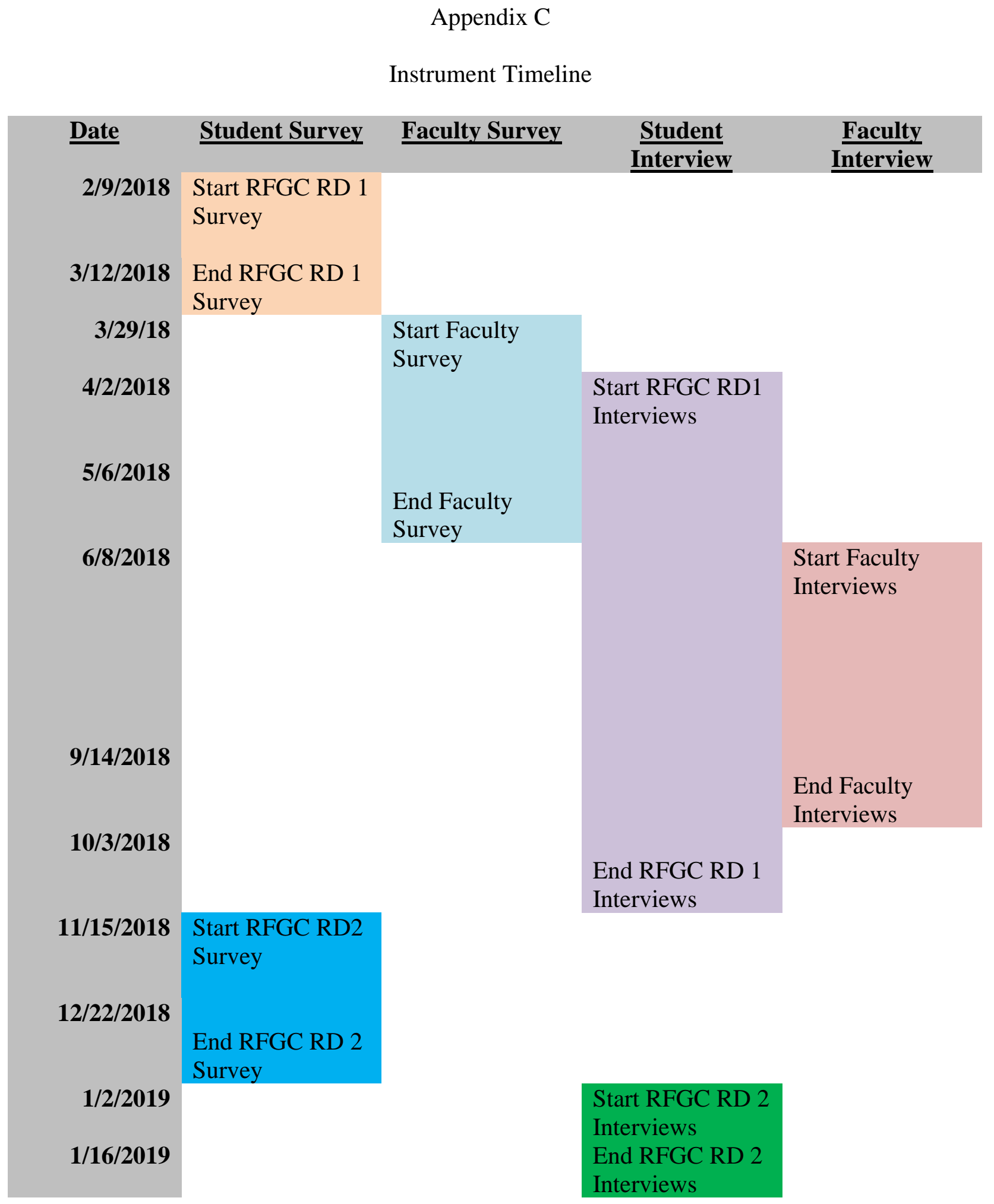


ENABLING AND THREATENING FACTORS AFFECTING PERSISTENCE

\section{Appendix D}

RFGC STEM Student Survey (Round 1 and 2)

\section{Rural First-Generation College STEM Major Survey Instrument}

Consent and age verification question for electronic survey.

Please indicate whether you consent or do not consent to participate in this study by selecting one of the response options below.

o Yes, I consent to participate in this study and confirm that I am 18 years old or older.

o No, I do not consent to participate in this study or I am not 18 years old or older.

1. Would you be willing to participate in an interview to develop a deeper understanding of rural First-generation STEM students' persistence?

a. If yes, please provide the best email address and/or phone number to contact you

b. No

2. Are you a First-Generation college student? (A first-generation college student is one that neither parent(s) nor guardian(s) has graduated from an institute of higher education with an associates or bachelor's degree.)
a. Yes
b. No
c. Not sure (may we contact you to confirm this?)
d. Other (Not sure or please comment/specify)

3. What is the name of the high school you graduated from? What is the zip code of the school district offices?

4. What was your home address zip code when you graduated high school?

5. While in high school, did you live in a rural area, less than 2500 population?
a. Yes
b. No
c. I do not know
d. Other (please specify)

6. Which of the following best describes the STEM discipline in which you are majoring? (Choose all that apply)
a. Chemistry
b. Computer Science
c. Engineering
d. Geosciences 
e. Biology or other Life Sciences

f. Mathematics

g. Physics and Astronomy

h. Psychology

i. Social Science

j. Science Education

k. Math Education

1. Other (please specify)

7. What is your specific major(s)?

8. Please describe what made you decide to enroll in a Science, Technology, Engineering, or Mathematics (STEM) major.

9. For the next semester, do you plan to stay in your declared STEM major?
a. Yes
b. No

If they answer no:

i. Do you plan on returning to school/college next semester?

1. Yes

2. No

If they answer yes:

i. What is your intended major for next semester

c. Depends, please clarify:

10. If you answered "No" to the previous question, please describe why you are not returning to your declared STEM major next semester.

With each question below, you have the option of clarifying or adding to your answer in the open prompt, "Additional comment".

11. Below are some reasons that might make staying in a Science, Technology, Engineering, and Mathematics (STEM) $\begin{array}{cccc}\begin{array}{c}\text { Untrue } \\ \text { of me }\end{array} & \begin{array}{c}\text { Somewh } \\ \text { at untrue } \\ \text { of me }\end{array} & \begin{array}{c}\text { Somewh } \\ \text { at true of } \\ \text { me }\end{array} & \begin{array}{c}\text { True of } \\ \text { me }\end{array} \\ & \end{array}$ program difficult. How true will each of the 
following statements be about you for this coming semester?

a. It is difficult to adjust to the academic demands of my STEM classes.

Additional comment:

b. I am having a hard time developing study skills that enable me to pass my STEM courses. Additional comment:

c. I do not understand what my professors expect of me academically. Additional comment:

d. I am intimidated by my professors. Additional comment:

e. The math I have to do in my STEM classes is too hard. Additional comment:

f. My STEM classes have too many students in them, so I do not get individual support from my professors. Additional comment:

g. Professors in my STEM classes tend to lecture a lot. Additional comment:

h. STEM classes are more boring than I expected. Additional comment:

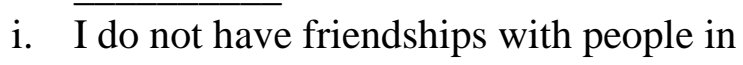
my STEM classes. Additional comment:

j. My social life interferes with studying. Additional comment:

k. Because I have a job, I do not have as much time as I need for studying. Additional comment:

1. I might not be able to afford finishing my degree. Additional comment:

m. Because I have responsibilities at home, I do not have as much time as I need for studying. Additional comment:

n. I don't know where to get help with my coursework. Additional comment: 
o. I don't know where to get help if I feel depressed or worried. Additional comment:

p. I am lonely or homesick. Additional comment:

q. I do not feel safe on campus. Additional comment:

r. I do not feel that I belong in college. Additional comment:

s. What other challenges make staying in your STEM classes/major difficult?

t. Do you have anything else to add in regard to items that may make staying in a STEM major difficult?

12. How true of you are the following statements?

$\begin{array}{cccc}\begin{array}{c}\text { Untrue } \\ \text { of me }\end{array} & \begin{array}{c}\text { Somewhat } \\ \text { untrue of } \\ \text { me }\end{array} & \begin{array}{c}\text { Somewhat } \\ \text { true of me }\end{array} & \begin{array}{c}\text { True of } \\ \text { me }\end{array} \\ & & \end{array}$

a. I have a clear sense of my rural background and what it means for me. Additional comment:

b. I am happy that I am from a rural community. Additional comment:

c. I have a strong sense of belonging to my rural community. Additional comment:

d. I have a lot of pride in my rural background. Additional comment:

e. I feel a strong attachment to my rural background. Additional comment:

f. I am embarrassed to be from a rural place. Additional comment:

g. Do you have anything else to add in regard to your rural background and relation to college?

\section{Demographic Information}

13. Have you received your final course grades from this most recent college semester?

a. If yes, what was your college GPA from this semester?

b. If no, what do you think your college GPA will be from this semester?

14. What is your overall college GPA?

15. What is your gender? 

a. Male
b. Female
c. Other (please specify)

16. Which categories describe you? Select all that apply.
a. Appalachian
b. White
c. Hispanic or Latino/a
d. Black or African American
e. Asian
f. American Indian or Alaska Native
g. Middle Eastern or North African
h. Native Hawaiian or Other Pacific Islander
i. Some other group (please specify)

17. During this school year, were you eligible for a Pell grant?
a. Yes
b. No
c. Don't Know (please specify)

18. Which of the following best describes you? (You are employed if you receive wages in return for work or services completed.) Select one.
a. Employed full-time (minimum 40 hours per week)
b. Employed part-time (fewer than 40 hours per week)
c. Not employed
d. Other (please specify)

19. What is your age?

20. In what year of college are you?
a. Freshman
b. Sophomore
c. Other (please specify) 
21. Which bests describes your enrollment status?
a. Full time student (enrolled 12 hours or more per semester)
b. Part time student (enrolled in fewer than 12 hours per semester)
c. Other (please specify)

Logic - If answer is a) Full time then direct to 21a. If they answer b) part time or c) other then, direct participant to $21 \mathrm{~b}$.

1. Including this semester, how many semesters have you completed in higher education?

2. Including this semester, how many hours have you completed? Do not include credits earned while in high school.

22. Did you earn college credits while in high school?
a. Yes, please list the total number of hours you have taken and list each college course that you took while in high school
b. No
c. Other - please specify

23. In what college are you currently enrolled?
a. Fairmont State University
b. West Virginia University
c. West Liberty University
d. Other (please specify)

24. Have you participated in:
a. The First Two program
b. WV GEAR UP
c. Your institution's summer orientation (please briefly describe)
d. I have not participated in any programs focused on college
e. Other (please specify)

25. How many of your siblings have attended, or are currently attending, college? 
ENABLING AND THREATENING FACTORS AFFECTING PERSISTENCE
a. None
b. One
c. Two
d. Three or more
e. I am the oldest child, and my younger siblings are not old enough to attend college yet.
f. I do not have any siblings.
g. Other (please specify) 
ENABLING AND THREATENING FACTORS AFFECTING PERSISTENCE

\section{Appendix E}

\section{STEM Faculty Survey Questions}

Consent and age verification question for electronic survey.

Please indicate whether you consent or do not consent to participate in this study by selecting one of the response options below.

o Yes, I consent to participate in this study and confirm that I am 18 years old or older.

o No, I do not consent to participate in this study or I am not 18 years old or older.

1. Would you be willing to participate in an interview to develop a deeper understanding of Rural First-generation STEM students' persistence?

a. If yes, please provide the best email address and/or phone number to contact you

With each question, you have the option of clarifying or adding to your answer in the open prompt, "Additional comment".

2. Below are some reasons that might make staying in a Science,

Untrue Somewh Somewh True at untrue at true
Not Applicab

le Technology, Engineering, and Mathematics (STEM) program difficult for rural first-generation college students. How true do you think each of the following are for rural first-generation students you have taught? (If you are unaware of having taught rural first-generation students, select the Not Applicable response option)

a. Difficulty adjusting to the academic demands of STEM classes. Additional comment:

b. Difficulty developing study skills. Additional comment:

c. Difficulty understanding what professors expect academically. Additional comment:

d. Feeling intimidated by professors. Additional comment: 
e. Finding the math, they have to do in in their STEM classes too hard. Additional comment:

f. Finding that STEM classes have too many students in them, limiting individual support from professors. Additional comment:

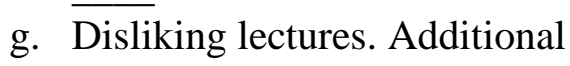
comment:

h. Finding STEM classes to be more boring than expected. Additional comment:

i. Lack of connection to other STEM students outside of classes. Additional comment:

j. Interference of social life with studying. Additional comment:

k. Not having as much time as needed for studying because they have jobs. Additional comment:

1. Being unable to afford finishing their degree. Additional comment:

m. Not having as much time as needed for studying because they need to help their family. Additional comment:

n. Feeling lonely or homesick. Additional comment:

o. Feeling unsafe on campus. Additional comment:

p. Feeling that they do not belong in college. Additional comment:

q. In your experience, what other challenges make staying in STEM classes/major difficult for rural first-generation students?

r. Do you have anything else to add in regard to question \#2?

3. My institution does a good job of:

a. Communicating to new students
what it has to offer
Disagree Somewh Somewh Agree at agree disagree
Not applicabl e


academically. Additional

comment:

b. Enrolling new students who can benefit from what this institution has to offer. Additional comment:

c. Informing new students about the institution's history and traditions. Additional comment:

d. Informing new students about the values this institution considers important. Additional comment:

e. Keeping faculty informed about the academic support services where they can refer new students who are having difficulties. Additional comment:

f. Keeping faculty informed about the personal support services where they can refer new students who are having difficulties. Additional comment:

g. Helping new students get off to a good start academically.

Additional comment:

h. Facilitating new students' early involvement in the academic life of the institution. Additional comment:

i. Facilitating new students' early involvement in the nonacademic life of the institution. Additional comment:

j. Conveying to new students the sense that, if they make the effort, they can succeed here. Additional comment:

k. Conveying to new students the sense that they "belong" here.

Additional comment:

1. Do you have anything else to add in regard to question \#3 ? 
4. In your courses that serve primarily first-year students, how often do you use the following?

a. Lecture

Additional comment:

b. In-class discussion

Additional comment:

c. Collaborative/cooperative learning

Additional comment:

d. Experiential/problembased learning

Additional comment:

e. Group projects

Additional comment:

f. Multiple drafts of written work

Additional comment:

g. Community service as an integral part of the course

Additional comment:

h. Community service for extra credit only

Additional comment:

i. Frequent feedback to students on their progress

Additional comment:

j. Detailed feedback to students on their progress

Additional comment:

k. Multiple-choice tests/exams

Additional comment:

1. Essay or other open-ended quizzes or exams

Additional comment:

m. Papers or other openended assignments

Additional comment:

n. Student presentations

Additional comment:

o. Technology to further discussion outside of class
Not at all Rarely Sometim Often Not

es applicabl

e 
Additional comment:

p. Case studies/real world examples

Additional comment:

q. Hands-on experiences

Additional comment:

r. Assignments or exercises

focusing on application

Additional comment:

s. Do you have anything else to add in regard to question \#4?

5. How many courses do you teach that serve primarily first-year students (exclude first-year seminars)?

6. Of those courses, how many are, in your view, too large to allow you to engage students individually?

7. In the past two years, approximately how many times have you participated in the following?

Not at
all

Once Twice Three

or

more

times
a. A conference, workshop, or other formal activity that focused on teaching and learning on first-year STEM students and how to help them succeed
b. A conference, workshop or other formal activity
c. Read literature related to first-year STEM students and how to help them succeed
d. Do you have anything else to add in regard to question \#7?

8. By what institution are you employed?
a. Fairmont State University
b. West Virginia University
c. West Liberty University
d. Other (please specify)

9. What is your current academic rank? Please select only one. 

a. Full Professor
b. Associate Professor
c. Assistant Professor
d. Instructor/Lecturer
e. Emeritus Professor
f. Staff member
g. Adjunct
h. Other (please specify)

10. During this semester, are you employed by your institution full-time or part-time?
a. Full-time
b. Part-time

11. Including this year, how many years have you been teaching STEM courses (full- or parttime)?

12. Including this year, how many years have you been employed by this institution (full- or part-time)?

13. Which of the following best describes the STEM discipline in which you primarily teach? Select one.

m. Chemistry

n. Computer Science

o. Engineering

p. Geosciences

q. Biology or other Life Sciences

r. Mathematics

s. Physics and Astronomy

t. Psychology

u. Social Science 
v. Science Education

w. Math Education

x. Other (please specify)

14. What is your gender?
a. Male
b. Female
c. Other (please specify)

15. Which categories describe you? Select all that apply.
a. White
j. Hispanic or Latino/a
k. Black or African American
1. Asian
m. American Indian or Alaska Native
n. Middle Eastern or North African
o. Native Hawaiian or Other Pacific Islander
p. Another group (please specify)

16. In what locale did you spend most of your childhood years?
a. Rural
b. Town
c. City
d. Suburbs

17. Do you teach a course that is a requirement for a STEM major? If so list all STEM courses that you teach 


\title{
Appendix F
}

\author{
RFGC STEM Student Interview Questions (Round 1 and Round 2)
}

Semi-Structured Interview Questions:

1. Describe what has enabled you to persist or to be successful in your STEM major?

a. Describe your assets or strengths as a STEM major?

b. Which of these is your greatest asset or strength? (to being a STEM major?

i. How is this asset or strength a benefit?

2. Describe additional assets or strengths that may be significant for other rural FGC STEM students? (to persist in a STEM major)

a. How do these additional assets or strengths benefit them as a STEM major?

3. Describe what may threaten or keep you from persisting (being successful) in your STEM major?

a. Describe the challenges or issues that you may have faced in this past semester as a rural FGC STEM major?

b. Describe your greatest challenges or issues you have faced?

i. Why is this your greatest challenge or issue?

c. Describe what weaknesses you may have as a rural FGC STEM major?

i. Why are they a weakness?

ii. Which of these is the greatest weakness?

d. Of these challenges or issues, which were unanticipated (which surprised you)?

4. Describe how you handled or dealt with challenges or issues that you may have faced as a STEM major?

a. What have you found as successful means to overcoming these challenges or issues?

5. Describe additional threats or challenges or weaknesses that may be significant for other rural FGC STEM students? (to persisting in a STEM major)

6. Describe how your pre-college experiences (academic and/or personal or social) enable or threaten your persistence or success in your STEM courses?

7. Describe your academic relationships, those with your peers and with the faculty and staff?

a. Describe how these have impacted your persistence?

8. Describe how your expectations of your STEM classes were or were not met?

a. Describe your expectations of your STEM major?

b. Describe your expectations of college?

9. Describe your feelings/opinions toward your college class experiences, especially your STEM courses?

10. Have your career plans changed since you started college? If so how?

11. What advice do you have for high school students who plan to be STEM majors?

12. Describe any other concerns you had or have as a STEM major?

13. Is there anything else you would like to add that I have not asked about? When you first heard about this study, is there anything you thought I would ask, but I have not asked? Is there anything else you think I should be aware of or know? 


\section{Appendix G}

\section{STEM Faculty Interview Questions}

\section{Semi-Structured Interview Questions:}

In your opinion:

1. Describe the factors that enable a Rural FGC student to persist in a STEM major?

a. Describe the assets or strengths that a rural FGC student may have?

b. Which of these is the greatest asset or strength? (of a rural FGC STEM student)

i. How is this asset or strength a benefit?

2. Are these enabling factors different for those students who are not Rural and/or FGC?

3. Describe the factors that threaten a Rural FGC student from persisting in a STEM major?

a. Describe the challenges or issues that a rural FGC student may experience as a STEM major?

b. Which of these is the greatest challenge or issue? (to a rural FGC STEM student persisting)

i. Why is this their greatest challenge or issue?

c. Describe the weaknesses of rural FGC students in a STEM major?

i. Why are they a weakness?

ii. Which of these is the greatest weakness?

d. How should they handle or deal with these challenges or issues?

4. Are these threatening factors different for those students that are not Rural and/or FGC?

5. Describe pre-college experiences that would be beneficial or would enable rural FGC students to persist in a STEM major?

6. Describe academic relationships, student-student and student-faculty/staff that would be beneficial or would enable rural FGC students to persist in a STEM major?

7. Describe what Rural FGC students should do in your class to be more successful?

a. Describe if students do this or not?

8. Describe what Rural FGC students should do in their major to be more successful?

a. Regarding college in general, what should they do to be more successful?

9. What advice do you have for high school students who plan to be STEM majors?

10. Describe any other concerns that you have with Rural FGC STEM students?

11. Describe any other concerns that Rural FGC Stem students should have?

12. Is there anything else you would like to add that I have not asked about? When you first heard about this study, is there anything you thought I would ask, but I have not asked? Is there anything else you think I should be aware of or know? 


\author{
Appendix $\mathrm{H}$ \\ Exodus Interview Questions \\ Those who leave (exodus) a STEM major and are RFGC
}

Semi-Structured Interview Questions:

1. What was your STEM major?

2. Describe your reasoning for leaving your STEM major?

a. What, if anything, would have led to a different decision (leaving STEM Major)?

b. What would have helped you to continue as a STEM major?

c. What would have made you a stronger STEM student?

3. If you are switching to a new major, what made you decide on your new major?

a. Have your career plans changed since you started college? If so how?

4. Describe what has enabled you to persist or to be successful in your STEM major?

a. As a STEM major, what were your assets or strengths?

b. What was your greatest asset or strength to being a STEM major?

c. How was this asset or strength a benefit?

5. Describe additional assets or strengths that may be significant for other rural FGC STEM students? (to persist in a STEM major)

a. How do these additional assets or strengths benefit them as a STEM major?

6. Describe what threatened or kept you from continuing as a STEM major?

a. Describe the challenges or issues that you may have faced this past semester as a rural FGC STEM major?

b. Describe your greatest challenge or issue you have faced?

i. Why was this your greatest challenge?

c. Describe what weaknesses you may have as a rural FGC STEM major?

i. Why are they a weakness?

ii. Which of these is the greatest weakness?

d. Of these challenges or issues, which were unanticipated (surprised you)?

7. Describe how you handled or dealt with challenges or issues that you may have faced as a STEM major?

a. What have you found as successful means to overcoming these challenges or issues?

8. Describe additional threats or challenges or weaknesses that may be significant for other rural FGC STEM students? (to persist in a STEM major)

9. Describe how your pre-college experiences (academic and/or personal or social) have enabled or threatened your persistence or success in your STEM courses?

10. Describe your academic relationships, those with your peers and with the faculty and staff?

a. Describe how these have impacted your persistence?

11. Describe how your expectations of your STEM classes were or were not met?

a. Describe your expectations of your STEM major?

b. Describe your expectations of college?

12. Describe your feelings/opinions toward your college class experiences, especially your STEM courses?

13. What advice do you have for those students who plan to be STEM majors? 
14. Describe any other concerns you had as a STEM major?

15. Is there anything else you would like to add that I have not asked about? When you first heard about this study, is there anything you thought I would ask, but I have not asked? Is there anything else you think I should be aware of or know? 